Portland State University

PDXScholar

6-1997

\title{
Opening Doors: Culture Learning and Conversational Narratives with First Generation Hmong Refugee Women
}

Lucy Vincent Kimbro

Portland State University

Follow this and additional works at: https://pdxscholar.library.pdx.edu/open_access_etds

Part of the Applied Linguistics Commons, and the First and Second Language Acquisition Commons Let us know how access to this document benefits you.

\section{Recommended Citation}

Kimbro, Lucy Vincent, "Opening Doors: Culture Learning and Conversational Narratives with First Generation Hmong Refugee Women" (1997). Dissertations and Theses. Paper 4466.

https://doi.org/10.15760/etd.6350

This Thesis is brought to you for free and open access. It has been accepted for inclusion in Dissertations and Theses by an authorized administrator of PDXScholar. Please contact us if we can make this document more accessible: pdxscholar@pdx.edu. 


\section{THESIS APPROVAL}

The abstract and thesis of Lucy Vincent Kimbro for the Master of Arts in Teaching English to Speakers of Other Languages were presented February 7,1997 , and accepted by this thesis committee and the department.

COMMITTEE APPROVALS:

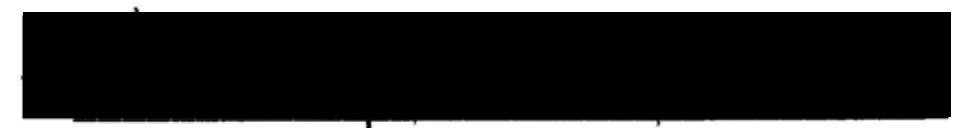

Kimberley Brown, Chair

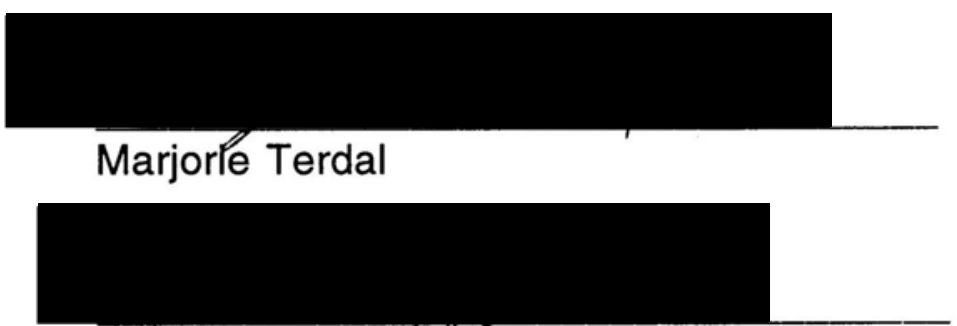

Susan Poulsen

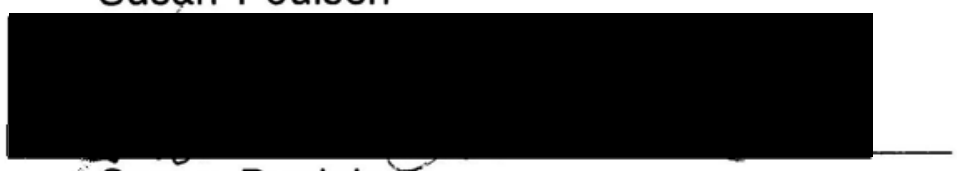

- Susan Danielson

Representative of the Office of Graduate Studies

DEPARTMENT APPROVAL:

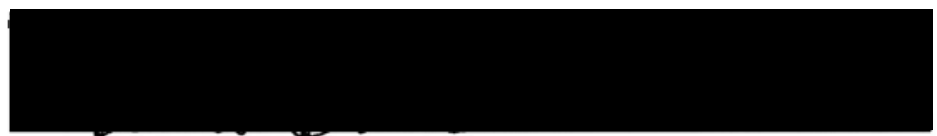

Heanette S. DeCarrico, Chair

Department of Applied Linguistics

ACCEPTED FOR PORTLAND STATE UNIVERSITY BY THE LIBRARY

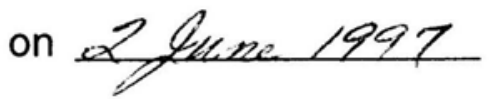




\section{ABSTRACT}

An abstract of the thesis of Lucy Vincent Kimbro for the Master of Arts in Teaching English to Speakers of Other Languages presented February 7, 1997.

Title: Opening Doors: Culture Learning and Conversational Narratives with First Generation Hmong Refugee Women.

The life experiences of two first generation Hmong refugee women form the basis of this study. Through loosely structured but guided interviews, memories of their lives in Laos and in refugee camps in Thailand, as well as their perspectives, feelings, and opinions about current aspects of their lives; the effects of American culture on their family; and their engagement in the language and culture learning process are explored.

An examination of the involvement of Hmong women in research and ethnographic accounts concerning Hmong culture, history, and experience, show that Hmong women's perspectives have often been overlooked or disregarded. One purpose of this study is to afford an opportunity to hear the voices of these Hmong women, whose lives are centered in the home and in maintenance of family, and whose responsibilities and cultural roles have limited their contribution to research and literature on the Hmong and their participation in refugee and immigrant resettlement and English language programs. 
The data for this study was collected in tape recorded interviews using an informal, loosely structured interview process: a conversational narrative rather than a formal oral history interview. This data was then transcribed and reconstructed to form both a chronological personal history and a view of the culture and current lives of the informants.

The perspectives of the women in this study, revealed through the conversational narratives, are shown to reflect the informants past reality and demonstrate their attempts to adjust to a new cultural identity and environment. Moreover, conversational narratives and oral histories are shown to be potentially valuable resources for culture and language learning and suggest meaningful applications for English as a Second Language education and refugee resettlement. 
OPENING DOORS:

CULTURE LEARNING AND CONVERSATIONAL NARRATIVES

WITH FIRST GENERATION HMONG REFUGEE WOMEN

by

LUCY VINCENT KIMBRO

A thesis submitted in partial fulfillment of the requirements for the degree of

\author{
MASTER OF ARTS \\ in \\ TEACHING ENGLISH TO SPEAKERS OF OTHER LANGUAGES
}

Portland State University

1997 
Dedicated to my good friend, Valee Her: strong, smart woman and loving mother, who lived her life with compassion and a sense of wonder and humor. 


\section{ACKNOWLEDGEMENTS}

My interest in documenting the lives of women in transitional cultures has its roots in the life experiences of my mother. Born in the small town of Richwood in the mountains of West Virginia, and "growing up hillbilly," my mother as a young adult did not hesitate to actively involve herself in the profound cultural transitions women were facing in the 1930s and 40s. Leaving her hometown to attend college, and leaving college to return to Richwood, she ran the family newspaper business until she married my father and, rather than settling down, began a life of traveling from place to place around the country. In the early 1950s, with five young children at home, my mother went back to school for her Master's Degree in Education. At the same time, she was making adjustments to changing cultural and personal roles and expectations, yet somehow remaining the "heart" of the family

In the early 1980s, my husband and I sponsored an extended family of Southeast Asian refugees. My association with the women in this Hmong family fueled my interest in women's cultural studies, especially women whose lives were centered around the home and their families, but were intensely involved with adjustment to a changing cultural environment.

Some years later, as a student in the TESOL Master's Program at Portland State University, I began to notice how often my experiences with the Hmong families related to what I was learning in my classes, and how 
very much I drew on that experience in developing my own teaching philosophy and style.

I owe my deepest gratitude to my mother, Billie Vincent, and to my informants, Mai Vang and Chia Her for their courage, resourcefulness, and sense of humor and for sharing with me the struggle, confusion and adventure of women's lives in changing times. In addition, I thank my mother for inspiring me with a love and enthusiasm for teaching, and for demonstrating to me how to be present with my students, open to what we can learn from each other.

This study could not have been completed without the intellectual challenge, emotional support, and personal encouragement of my advisor Kim Brown and my teacher and mentor, Marge Terdal. These two strong, perceptive women helped me to recognize and appreciate my own strength and ability to contribute something of value to the field of language learning while somehow balancing my roles as researcher, teacher, and mother of six children.

Finally, I must, of course, thank my husband, Bill Kimbro, and my children Jake, Dan, Joe, Maria, Tony, and David for bearing with me as I worked on this study, and for participating wholeheartedly in our friendship with the Hmong families. My daughter, Maria, deserves special thanks for accompanying me on several trips to California to collect data for this study; for believing and for telling me: "You're good enough and smart enough to get this done;" for managing the practical details of our sometimes chaotic home life while I remained plugged into my computer; and, most of all, for sharing the laughter and the joy. 


\section{PREFACE}

\section{MAI'S DREAM}

You know, I always think about in my dreams when I was a little girl in Laos. I had one brother and he and his cousins were living in the town and would go to school. When he came to visit us, he was talking about a beautiful country. I didn't know why. He was talking to me about, "If you would only go to school, maybe later on my father or my parents will go to the other country and have a beautiful house and beautiful style and beautiful customs and everything. So we have to go. You want to go or stay?" My heart was feeling really like beautiful that time. This wasn't a dream. This was real. He just told me the truth, but that time I was still a little girl. I still lived in Laos.

I think a year later we just moved to Thailand. We moved to Thailand but that wasn't it. It wasn't beautiful like he told me. I always thought about that, "Maybe he is just a liar. Maybe it isn't true." I always thought about the world and what he told me before when we lived in Laos. But I said one day maybe we will see the view, the beautiful country like he said. He said the world was shiny and the light was turned on like the sun. He told me that. He was just a little boy too, but he went to school. I think he heard the story and he talked to me.

And then, the time that American people came to interview us to go to United States, I was thinking about that: "Maybe this time I will go see the 
beautiful country that he told me about." Now I did. I'm happy for that. I never forgot his words. So when I got to Oregon I was excited for that. So I didn't miss anybody in the past. I was really happy. I didn't know anybody else but myself...like I changed my new life or my new body...everything. 
TABLE OF CONTENTS

PAGE

ACKNOWLEDGEMENTS $\ldots \ldots \ldots \ldots \ldots \ldots \ldots \ldots \ldots \ldots \ldots$ iii

PREFACE $\ldots \ldots \ldots \ldots \ldots \ldots \ldots \ldots \ldots \ldots \ldots \ldots \ldots \ldots \ldots \ldots \ldots, v$

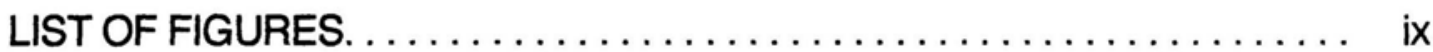

CHAPTER

I INTRODUCTION .......................... 1

॥ REVIEW OF THE LITERATURE $\ldots \ldots \ldots \ldots \ldots \ldots \ldots \ldots$

Background of the Hmong $\ldots \ldots \ldots \ldots \ldots \ldots \ldots$

Women in Research on Traditional Hmong Society in Southeast Asia ....................... 12

Research on the Resettlement Experience of Hmong Women in the U. S. . . . . . . . . . . . . 16

Conclusion ........................ 19

III METHODOLOGY .......................... 21

Introduction of Subjects $\ldots \ldots \ldots \ldots \ldots \ldots \ldots \ldots \ldots \ldots$

Description of Informants $\ldots \ldots \ldots \ldots \ldots \ldots \ldots \ldots$

Development of Research Topic . . . . . . . . . . 30

Theoretical Approach and Method of Inquiry ....... 31

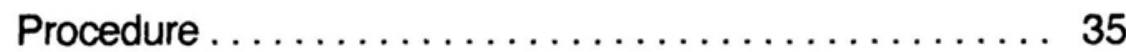


IV THE CONVERSATIONAL NARRATIVES ......... 45

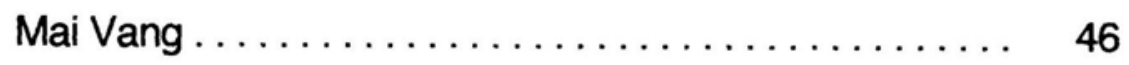

Chia Her ......................... 91

V SUMMARY AND DISCUSSION. . . . . . . . . . . 122

The Narratives as a Reflection of Hmong Women's Perspectives and Experienced Hmong History . . . . . 122

The Value of Hmong Women's Experienced Histories . . . . . . . . . . . . . . . . . . . . 128

Implications for ESL and Refugee Resettlement . . . . 132

My Experience of the Research Process as an ESL Teacher . .

Limitations and Further Research. . . . . . . . . . . . . 142

Conclusion ........................ 144

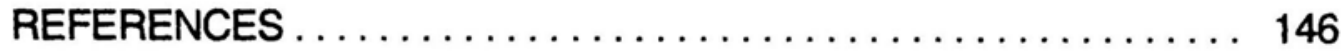




\section{LIST OF FIGURES}

FIGURE

PAGE

1. The Vang and Kimbro children. Oregon, $1980 \ldots \ldots \ldots \ldots 4$

2. Hmong tapestry $\ldots \ldots \ldots \ldots \ldots \ldots \ldots \ldots \ldots \ldots \ldots$

3. The Vang and Kimbro children in Oregon, $1981 \ldots \ldots \ldots 23$

4. Chan Vang and Maria Kimbro. Oregon $1981 \ldots \ldots \ldots \ldots 24$

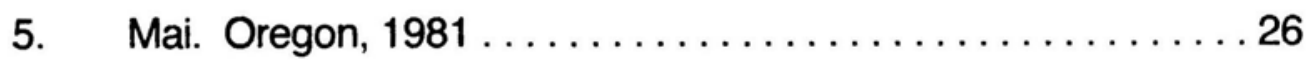

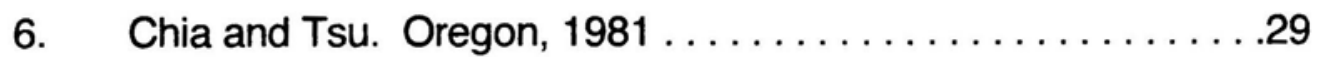

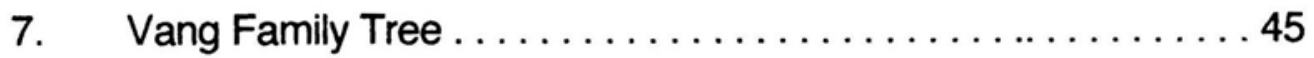

8 Tsu Vang. Thailand, $1978 \ldots \ldots \ldots \ldots \ldots \ldots \ldots \ldots$

9. Chia Her. Thailand. $1978 \ldots \ldots \ldots \ldots \ldots \ldots \ldots \ldots$

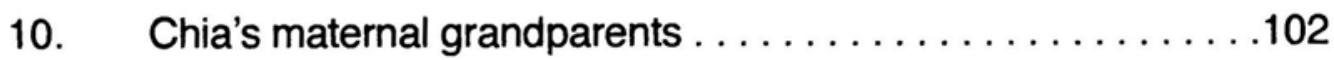

11. Yalee. Oregon, $1982 \ldots \ldots \ldots \ldots \ldots \ldots \ldots \ldots \ldots \ldots \ldots$

12. Kia and Chia. Oregon, $1982 \ldots \ldots \ldots \ldots \ldots \ldots \ldots \ldots \ldots \ldots \ldots$

13. Pa Tong Yang. Oregon, $1982 \ldots \ldots \ldots \ldots \ldots \ldots \ldots \ldots \ldots$

14. Yalee. Oregon, $1982 \ldots \ldots \ldots \ldots \ldots \ldots \ldots \ldots \ldots \ldots \ldots 141$

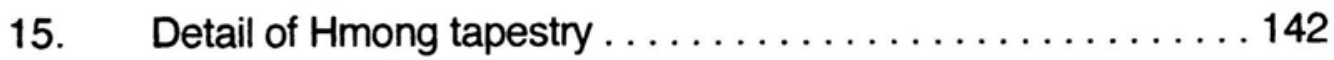

All photographs were taken by Lucy Vincent Kimbro. 


\section{CHAPTER 1}

\section{INTRODUCTION}

American military involvement in the war in Southeast Asia in the 1960's and 70's and our subsequent withdrawal from that area in 1975 helped create a situation in which hundreds of thousands of Vietnamese, Cambodians, and Laotians fled their homelands. The United States government, recognizing that great numbers of these refugees were forced to leave because they had supported, directly or by association, the U.S. presence in their countries, instituted a policy that allowed Southeast Asians to immigrate to the United States. Between 1975 and 1989 almost one million Southeast Asian refugees were admitted (Tollefson, 1989, p. xiv).

The Hmong, a self-reliant and semi-nomadic tribal group who had occupied the highest levels of habitable mountain regions of Laos and Thailand, made up one group admitted for resettlement in the United States. Because of their involvement with the CIA against the Pathet Lao, the displacement of the Hmong and the disruption of their traditional way of life began well before their arrival in the United States. Many Hmong facing conscription and persecution by the Pathet Lao left their villages and farms in the mountains of northern Laos for refugee camps in southern Laos. As the war escalated, the Hmong were again forced to flee, this time to refugee camps in Thailand. Of the 300,000 Hmong in Laos, almost a third left in the period between 1975 and 1987 (White, 1987, p. 787). In these camps the 
refugees waited for the war to end, either to return home or to resettle in countries willing or obligated to take them.

Until they moved into the camps, most Hmong had lived relatively isolated from Western culture. In the camps, interaction with foreign aid workers dramatically increased their exposure to Western customs, technology, and medicine. In addition, schools were set up in some camps, providing many Hmong children with their first formal educational experience.

A number of international relief agencies, in an attempt to alleviate the suffering, insecurity, and loss endured by the refugees in the camps in Thailand, assisted the government in the resettlement program. Sponsors were sought, individuals as well as groups, throughout the United States. The resettlement of Hmong refugees has continued and there are now over 125,000 Hmong living in the United States (Hamilton-Merritt, 1993, p. xvii).

In the late 1970s, my husband and I and our four children sponsored an extended family of Hmong refugees. At that time we were living in a rural area in the mountains of eastern Oregon. The first group of this family left the refugee camp in Thailand, where they had lived for five years, and arrived in eastern Oregon in December of 1979. Aside from relief workers and immigration officials, our family represented their first contact with Americans. Acting as "gate-keepers" to American culture, life-style, values, and language proved to be not only an extremely rewarding experience and a tremendous responsibility, but an invaluable opportunity to observe and participate in the process of resettlement. As we became friends with this Hmong family, and with their relatives who arrived over the next year, we 
grew to recognize the strength, courage, and adaptability of these individuals and to appreciate the unique culture that had sustained them through profound turmoil and transition.

The process of resettlement in which these Hmong newcomers and our family participated necessarily involved an intense focus on communication and language learning. Language acquisition does not, however, occur in isolation from either the target or the native cultural environment. During the two and a half years that these Hmong families lived in eastern Oregon, this direct, inevitable, and complex relationship between language acquisition and culture learning was expressed most freely through the interaction of the children, theirs and ours. It soon became quite apparent that relevant connections and real communication were facilitated as the children crossed and recrossed the cultural barriers that we, as adults, were hesitant to negotiate. The children tried on and experimented with each others' food, clothing, toys, customs, and language. When they made culture or language "mistakes" we all laughed and felt more comfortable making mistakes ourselves. They opened a door for us into each other's lives and culture, a door through which we all eventually learned to step in both directions.

By helping to overcome cultural barriers and establish a relationship based on trust, respect, and common concerns, the children had a positive effect on their own and on their relatives' process of language acquisition, a process that involves making connections between knowledge or life experience and information encountered in the learning environment. However, the children's presence also put constraints on the learning environment itself. Three of the five adult women in this extended Hmong 
family had young children, were pregnant or nursing babies, and were unable or reluctant to participate in the limited formal English as a Second Language (ESL) opportunities that were available. From an American standpoint, it is usual to equate "learning environment" with a formal educational context. For these women, however, the learning environment consisted of their own homes, their sponsor's or friends' homes, social service agencies, doctors' offices, and the grocery store.

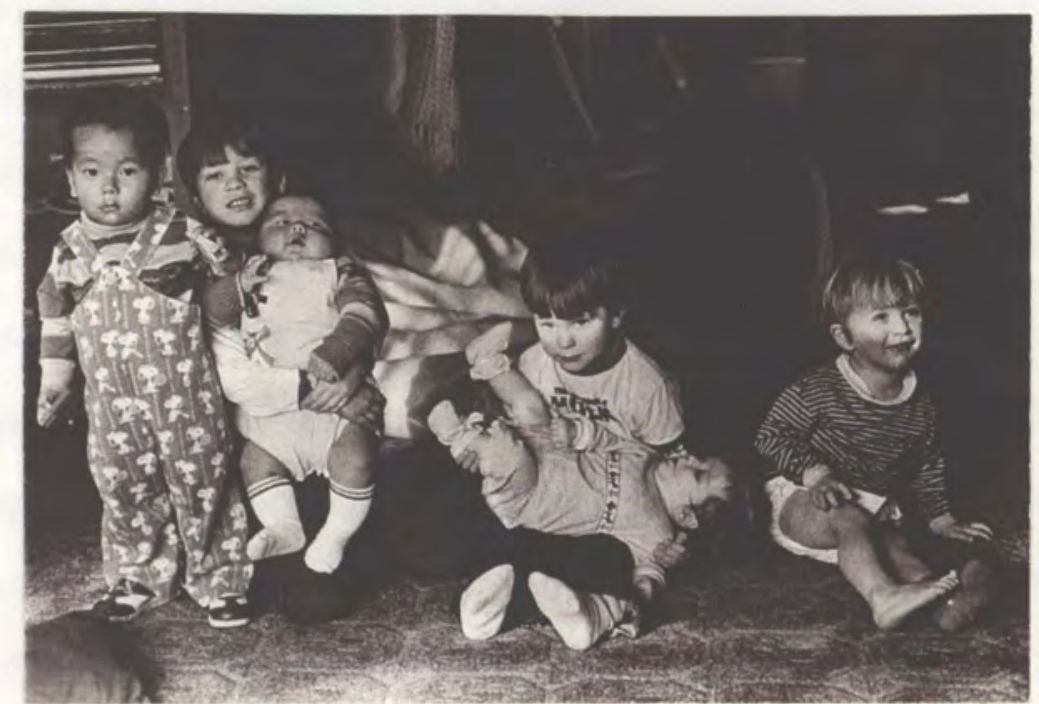

Figure 1. The Vang and Kimbro children. Oregon, 1980.

The learning situation that these particular women faced reflects a general pattern that is still prevalent in Hmong families today. Hmong women are especially susceptible to constraints on their participation in formal educational programs, on both the secondary and adult level. There are several reasons for this, including the following: the central role of girls and women in Hmong social structure as mothers and home caretakers; the 
cultural pattern in which Hmong women marry and begin to bear children at a young age and nurse their children well into the toddler stage; the primary value Hmong culture places on the family and clan over individual ambition or success; and the emphasis of many adult refugee ESL programs on instruction based on meeting employment needs, resulting in a de-emphasis on language needs of those refugees not seeking employment.

For most immigrants and refugees, learning the dominant culture's language is an essential tool for assimilation and success in their new home. Inability to communicate in the dominant language limits refugees and immigrants in terms of political empowerment, educational opportunities, economic advancement, social integration outside their ethnic communities, and interaction with their children. However, many first generation Hmong women find themselves isolated from social interaction with Americans for cultural reasons: their responsibilities in the home, constraints on their participation in formal educational programs, their lack of past formal educational experience in Laos and Thailand, and their traditional subordinate role in Hmong society.

In the spring of 1982, the extended Hmong family that we had sponsored moved to California and reunited with other family members and a growing Hmong community. Over the past fourteen years our families have stayed in contact, sharing news of numerous births, the tragic death of one of the Hmong women, and the celebration of occasional visits. In California our Hmong friends continued the process of resettlement and adjustment to American culture while attempting to maintain their traditions, values, and language. 
This study is based on the experiences of two first generation immigrant women in this dynamic Hmong family. Through unstructured but guided interviews, I have attempted to capture their personal histories and memories of their life in Laos and Thailand, as well as their perspectives, feelings, and opinions about current aspects of their lives, the effects of American culture on their family, and their engagement in the language and culture learning process. An effort was made to direct the interviews so that eventually a chronological personal history of the women could be reconstructed. However, the women themselves framed their individual narratives in the context of consistent themes reflecting their roles as wives and mothers and concerns about health, language, and cultural changes.

Because of my role as sponsor and close friend, and because of the dynamics and demands of conducting the interviews in informal settings, the recorded interviews became more interactive and conversational than what might be considered a formal oral history. Grele (1985) suggests that most people form "a basic understanding of their own past through conversations with others" (p. vii) and recommends using a different term for "oral history:"

Given the active participation of the historian-interviewer...and given the logical form imposed by all verbal communication, the interview can only be described as a conversational narrative: conversational because of the relationship of interviewer and interviewee, and narrative because of the form of exposition--the telling of a tale. (p.135) Grele's term "conversational narratives" will be used in reference to the interviews in this study, while "oral histories" will refer to more traditional and formal interviews. 
These reconstructed narratives are intended to provide a glimpse into the history, culture, and current lives of first generation Hmong refugee women in the process of resettlement from the perspective of the women themselves. Background on the Hmong and on the role of women in the development of western ethnographic and historical research on the Hmong will be examined. Following the conversational narratives, a summary and discussion of the women's perspectives, the narrative process, and the relevance of oral history and conversational narratives for Hmong women will be given. Finally, the role and potential value of oral history and conversational narratives in the process of language and culture learning will be discussed. It is hoped that this study will serve to stimulate awareness, interest, and development in the areas of refugee resettlement and second language and culture learning while contributing to the literature of immigrant womens' voices. The following are Guiding Questions that were used to direct this study and will be addressed in the following chapters:

Chapter II: What involvement have Hmong women had in the recording and expression of their own culture, history and experience?

Chapter IV: What are these particular women's memories and perceptions of their life experiences?

Chapter V: How does their engagement in the narrative process reflect their perspectives and experienced history?

Chapter V: How do conversational narratives support language development and culture learning? 
CHAPTER II

\section{REVIEW OF LITERATURE}

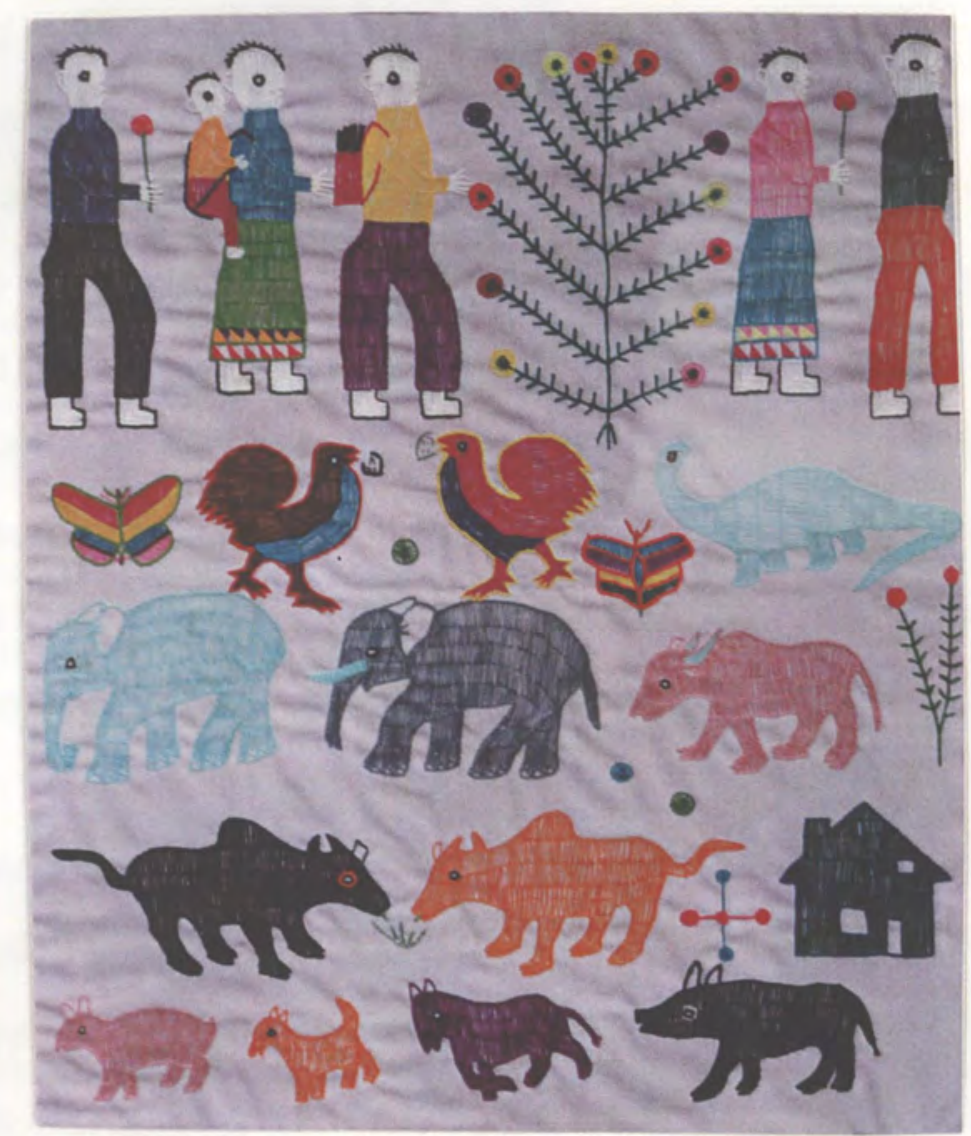

Figure 2. Hmong tapestry.

In this section, the background of the Hmong in Laos and in the refugee camps in Thailand will be discussed. In addition, the traditional cultural expectations and roles of Hmong women as well as the changes in these expectations and roles brought on by the process of resettlement in America will be considered through a review of literature concerning Hmong 
culture in Southeast Asia and in the United States. The part Hmong women have played in the creation of the literature, and ethnographic research concerning the Hmong as well as educational program development in the area of refugee resettlement will also be discussed.

\section{Background of the Hmong in Southeast Asia.}

The ancestral home of the Hmong is China, where they are referred to as "Miao." With the ascendance of the Han dynasty in the third century B. C., many of the Hmong and other minority groups who refused to assimilate were forced to move southward out of China (How-Man, 1984, p. 290). In the early 19th century, groups of Hmong migrated from China to what is now Laos and Northern Thailand and settled in the mountain regions where they remained a fairly isolated, independent, and self-reliant people. Colonization of Indochina by the French in the late 19th century resulted in the formation of the modern nation-states and brought some changes to the Hmong's traditional economy and lifestyle. Because the Hmong were forced to occupy the marginal areas of the mountains, they began to depend more and more on the cultivation of the opium poppy which they could sell as a cash crop. In spite of this change and some increased exposure to other ethnic groups, as well as Western missionaries, they remained relatively isolated until the American CIA and military became interested in arming, training, and using them as soldiers against the Pathet Lao in the 1960's. Before this time, few people in the United States had ever heard of the Hmong.

Refugee Camps. In 1975 when the United States pulled out of Laos, the Hmong lost their allies and were persecuted more intensely by the Pathet 
Lao, who targeted Hmong villages for destruction (White, 1968, p. 7). The Hmong fled Laos in great numbers, most of them heading for Thailand. The arrival of tens of thousands of Hmong on the Thai border and the establishment of refugee camps in Thailand finally brought the Hmong to the attention of the Western media and the general public in the United States. Even so, according to Haines (1989), the Hmong waited in the Thai camps for resettlement longer than any other refugee group, an average of nearly three years (p. 145). As recent as 1992 , there were still about 45,000 people, many thousands of them Hmong, remaining in Thai refugee camps (Cha and Small, 1994, p. 1046).

Hendricks (1986), writing about change and the integrity of Hmong culture over time, claims that it is a mistake to think that an unchanging traditional way of life existed before resettlement in the West. Moreover, he says that "the concept of culture implicitly assumes it is dynamic and that over time varying degrees of change will take place in any society" (p. 3).

Certainly these long stays in the refugee camps in Thailand fostered both subtle and obvious changes in Hmong culture, social structure and expectations. Cha and Small (1994) suggest that the Hmong culture in the refugee camps is a distinctive product of the inevitable changes imposed by living in the camps. What one is seeing and preserving, they say, is not traditional culture, but a refugee camp culture that is unlike prewar Hmong culture "in the way people make a living, in the sexual division of labor, in their politics and social life" (p. 1055).

Smalley (1986) discusses the changes that took place in Hmong life and culture during this time and points out that the restrictions on movement 
out of the camp brought a halt to the Hmongs' semi-nomadic way of life, as well as limiting possibilities for economic self-sufficiency (p. 18). In fact, Cha and Small maintain that these limitations were planned. Camp officials, they claim, practiced a "general policy of 'benign deterrence,' which means that day- to-day life in the camp is not made to be attractive, so that refugees will not want to continue to stay there." This policy, they say, was intended to restrict economic self-sufficiency (p. 1048). According to Quincy (1995), providing "less than minimal assistance to the camp inmates" was planned by the Thai government "as a disincentive for other would-be immigrants " ( $p$. 215).

In addition to economic changes, Smalley points out that extended families were often disrupted in the desperate flight from Laos, and camp conditions placed further limitations on the ability of family groups to stay together. Furthermore, many extended families were separated as immediate family groups were sponsored at different times and resettled in different areas and sometimes even different countries. According to Strouse (1985), the refugee immigration policy was based on the belief that dispersing the refugees across the United States would prevent "ethnic clustering." It was thought that by avoiding the concentration of refugees in any particular area, no one area would be overly burdened by the social, economic and educational changes and demands resulting from a rapid increase of immigrants (p. iv). Moreover, Strouse says, the "government policy makers believed that by spreading refugees among the fifty states it would guarantee that refugees, their language and culture would remain unidentifiable" (p. 20). 
Smalley (1986) emphasizes that the experience of the Hmong coming into the United States was much more diverse and complex than most people realize. According to Smalley, how individuals dealt with these changes varied:

Some people had been swept along by changing events, without learning to do much more than minimal coping for survival. Others had responded to the new situations by learning new skills and adapting creatively to new opportunities. (p. 18)

Resettlement in the U.S. Southeast Asian refugees admitted into the United States since the late 70's have been a very diverse group in ethnicity and culture, education and skills, economic status, and religion. However, they have generally held in common, as they entered the United States, the physical and emotional suffering from war, disruption of family, homelessness, dependence on government or charitable assistance, and the necessity to learn to function in a new language and culture. The Hmong, according to Haines (1989), because of their former isolation, rural background, and their lack of education and transferable occupational skills, "arrived with comparatively fewer 'human capital' resources than any other legal immigrants in recent U.S. history, and experienced much more traumatic migration histories" (p. 143).

\section{Women in Research on Traditional Hmong Society in Southeast Asia}

In the early 1960's the government of Thailand and U.N.E.S.C.O. commissioned an anthropological survey of the mountain tribal groups including the Hmong. Geddes participated in this survey and in another U. N. 
study in the early 1970 s. From these he produced an in-depth descriptive study of Miao (Hmong) living in a single large village in northern Thailand. This work, Migrants of the Mountains (1976), includes an analysis of the economy, history, and description of social relationships of the Hmong .

Geddes discusses Hmong women primarily in relation to their roles as wives and he admits that he has, in this study, "looked at the society from a man's point of view" (p. 47). According to Geddes, women do not participate in public debates or negotiations and their input is usually limited to private deliberations within the family (p. 61).

Geddes emphasizes the importance of clan groupings which are fundamental to Hmong social structure and marriage lines. In this patrilineal system, women are brought in as wives to their husband's clan and their husband's clan then has rights over a woman to keep her and their children (p. 57). Because of this system, Geddes says, that when considering clan membership, the status of women is much more ambivalent than the more secure status of men, and that the political dominance of men is maintained by this ambivalence. When a woman joins her husband's clan through marriage, she changes her "spiritual allegiance" from her father's clan to her husband's, participates in the religious ceremonies of his clan, and "when she dies, her spirit joins those of her husband's clan" (p. 61). Women are brought into the husband's clan and marriage is assured through the payment of a bride-price. Geddes asserts that the most important utility of bride-price is "the symbolization it gives to a new creative act" and that it celebrates the worth of the woman (p. 58). It also means that in order to divorce, the husband must be generously compensated by the wife or her 
parents (p. 59).

Another important ethnographic study of the Hmong came from Cooper (1984), who did fieldwork in the 1970 s in northern Thailand. In this work, Resource Scarcity and the Hmong Response, Cooper uses an historical approach and focuses on economic changes and the adaptations made by the Hmong to these changes.

One significant economic change, Cooper notes, that affected the role of women in Hmong society involved the transition from subsistence farming to cultivating opium on a large scale as a cash crop. This transition from an economy based on trade to a monetary system affected social relations and the division of labor, with women taking on more of the labor and the men taking a more authoritarian role in handling negotiations and sales.

However, Cooper points out that "the ideology of male supremacy in Hmong society goes back far beyond the introduction of large scale cash-crop opium production" to their roots in China (p. 138). The "institutional selling of women" in marriage arrangements is an example Cooper gives in relation to this traditional sexual inequality (pp. 134-135).

Tapp (1989) presents another view of Hmong culture and history in his work Sovereignty and Rebellion, which is based on years of fieldwork and extensive interviews conducted with "all household heads" (p. 6) in a Hmong village in northern Thailand. Rather than a general ethnographic study, Tapp focuses particularly on Hmong geomancy, messianism, and literacy. Tapp supports his extensive fieldwork and presentation of Hmong history and belief with folk tales and legends. This was done, he says, in order to include "the ideas and statements of actors about themselves and their society" (p. 3), 
although it should be noted the "actors" he interviewed were all male "household heads" (p. 6). This strategy is especially relevant for the Hmong in light of the fact that the Hmong had no written language until the 1950s when Catholic and Protestant missionaries designed one using the Roman alphabet. Instead, they have relied on a rich oral tradition to pass on their history and culture.

Given the traditional subordinate role of women in Hmong society, it is, perhaps, not surprising that women are rarely mentioned by researchers as key players in historical contexts or as informants in ethnographic accounts. Furthermore, the major ethnographic works about the Hmong in Southeast Asia were written by men. Indeed, Donnelly (1994) claims that "all the works published about the Hmong in Southeast Asia so far have been written by men, who have had little access to the conversations of Hmong women, even though they have sometimes been interested in it." What has been written about Hmong women in Southeast Asia, she claims, is "an external view of women's place in Hmong society rather than conveying the women's own perceptions of their experiences" (p.14).

One exception to Donnelly's claim that all research on the Hmong in Southeast Asia has been produced by men and that women's perspectives have been overlooked is Cha and Small's 1994 study "Policy Lessons from Lao and Hmong Women in Thai Refugee Camps." These two women examine the role of Hmong women in several aspects of camp structure and services, including administration, service, and training programs in Thai camps. Cha and Small found that Hmong women did not participate in camp leadership; in fact, they found no women in any of the groups with decision- 
making responsibilities (p. 1049). The women's representation by men weakened their contribution to the development or implementation of camp policies and programs. This "invisibility of women," they suggest, "translates into programs that fail to understand or meet the needs of women refugees." Consequently, they claim, women often view the programs as irrelevant, and this leads to the scarcity of women participants in any camp programs (1049).

Research on the Resettlement Experience of Hmong Women in the U.S.

The body of literature on the Hmong resettlement experience since the early 1980 s is fairly extensive and varied: from "Butchering the Hmong Way" (Ashenbrenner, 1992) to ESL teaching guides; from longitudinal studies on "Factors in Individual Acquisition of English" (Green \& Reder, 1986) to statistical analysis of Hmong pregnancy and birth weight (Helsel, Petitti, Kunstader, 1992). These studies cover topics in acculturation, native crafts, vocational skills, gardening, health, resettlement and resources, and education and language learning concerns. However, in relation to first generation Hmong women and their participation in and perspectives on Hmong history and culture and the resettlement process, there is relatively little material available, most of it having to do with traditional crafts, literacy, and health.

Mason (1986) addresses the issue of vocational training for Hmong women. For this study she surveyed employment training programs available to Hmong women in the Minneapolis area, collecting statistical data and interviewing administrators, instructors and Southeast Asian interpreters involved in employment training. Mason contends that training programs 
accessible to women have been "inadequate and inequitable." Furthermore, she says that vocational programs "targeted for male heads of households. . . prepare them for employment in the economic mainstream, while women are channeled into ... marginal work such as housecleaning and cottage industry sewing" (p. 101). These findings confirm Cha and Smalls' (1994) observation of the lack of Hmong women's input in refugee camp programs in Thailand and the subsequent failure of the programs to meet the refugee women's interests and concerns.

Changes in Hmong attitudes about marriage are examined in a study by Meredith and Rowe (1986) in which they interviewed Hmong men and women in Omaha using a questionnaire on values. Several aspects of critical shifts in relation to marriage concepts including the practice of polygamy, marriage age, and bride price, as well as more general concepts of gender equality in marriage are noted (p. 129) These shifts demonstrate, according to the authors, a move toward Hmong acceptance of American views. However, they also suggest that responses to statements on equality in marriage "reflected a strongly male-dominated society" and that "attitudes on the roles of husbands and wives had changed little" (p. 129).

A few educators and researchers have elicited the Hmong perspective through retrospective interviews and oral histories. Moore (1990) presents brief views of several male Hmong teenagers in Minneapolis, highlighting one young college student and giving some commentary on his story. In a more comprehensive work, Tenhula (1991) examines the resettlement experience and the common problems refugees face in this process in an extensive compilation of narrations, dialogs and poems with a variety of 
Southeast Asian refugees in the United States. He deals with quite a diverse group of informants from Laos, Thailand and Vietnam; however, he includes only three Hmong, all men: a general, a soldier, and a farmer.

Howard (1990) presents an anthology of the Southeast Asian refugee experience through short personal essays on the process of resettlement. In this project, Passages, Howard elicited and compiled essays from Vietnamese, Cambodian and Hmong students attending California State University in Fresno, California. She asked these young men and women to write about their feelings and memories of their past and current situation and "to re-encounter their painful wounds" (p. xi). The process of remembering and writing provided, Howard claims, a "release of loss, shame, and guilt," and brought about "a sense of forgiving and understanding which enabled them to take on new perspectives in their lives" (pp. xi-xii). This collection of autobiographical essays from Hmong college students in the United States, is intended, Howard says, "to provide the student writers' parents and grandparents a means of expressing their own 'deep sorrows through the voices of the young"' (p. xii).

A notable exception to the lack of first generation Hmong women's voices in research concerning the Hmong in the United States is Donnelly's Changing Lives of Refugee Hmong Women (1994). This work combines an examination of Hmong life in America supported with short passages of retrospective interviews from mostly middle-aged refugees who have been in the U.S. for less than eight years. Donnelly focuses on gender relations as she explores Hmong society, discussing traditional marriage, child-rearing, and gender roles, as well as changes in these areas. She points out that 
these areas, especially gender concepts, determine the challenges that Hmong face in attempting to preserve "ethnic hierarchies" (p. 183). Before marriage, a woman works under the command of her father and brothers and, once married, under her husband. "Access to choice," Donnelly maintains, "and therefore training and experience in decision making, was accorded to men and boys, but not to women and girls" because men provided the economic basis of the household, and "the unit of decision was actually the household, not the individual" (p. 29). Furthermore, Donnelly points out that the main reason for Hmong women to marry was to establish the framework for childbearing and raising and that it is not until a woman has produced children that she is considered an adult (p. 33).

In her examination of change in Hmong society in America, Donnelly suggests that the Hmong believe that the maintenance of these conventional household social relationships in the home provides the means for the integrity and continuation of their cultural identity (p. 184). She concludes that the changes in these relationships and roles she observed were not as great as she had expected. Hmong, she says, "can change their economic and educational goals, their clothing styles and household paraphernalia, parts of their vocabulary . . . and still be certain they are Hmong" (p. 192).

\section{Conclusion}

It is evident that there is a growing amount of literature in several fields, especially education and social sciences, concerning both Hmong culture and Hmong engagement in the process of acculturation, education and language learning, and employment. However, it is also evident that first 
generation and other Hmong women with household and child care responsibilities have often been overlooked or disregarded in relation to historical and ethnographic research, education, and program development. Except for Donnelly's work, their voices remain mostly unheard.

Many factors contribute to this omission. Hmong women hold a lower place in the social and family hierarchy than men. This limits their participation in decision making, public discourse, and contacts outside their extended families. In addition, family and children are a core value in Hmong culture and women are expected to subjugate desires or plans that may conflict with the demands and responsibilities of marrying young, bearing, and raising children. Furthermore, the vast majority of Hmong women had very little or no experience with formal education or literacy before arriving in the United States. Once here, their family responsibilities have often limited their participation in language programs which have usually not been set up to accommodate these women. As a result, language difficulties and inaccessibility to people outside their ethnic communities are contributing factors.

As a scholar, a mother, and as an educator, I believe that it is important to recognize the difficulties first generation Hmong women face; the support they give to their families' ultimate success in America; their potential for contributing to a better understanding and appreciation of Hmong culture, history, and resettlement; and the role their voices could play in culture sharing and the development of educational programs and curriculum. 


\section{CHAPTER III}

\section{METHODOLOGY}

\section{Introduction to Subjects}

In the fall of 1979 , after reading an appeal from the Catholic Relief Services, my husband and $\mathrm{I}$ and our four children decided to sponsor a family of Southeast Asian refugees. We applied, were accepted as sponsors, and received a list of six Cambodian and Laotian families from which to choose. We read and discussed the list over and over, feeling rather helpless in trying to make such an important decision with so little information. We finally made the decision based on the fact that one family from Laos had a baby who was only two moths old, the same age as our daughter. We knew their family name was Vang (all names have been changed to ensure confidentiality) and their ages, but the only other information we had was that this family was part of an ethnic group called Hmong, about whom we knew nothing.

At that time, we were living on a farm near a small town in the Grande Ronde Valley in the northeastern part of Oregon. This valley was surrounded by an extensive and very high mountain range and, because of the altitude of the valley, the climate was quite harsh during the winter months. It was an isolated rural area whose economy was based on logging, farming, and ranching. There was little ethnic, racial, or cultural diversity in the area and the political and social climate was conservative and somewhat provincial. 
This isolated rural environment offered some potential advantages to the incoming refugee families, especially since their livelihood in Laos had been based on farming and their lifestyle centered in small communities. However, it also meant that they would lack the support of a common ethnic community and that their physical and cultural differences would stand out more sharply. In addition, some social services for refugees were not available in the valley, and there were few ESL classes.

The first group of the Vang family arrived in the winter of 1979 . This group consisted of Doua Vang, the oldest son of the patriarch of the Vang family, Doua's wife Yalee, their two young sons, and an unmarried sister, Hua, who was about twenty years old. Doua was the only one of this group who spoke any English or was literate.

In the spring of 1980 , Doua asked us to sponsor his parents and other family members. By this time, we had learned much more about conditions in the camps in Thailand, as well as about the primary role of the extended family in Hmong society. Moreover, our lives and our children's' lives had already been changed and enriched by our friendship with Doua and his wife, children, and sister Hua.

Doua and Hua's parents, Chou Pao and Kia, arrived at the small airport in Pendleton, Oregon in June of 1980 along with their youngest daughter Mai, their youngest son Tsu, his wife Chia and daughter Chan. Needless to say, our lives became fuller and continued to change. The demands became greater, as did the rewards. Involved with children as I was at that time, I appreciated the gentle and attentive concern for the children, theirs and ours, that almost all members of the Vang family displayed. They maintained a 
sense of curiosity and humor, and their determination to reunite their family and willingness to care for and support each other was a meaningful model for our own family. It became obvious that we were fortunate to have as much to learn from them and their culture as they had from ours.

The expression of the vital process of reunification of the family could be seen in the great number of occasions to celebrate: American celebrations like birthday parties, July 4th, Thanksgiving and Christmas; and Hmong celebrations and ceremonies such as the birth of a child (three were born within the two years the Vangs lived in eastern Oregon), New Years, and occasions when Chou Pao, as shaman, decided it was time to reckon with the American spirits. Our farm afforded the space to gather and to raise, butcher and cook the pigs and chickens the Vangs raised for such occasions.

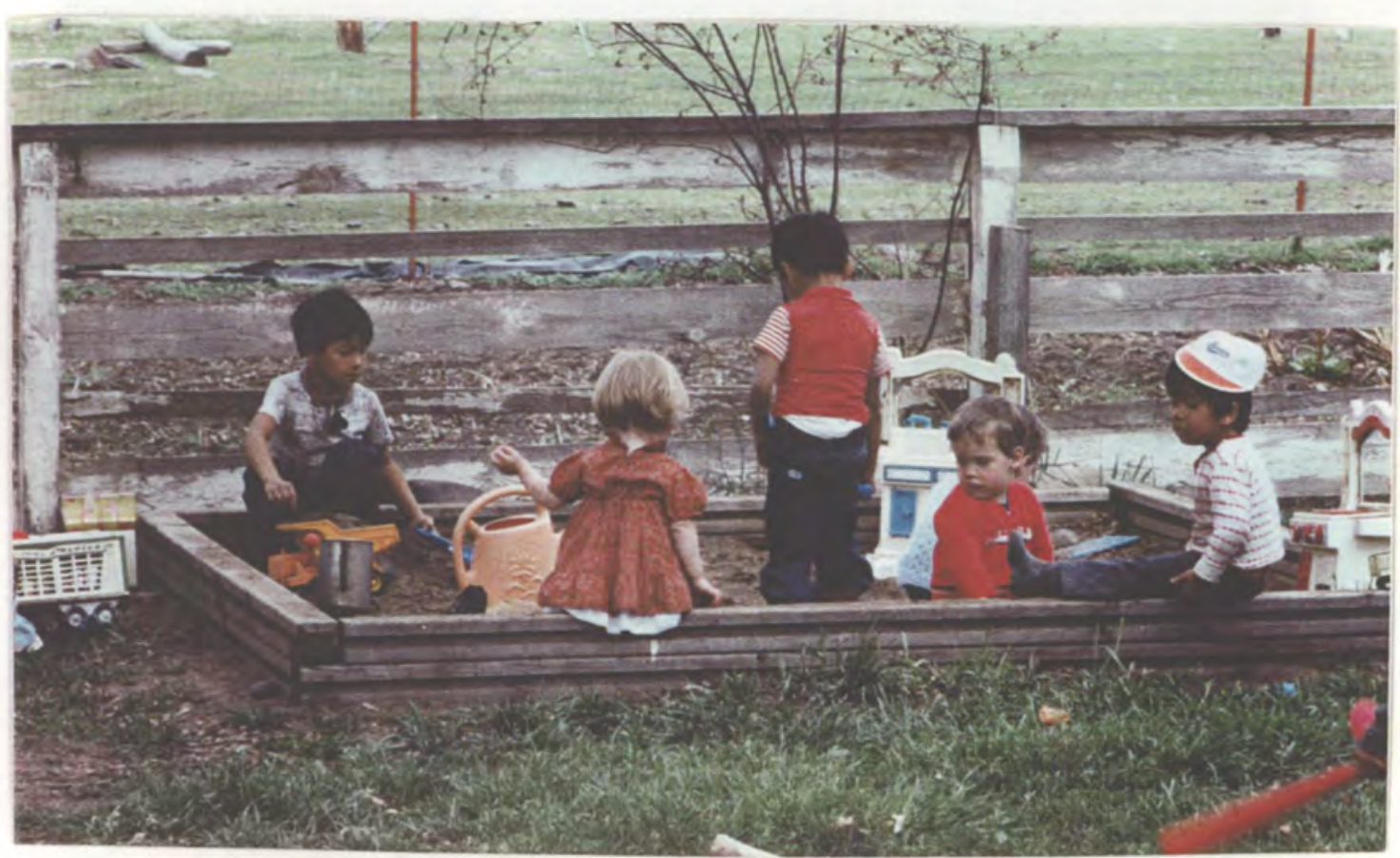

Figure 3. The Vang and Kimbro children and friends. Oregon, 1981. 
As our family's relationship with this extended Hmong family developed and became more familiar, my husband and I often found ourselves adapting to Hmong gender roles. Whether our families visited in their homes or on our farm, the men gathered in the living room or outside to drink beer and smoke American cigarettes through Chou Pao's three-foot long bamboo water pipe, while the women clustered in the kitchen cooking, holding or nursing babies, and attempting to communicate about children, food, and husbands.

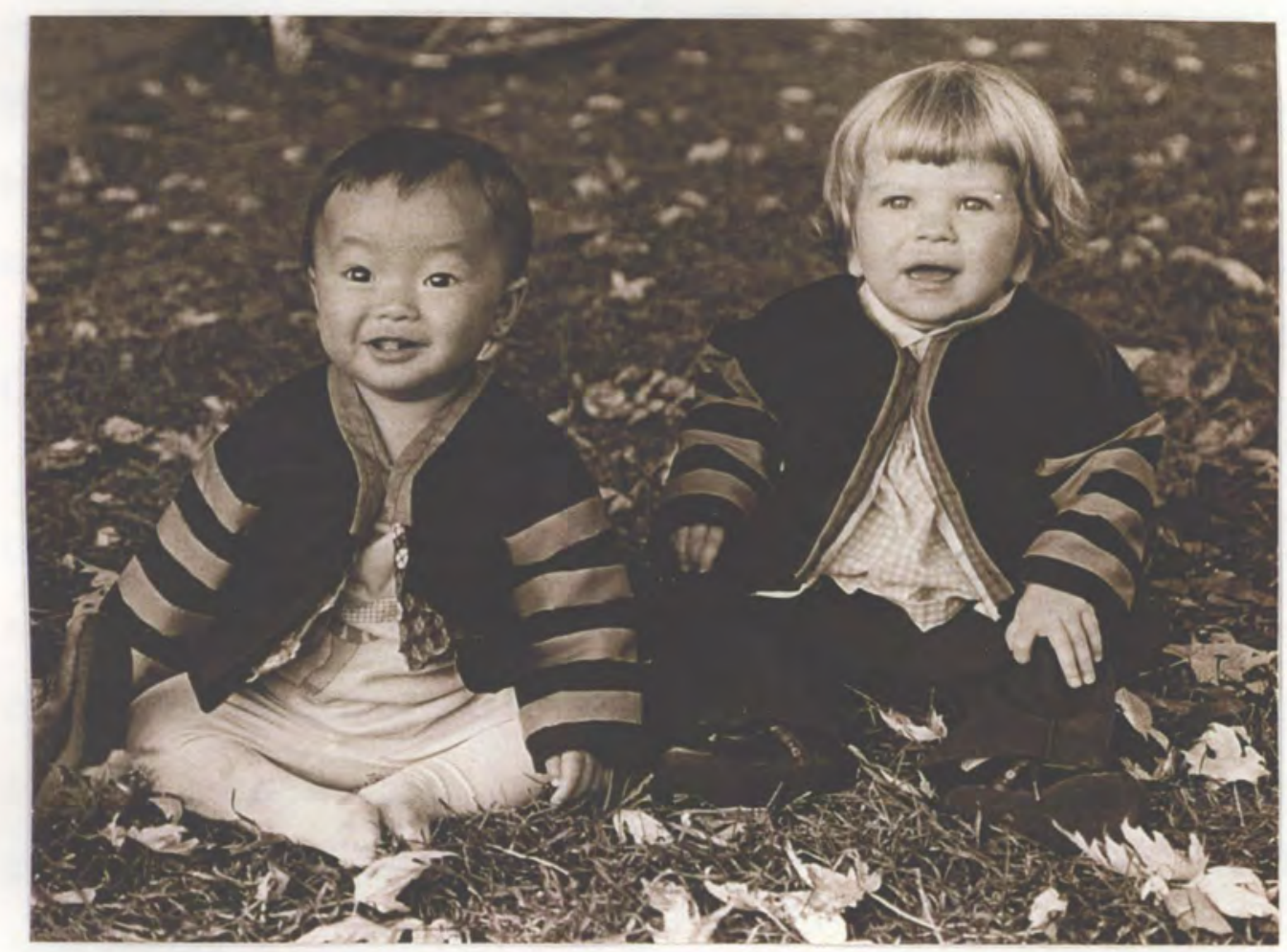

Figure 4. Chan Vang and Maria Kimbro. Oregon, 1981.

Although Doua, the oldest son, held a few jobs over the next year, unemployment was very high in the area and the younger son, Tsu, was unable to find work. Doua's family refugee assistance had run out and the other part of the family faced the same problem in the near future. Funding 
for adult ESL classes was quite limited and in the public schools it was nonexistent. Furthermore, although they had a little land around their houses, the Vang's were frustrated by the fact that they couldn't plant until after the last freeze, usually in mid-June.

Members of the Vang's extended family, including Chou Pao's first wife, Joua, and her grown children and their families, continued to arrive in the United States. A few of Joua's sons who had been placed in California encouraged the rest of the family to join them. In the spring of 1982, all of the Vang family moved to California. They joined relatives as well as a growing Hmong community--- "ethnic clustering" (Strouse, 1985, p. 4) at work in spite of government policy.

\section{Description of Informants}

Family Background. The Vang family originally lived in a village near Luangprabang, Laos. The head of the Vang family, Chou Pao, was a village shaman and also performed the official duties of judge for the Hmong community. Although he sent his sons to elementary school in Laos, Chou Pao himself never went to school and was illiterate. In the late 1960s, most of the people of their village were forced by the war to move closer to Thailand, near the city of Sayaboury.

In 1975, as the war spread and intensified, the Vang family left Laos and walked into Thailand. When Chou Pao fled to Thailand, he was accompanied by his two wives, seven sons and their wives and children, and three unmarried daughters. After several of Chou Pao's older sons immigrated to the United States, Chou Pao and his remaining sons and 
daughters joined them. According to immigration documents, Chou Pao and Kia were both about forty-five years old when they arrived in the United States. Most of the members of the family now live in California, although one of Chou Pao's daughters lives with her husband in France and one of Kia's daughters from her first marriage remains in Thailand with her husband.

Mai Vang. Mai is the youngest of the six children of Chou Pao and Kia Yang (married women usually retain their clan name). She was born in Laos in about 1965, and was about eleven years old when her family fled to Thailand; however, birth dates were not customarily remembered or recorded in traditional Hmong culture in Laos. Consequently, specific birth days, months and even years had to be chosen for each individual applying for immigration status in Thailand. When she came to the United States, Mai was about sixteen years old and unmarried.

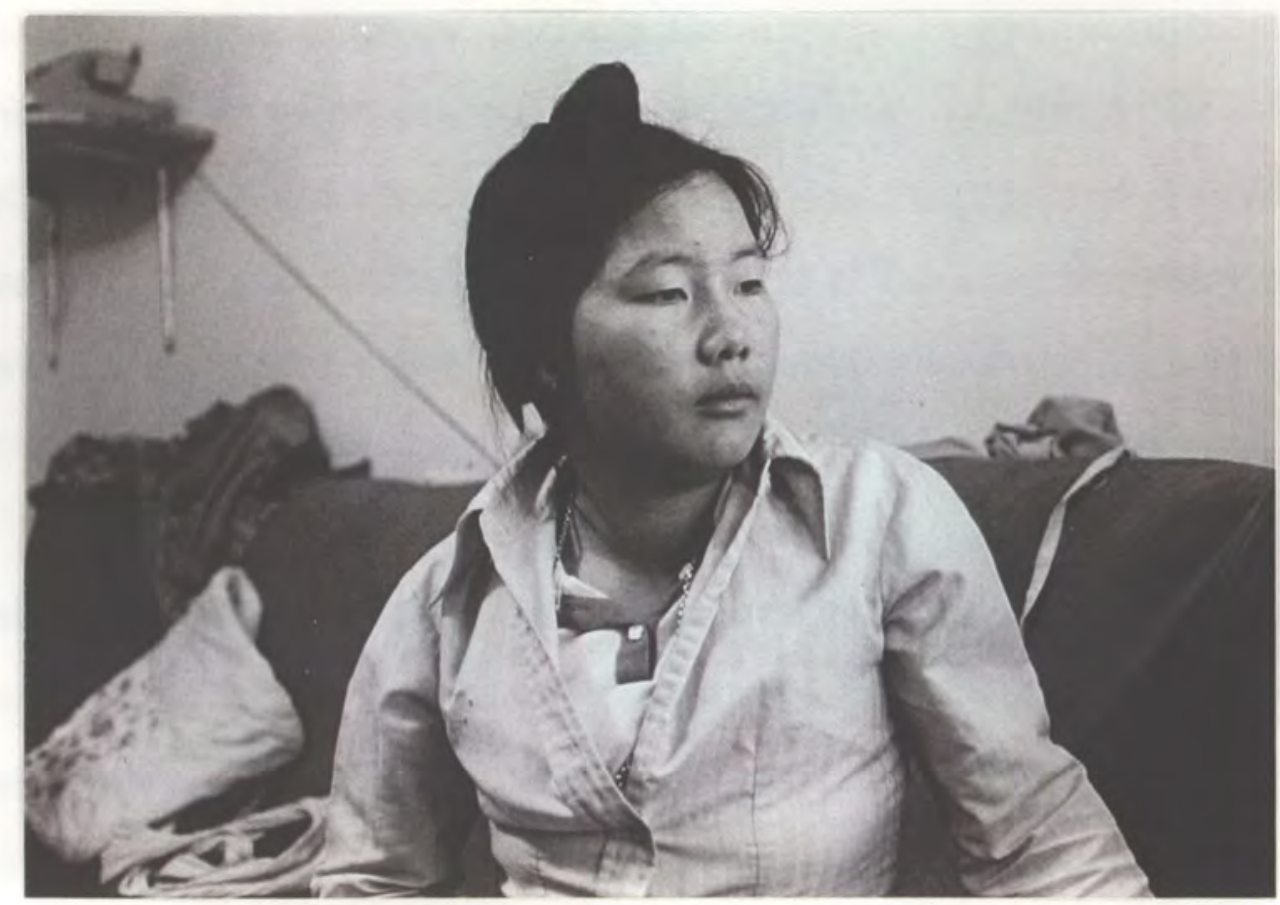

Figure 5. Mai. Oregon. 1981. 
In spite of the fact that she had never attended school in Thailand or Laos, was illiterate, and spoke no English, Mai was required to enter high school after her arrival in eastern Oregon. The small rural high school she attended placed her in Special Education classes since ESL instruction was not provided. She eventually graduated from high school in California with low level reading and writing skills but with fair communicative competence in English.

Mai now lives in Sacramento in a low-income suburban neighborhood within a few miles of her married sister Hua and her brothers Doua and Tsu. The neighborhood is ethnically and racially diverse with a predominance of African Americans and Southeast Asians. Mai and her husband rent a very small, modest, but fairly well-kept two bedroom house. Across the street and running a block in each direction is a row of empty houses, boarded up and in various states of decay. Mai expresses fear of harassment and crime in her immediate neighborhood. In an incident a few years ago, her mother, Kia, was threatened and chased by some local teenagers while walking some of the grandchildren home from a visit at Tsu's house several blocks away. Consequently, Mai does not walk through her neighborhood nor allow her children to play outside.

Mai and her husband have five children; the youngest and only son is about a year old. Although their oldest daughter attends a nearby public elementary school, their second daughter, Sandra, is learning disabled, and, at five years old, can speak only a few words. She is bussed a few mornings a week to a Special Educational program. Mai stays at home to care for her, her twins, and the baby. 
At home, she cultivates an intensive and quite productive garden in a very narrow strip of land, fenced off from her neighbors, which comprises her "backyard." From her garden, Mai provides her relatives with herbs and vegetables, and she displays an extensive knowledge of the medicinal properties of many of these native Southeast Asian plants.

Although household responsibilities and child care place limitations on her time, Mai joins her extended family, often on a daily basis, in activities including child care exchanges, family ceremonies, attempts to remedy health problems, or emergencies in the family.

Chia Her. Chia Her is the wife of Tsu Vang, Chou Pao and Kia's youngest son. She was born in Laos in about 1961. When she was a child, Chia's father died and her mother remarried. Consequently, Chia was separated from her mother and lived with her father's family, helping to care for her paternal grandfather. When she was about ten years old, Chia's family left Laos and settled in the Soptuang Refugee Camp where she eventually met and married Tsu Vang.

Chia was about eighteen or nineteen years old and had a seven month old daughter when she arrived in Oregon with her husband's family. Chia has never attended school, but her children and husband have taught her the alphabet and to write and sound out some English words. She is eager to become literate. Her verbal communication skills are strong.

Chia and Tsu have nine children and live with Chou Pao and Kia in a crowded three bedroom house near the rest of their extended family in Sacramento. Their neighbors on one side and across the street are Hmong. A Samoan woman, who lives next door, is one of the few people Chia speaks 
to on a regular basis in English besides her children.

In addition to her children, Chia is expected to care for her "father," Chou Pao (following Hmong custom, Chia refers to her husband's parents as her "father" and her "mother"). This requires much time since both her "parents" are frequently sick and frail. She does, however, get some help from her "mother," especially with the younger children who are very attached to their grandmother. The older children of Chia's brother-in-law Doua are frequent visitors since their mother died. They show up especially at mealtimes or when they have difficulties with their step-mother. Chia's own mother is still in Thailand because her husband has refused to immigrate. Chia and her mother continue to correspond. Since neither woman is literate, their correspondence is in the form of cassette tapes.

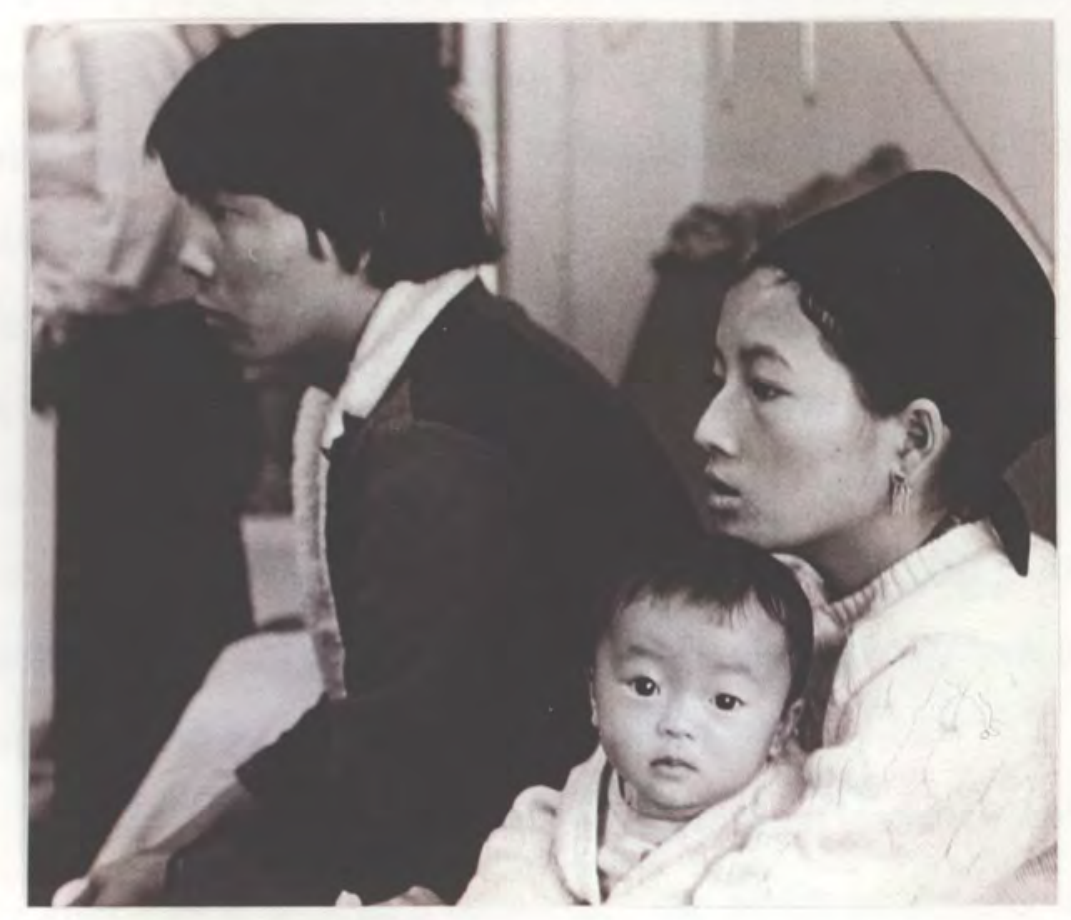

Figure 6. Chia and Tsu and Chan. Oregon. 1981. 
Development of Research Topic

My continuing involvement with these Hmong women, as well as my own experiences as the mother of six children, led me to a deep appreciation for the challenges faced by these refugee women whose lives were necessarily centered around child-bearing, child-rearing and household responsibilities. Over the years of my association with the Vang family and their relatives, I observed changes as the family adjusted to a new cultural environment. At times, conflicts between the first and second generation members of this family became apparent. This process of acculturation inevitably at work appeared to be countered to some degree by an active practice of Hmong traditions as well as pragmatic adaptations and creative compromises of both Hmong and American culture.

On my part, questions began to arise over the years that would later become a part of this study. What was it like to be a young Hmong girl growing up in a refugee camp? How had their experiences in the camps in Thailand affected their traditional family structure? Which American customs, behavior, or expectations worried them or made them laugh? What did they think about how we treated our children; the way in which American men and women related to each other; or our health care practices? What effects was American culture having on Hmong customs? What kinds of strategies were they using as they attempted to learn English and how could I encourage and facilitate this difficult process?

This association with these Hmong women and their families led directly to my intention to choose a research topic which would provide an opportunity to explore the culture, history, and language development of 
Hmong refugee women. Moreover, two of the women, Mai and Chia, were able to communicate in English and disposed to conversation.

\section{Theoretical Approach and Method of Inquiry}

My intentions to explore the culture, language development, and history of these Hmong women were predicated by the following assumptions. The first assumption was that the data that could be provided by these first generation Hmong women was a potentially valuable resource for the study of both culture and language education. Secondly, these women had powerful and crucial perspectives to contribute to historical and ethnographic accounts. The final assumption that guided the direction of this study was that two of the women were both competent and eager to tell their stories.

These assumptions mandated an emic perspective, in which the basis of the research is an "insider's" view of reality and which assumes the acknowledgment of multiple realities. This "phenomenologically oriented" paradigm, that Fetterman (1989) calls the typical model for ethnographic research, looks at reality as subjective and takes on a multicultural perspective because of its acceptance of multiple realities (p.15), in opposition to a positivist paradigm which theorizes the existence of an objective reality. A phenomenological paradigm appeared especially relevant because of the multiple realities that are inherent in any cultural study involving distinct gender roles. Moreover, multiple realities in relation to these particular women would necessarily come into play within this study. These realities would include the more traditional Hmong culture of the informants' lives in Laos and Thailand interacting with their exposure and 
acculturation over time to an American reality. The acceptance of multiple realities in our views of history or ethnography, as opposed to one objective reality, necessitates the inclusion of emic perspectives, without which history or ethnography are incomplete.

Johnson (1992), discussing the theory that informs research studies, suggests that epistemology, or the relationship of the "knower to the known," also guides the researcher in choosing either an objectivist or subjectivist approach to research. An objectivist epistemology, Johnson explains, claims that research can be objective and value free and is employed more frequently in quantitative studies, while a subjectivist epistemology maintains that the researcher can not be separated from the subject of the research endeavor and is the common approach taken in qualitative research (pp. 3132). Researchers, she claims, "bring their values into their research through theories they employ as guiding frameworks, through choices about what to study and what to exclude from study, and through the methodologies they use" (p. 32). Choosing a qualitative rather than quantitative approach for this study was, in part, based on the fact that I neither could, nor wanted to, distance myself from my informants and assume an objectivist epistological view of inquiry. The most essential premise on which this study was based is that these women are themselves "experts" on Hmong culture and the refugee experience in America and that their views are as valid and valuable as my own or as the views of the ethnographers or researchers who have tended to overlook their input.

Furthermore, my personal relationship with the Hmong had prompted my interest in an holistic exploration of their culture, life experiences, and 
perspectives, rather than focusing on one particular aspect of their lives, culture, or language development. Hoopes (1979), contrasting qualitative and quantitative approaches, asserts that "we not only must know the facts but must also imagine what the facts meant to the human beings who lived them" (p. 4). This subjective and more holistic view of research, possible in a qualitative approach, appeared more appropriate to my own intentions and to my expectation that this study would be significantly more meaningful if it could serve a direct and immediate purpose to the Hmong families involved as documentation of a part of their family history.

My choice of a qualitative approach pertains to my assumption that these women had powerful and crucial perspectives to contribute to historical and ethnographic accounts and to their families. These Hmong women, like most first generation refugees, fill a distinctive position in their culture, representing transitional cultural perspectives, insights, and practices that will be irrevocably changed and possibly lost in the process of acculturation in the next generation. Because of their focus on the family, their perspectives could be especially potent contributions to information about gender and family relationships since, as Seldon and Pappworth (1983) point out, "how relationships function in practice is often very different from how they are officially supposed to work" (p.39). These women in particular, representing a transitional culture, might be able to supply compelling oral evidence. and a qualitative study, in which the women's voices could be heard without the imposition of predetermined goals reached through a quantitative process employing questionnaires, surveys or measurements, would be the appropriate approach to explore my assumptions. 
Although theory may serve as a guide to method, in some cases, the method is sometimes also guided by the potential research situation. For example, the environment in which my contact with the informants would take place precluded an interventionist methodology. From personal experience, I knew that the environment and family situation in which these women lived was demanding of their time, group orientated, and filled with unplanned activities and unexpected emergencies: an environment in which the intervention of the researcher in setting up the situation, or controlling variables or contextual factors would be not only inappropriate but also impractical.

Ultimately, I knew that in exploring the memories and perspectives of the life experiences of these Hmong women, my familiarity with the family might tempt me to impose my own perspectives by anticipating particular answers or determining the content and direction of the interviews. In addition, being well aware of the active and often unpredictable nature of daily life in a household with many relatives and children, I knew that I would need to keep the interview process flexible and informal. Furthermore, I wanted to avoid a situation in which my informants or their families felt that they were objects of scrutiny or in which they felt obligated to answer questions on subjects which made them uncomfortable. Finally, because of my past relationship with my informants as sponsor and friend, we had already become part of each other's history and I knew it would not be possible to distance myself entirely from these women and their families in the process of conducting research. For these reasons, I anticipated that a qualitative model in which the informants actively participated in the selection 
of the form, content and direction of the data would allow for a deeper and more valid understanding of the experiences, concerns and themes that the informants might discuss. I became convinced that a loosely structured, open-ended oral interview process that was both retrospective and conversational would serve as an appropriate method through which to elicit individual points of view of personal history, perceptions of resettlement and current concerns, and to explore the research questions.

\section{Procedure}

The interviews were conducted during three visits with the Vang family in Sacramento between 1992 and 1995. Each of the visits was approximately a week long. During these times, I stayed in Chia's, Mai's or their sister Hua's home. This arrangement, although distracting, proved to be advantageous. For one thing, it afforded opportunities for visiting with curious neighbors, talking or playing with the children, or making courtesy visits to other relatives' homes, so that hours spent interviewing could be relatively uninterrupted without being perceived as rude. Furthermore, since it was often impractical to schedule the interviews ahead of time due to inevitable demands or emergencies usually related to children and relatives, my being on hand allowed us to take advantage of unexpected quiet stretches of time or to leave all the older children at Chia's house, while Chia and I took the babies to Mai's house where we would find a relatively quiet setting. The most significant advantage to this arrangement was that all the interviews were conducted in a setting natural to the women involved: physically and emotionally more comfortable than a public or even private 
formal setting.

My ongoing presence in my informants' homes imposed disadvantages as well, most notably, the difficulty in saying "no" to proposed activities, adventures, or meals when I needed time for writing notes and reflections on the day's interviews and related experiences and observations. However, most everyone went to bed early in all three households and I tried to use that time to at least make notes on the day's work and prepare for the next interview. Recopying notes or transcribing anything was usually out of the question. I must admit, this was the most difficult aspect of the project. Unfortunately, I read Ives' (1994) useful suggestion to put your field notes directly on cassette tape and transcribe them later (p. 47) after I had completed all the interviews.

This natural setting most often included the presence of young children who interrupted now and then, but didn't usually influence the content of the conversations. However, I quickly discovered on my first visit that it was always necessary to conduct the interviews when the informants' husbands or other male relatives were not present. If present when questions were asked, even those spoken directly to the women, the men would speak for them, explaining, supplying words, and quickly taking over the conversation. Consequently, the women often drifted off to quiet the children, answer phones, or begin cooking. Interestingly, this male dominated conversation occurred even if the womens' language skills were better than their male relatives.

The narratives were collected as audio recordings. The number of interviews and their length were determined in part by the immediate 
situation, with sessions running from about forty-five to ninety minutes at a time with brief distractions from children playing or arguing, roosters crowing, and curious relatives dropping by. There are a little over thirteen hours of recordings, equaling 250 pages of transcribed conversations, including two thirty to forty minute interviews with Chia's husband and with their two oldest daughters.

The informants were interviewed together and separately, depending on their accessibility. During most of the interviews, both women were present, although one might leave the room for a few minutes and then return. One ninety minute interview with Chia alone was recorded. When together, one woman would usually speak, while the other handled distractions. While seldom directly interrupting each other, Mai and Chia did not hesitate to add information, explanations or supportive anecdotes.

The content of the conversations fell into three categories: retrospective narrative in which one woman discussed her past experiences; descriptions or explanations of Hmong customs and traditions and comparisons with American culture; or conversations about current concerns, situations, or problems. In the latter two categories, the interviews, if both women were present, became more interactive and conversational. Although I usually began the direction of an interview with a retrospective question, the content was fluid. Sometimes a sustained narration of past experiences occurred, loosely following a chronological pattern. At other times, the women digressed: for explanations and analysis of customs and behavior; for questions about comparative American behavior; for providing a relevant anecdote; and for expressing anxieties or problems in their current lives. 
The following, is an example of one interview session conducted at Chia's house on my third visit. Present are Chia, Mai's daughters, and myself:

We are gathered in the living room around the coffee table. Mai sits on an easy chair and Chia and I sit with Sandra (Mai's second daughter) on the couch across from Chia. The room is very small and the drapes are closed so it's kind of dark. The TV is on, but Mai turns the sound down. Sandra is watching the picture, laughing and dancing to some imaginary music. She touches the tape recorder on the coffee table between us and Chia pulls her around onto her lap. I start the session with a question: 'When you were in the camps before you came to the U.S., were there things people told you about the U.S.?

While Chia talks, one of the twins (five months old) crawls over fussing. Mai wraps a baby blanket around her tightly, bounces her on her knee while she talks, eventually giving her a bottle and holding her closely and she falls asleep. Both women contribute, back and forth with stories about the bad things they were told might happen when you go to America. Mai says they were scary things, but they're both laughing as they speak. (personal journal entry, April, 27, 1995) In the beginning, after reading my notes the night before, I planned questions to ask in order to fill in gaps of time in the retrospective narrative. In addition, I thought I might need to have some questions on hand to keep conversation going. I found, however, that after the initial question, I often did not need or want to bring up a topic or ask a leading question. Instead, Mai and Chia readily brought up subjects or quickly filled in pauses. We became 
immersed in the telling or listening--the process--and any goals I might have set were never reached in a linear fashion.

Although the narratives were elicited through unstructured interviews with open-ended questions allowing the informants to direct the form and content, other questions were posed in order to make sense of the information or to fit it into a chronological framework that corresponded to the other informant's experiences. These other questions to the informants tended to be for the following purposes: to clarify relationships--Interviewer: "Your mother's brother?" Chia: “No, it's my father's father." (Transcript \#1, p. 1); to establish place-- Interviewer: "Was that in Laos?", Chia: "Yeah, in Laos" (Transcript \#1, p. 1); or to clarify information--Mai: "But in our country we never kiss, we never hug and we are shy." Interviewer: "Even the husband and wife?" (Transcript \#2, p. 45). Other questions developed or were refined in the process of interviewing.

The process of creating the documents reflects the structure of these women's everyday life: dealing with distractions and disorder, organizing and reorganizing, changing expectations and direction, and remaining flexible. The conversational narratives that were created through this process reflect this decidedly non-linear structure as well. In addition, the interviews, usually involving essentially three speakers and three basic content categories were complex. In order to reveal the power of their stories without intervening with explanations or descriptions of my own, and for the purpose of cohesion and readability, I chose to present these two womens' words in reconstructed narrative form rather than the complete original 
conversational narration as transcribed from the taped interviews.

Changes to the transcribed narratives were made in four ways: separation of the informants' discussions into two individual narratives; changes in order; changes in language use; and elimination of data.

Separating the individual womens' discussions was facilitated by the fact that when they spoke, they most often directed their conversation to the interviewer rather than to each other, whether discussing a past experience or current concern. Additionally, these conversations did not usually include interchanges that depended on the other informant's response. Interaction between informants did occur occasionally when one or the other was reminded of a related experience, wanted to add her own view on an issue that the other one had brought up, or tried to help the speaker with troublesome vocabulary. The following is an example of this type of interaction taken directly from the transcribed interviews. At the time, we were looking at some photos of Mai and Chia taken when they had first arrived in Oregon:

Mai: I look a little like a old lady.

Interviewer: No you don't. Look at that. That's beautiful!

Mai: (laughs)

Interviewer: You look like a movie star.

Mai: Looks like I had like . . how do you call? (points to her neck in the picture)

Chia: Diarrhea.

Interviewer: Diarrhea? (all laugh) I don't think so.

Chia: She say she look like she have diarrhea (all laughing). 
Interviewer: Thyroid? (laughs).

Mai: (laughing) Yeah, thyroid! I look like that.

Chia: You know after I deliver my baby, so they say I had thyroid. Interviewer: Thyroid problems?

Mai: You remember when we living with you in Oregon, they told me and my mom that mom and me had 'thryarrhea.' (Transcript \#3, p. 17) At this point, the discussion moved from thyroid problems in pregnancy to Chia's description of her grandmother's thyroid operation in the camps in Thailand. In any case, although interacting at times in this way, Mai and Chia rarely contradicted each other and never argued.

Because of my association with the informants, I was familiar to some degree with the context and time frame of many of the events they described. For this reason, I could more easily collect the data without enforcing a strict chronological form and wait until after transcribing the data to establish a more chronological order. However, the natural division of the narratives as personal history; comparisons and points of view of Hmong and American culture; and descriptions, anecdotes and views on the informants' current lives led me to decide to reconstruct the narratives in thematic as well as chronological order for the dual purposes of culture sharing and creating an oral history.

Each woman's retrospective narrative was placed in the following chronological order labeled according to where the informants were living at that time, even though they were not necessarily expressed in this order in the original transcripts: Laos, Thailand/Refugee Camp, Eastern Oregon and California. 
Discussions of experiences and concerns in California were organized both chronologically and thematically around marker events or particular issues. These thematic categories include descriptions, feelings, and opinions or anecdotes related to a particular subject. The categories themselves were organized in a natural chronological pattern; for example, Marriage came before Pregnancy/Childbirth and Motherhood/Children. The topics the women chose most often to discuss in relation to their present lives in California included the following: Marriage, Pregnancy/Childbirth, Motherhood/Children, Health Concerns, Citizenship, Ethnic Discrimination, Language Concerns, Work, School Concerns, and Tradition/Change.

Changes in language use involved the elimination of repetitions of words or phrases, unfinished thoughts, words or phrases that were incomprehensible, fillers like "uhmmm" or "ahhh," misused or missing prepositions that made meaning unclear, and simple present verb tense where simple past tense was appropriate. The Hmong language does not use morphemes to indicate verb tense (Quincey 1988, p. 20); therefore, while wanting to preserve the original vocabulary and structure, I felt that changes from simple present to simple past tense would facilitate readers' understanding and would not detract significantly from the informants' individual expression of English language. Chia and Mai, although using simple past tenses for some verbs (particularly "be"), often spoke about the past in the present tense, sometimes using adverbs or adverbial phrases to indicate time. Frequently, only context provided the time reference. In order to clarify and make the narratives more readable, I changed present tenses to simple past as the following example demonstrates: 
Direct Transcription:

Mai: My father marry really young, but Joua I think she's older than my father cause my father don't have the mother, only the father and stepmother. The step-mother doesn't like them and doesn't love them and the $\mathrm{Pa}$ told him to marry young when he was teenage or something. (Transcript \# 1, pp. 43-44)

Reconstructed Narrative:

Mai: My father married really young, but Joua I think she's older than my father cause my father didn't have the mother, only the father and step-mother. The step-mother didn't like them and didn't love them and the $\mathrm{Pa}$ told him to marry young when he was a teenager or something.

Elimination of data included repetitious words, phrases, or content; speech directed at others not involved in the conversation (usually children); incomprehensible material or incomplete thoughts; personally sensitive content or content that had been requested to be omitted by the informants; and all of the interviewer's questions and comments.

\section{Conclusion.}

It was my intention throughout this project that the womens' voices speak for themselves and that my most important role as researcher was to allow them the opportunity to tell their stories. No individual researcher, however, from whatever background can be entirely neutral, whether involved in quantitative or qualitative research. Each brings into the research experience his/her own values and perspectives and, as Brown (1987) points 
out, "there is still a tendency for us to believe that our own reality is the 'correct' perception" (p. 123). Admittedly, my own personal and cultural perceptions and experiences have influenced my views and feelings about the Hmong people and culture, as well as the purpose and procedure of this study. Although, for the most part, I was able to avoid intervention to some degree in the setting or manipulation of the interview process, my relationship and interaction with my informants in that process necessarily influenced the results. Furthermore, my decision to reconstruct the interviews imposed my own standards for a reconstructed narrative form that was cohesive and coherent. In addition, my choices of what data to omit reflected my perceptions of what data was informative, interesting or valuable enough to include in the reconstructed narratives. In this endeavor, I have not presumed to be culturally neutral or value-free, but I have attempted in all aspects of the study and data collection that has directly involved my informants to allow the informants to speak for themselves, direct the content of the interviews, and to respond to questions in their own way or not to respond at all. 


\section{CHAPTER IV}

\section{THE CONVERSATIONAL NARRATIVES}

As previously stated, my intention throughout the development of this study has been to allow the informants to speak for themselves and to present their stories as a whole narrative, uninterrupted by the researcher's explanations or contextual descriptions. With this in mind, and recognizing that family relationships are an essential element of the informants' experiences and perspectives, I have included the following family tree for reference.

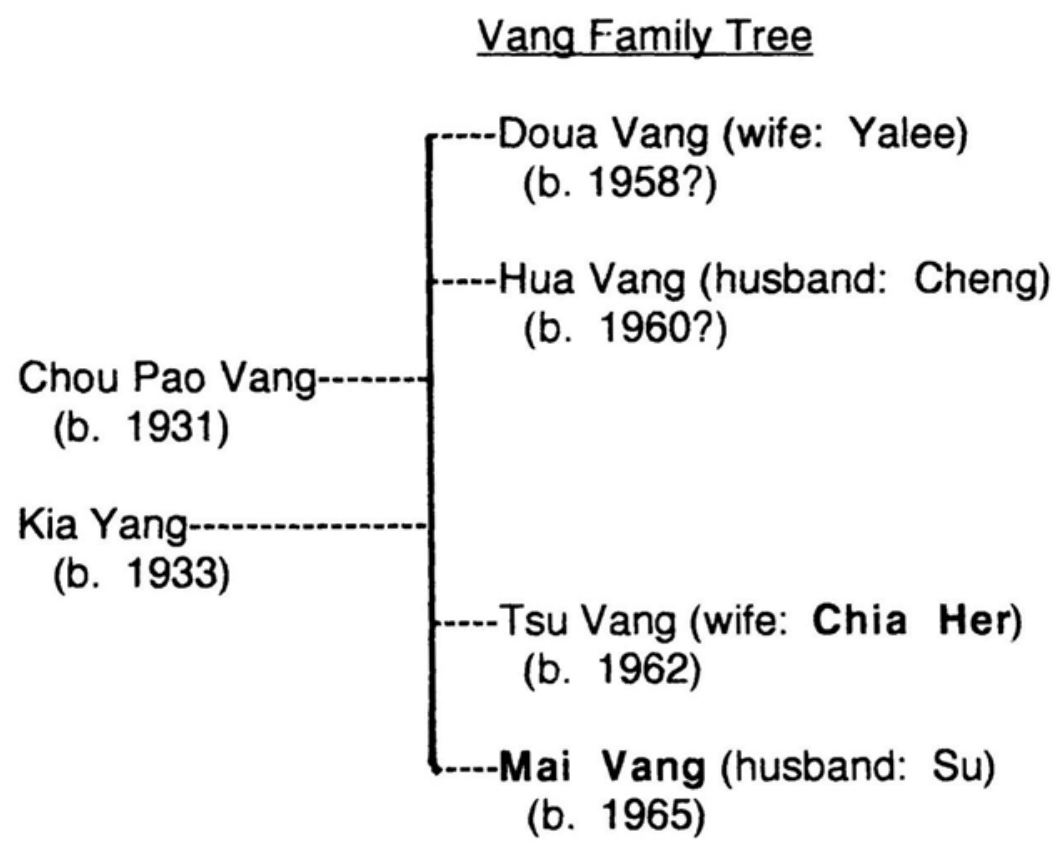

Figure 7. Vang Family Tree. (immediate family members only) 


\section{MAI VANG'S NARRATIVE}

\section{Laos}

My mother told me she had two husbands before she married dad. The first one she married she was like twenty. The time my mother married, they had to marry really old like American people, eighteen or twenty. They married young in the camps and when we moved to the United States, but before that they waited until they grew up enough and they knew how to do things really good in the parents' house and then they could marry. But when they were just a teenager, they said, “You're just a kid. You don't know how to do things. You can not really be some family's daughter-in-law if you can't do the work." They were really working hard in the farm, so you had to work hard. You had to know everything inside your parents' house so you could go marry another person.

My mom married the first husband and then she had two children. Then the husband went fishing. In that time, they didn't know how to swim and he fell in the water and he died. He died and then his brother just came to marry her. They keep you there in the husband's family because you had their children. If you married someone and they were already married, then you would be second wife. If he wasn't married, then you would be first wife. So she just married that younger brother and then they had two kids. But the second husband had a girlfriend and she passed away and came to get him, like a ghost. She came to make him really sick and he died. 
My mother had four children when she married my father. But one son and one daughter died and one son stayed with the other grandma. The grandma took him away when my ma married and wouldn't let him go with my mother. That son had a wife and three kids and he died in '77. The Communists killed him carrying a bomb or something. So my oldest sister she has a little bit different face too because she had a different father. She's the only one from the other husbands. She just stayed with my mother.

My father married really young, but Joua I think she's older than my father cause my father didn't have the mother, only the father and stepmother. The step-mother didn't like them and didn't love them and the $\mathrm{Pa}$ told him to marry young when he was a teenager or something. Grandpa said, "If you don't marry, when I die you don't have money to pay for the wife. You better marry right now so I have to pay for you." Then he just married real young, like a teenager. Joua was his first wife. She was a very fat girl, maybe eighteen years old. She told me when she was single she was really fat. She was fat but I didn't see because before they didn't have the camera and the pictures. They just remembered in the mind.

Joua and my mother were friends. They were nice, like sisters. But the first time they fought a little bit. She was a little bit mean to my mom. She told me, that's why I know. She said, "The first time I was a little bit mean to your mom, but all the time I couldn't do every heavy thing, just with your mom I could do it. I couldn't help it. So I quit being mean to her and we helped each other, like sisters."

Because my father always traveled around, he never helped in the farm. Only my mom and Joua helped each other go to the farm. My father traveled 
with some friends and uncles. Just traveled a lot. Sometimes he helped people with medicine and ceremonies. But sometimes they had trouble and they needed him to go do like a judge. So he always was gone like that. $\mathrm{He}$ was kind of like a leader. When anybody had fights and they went to something like a court, they needed him to go stay there and listen to what they said and which one's right, which one's wrong, and just make them happy together or make them separate.

So he was gone like that, and my mother told me Joua had a baby and my mother had a baby. Back then, you had firewood to cook food and they had a place under the firewood. When you had a baby, you had to sleep under the wood and your fire was near you. You had to cut like some grass, but really long grass, and you had to put the grass under the firewood and make like a house. You cut two bunches and then when you had a new baby, you had something to put on the floor. You put the grass between your legs and you just slept up there after you had the baby born for three days. You had to sleep there because they had no diapers and nothing for the woman.

And so the day my mother had my oldest brother, then Joua had her daughter. So my mother had her baby in the morning and she slept under the firewood. And then Joua had her baby in the afternoon, and she slept over the firewood. And my father was gone! When my mother delivered, Joua carried the baby, picked him up, and in the afternoon she had labor and my mother went to pick up her baby!

When my mother went in labor, she just labored. But Joua, she couldn't. If my mother didn't hold her under the arms, her baby didn't come out. She 
had to hold her arms, then her baby came out. It's very interesting.

Then, later, Joua just decided, "Well, if I'm mean to her, she laughs. How can I do that?" So after that she decided, "Maybe I should be nice to her, then she can help me. Everything's heavy. She's the taller and bigger. She's stronger than me." So Joua decided not to be mean so my mother would help her. When they went to the farm, she carried one baby on her back or on the front, and my mother carried one and they carried the basket with vegetables and rice in back. They always did that for the whole year until the babies grew up. So my father didn't really help them much. The sons helped a little when they grew up, but when they grew up they went to school.

Back in Laos the wives lived close but not the same house. Just a separate house. So they saw each other. That time Joua's sons were married so she wanted to stay with her older sons. They all got out of the one house because too many sons were married and they could not stay for good because one came this way, one came that way, and maybe they weren't good enough together, fight with each other sometimes, and just separate to stay by themselves a little bit. Joua lived with her children, the older and the younger ones.

My mother and father had six children. I had two brothers pass away. So my mom had ten children. I'm the youngest one.

My mother told me that before when they lived in Laos, they were really poor. The time I was born, they lived in like a farmhouse, small house in the mountains. The Communists were coming and hunting them. They knew they had to leave. When the Communists came they would go hide for a long 
time. The day she had me, the enemy, the Communists, followed my mother and they had to stay up on the mountain. They just cut a tree and put banana leaves on the floor and made like a bed and slept. They had nothing; no clothes, no blanket, and it was really cold. They were hiding in the mountain and they had no food and nothing to eat, just only drinking water. She was with her family but the kids were still young. They had nothing, just only her and her husband. They just made the sweet rice a little bit so my mother ate, but the kids they just ate some vegetables or something that grows in the jungle on the rock. They just ate those and the mother ate a little bit of rice. And she said, "Too hard to live in the mountain." Then it was raining, too. They lived there a year or half a year. She ate really bad things and that's why she had a problem with her stomach later. That's what she told me.

The Communists were really bad. They only saved the young children, and the old ones or the teenager they killed. They never let you live. They let the young children live because they said, "They don't know everything." And if you had eggs or like a chicken laid eggs in the backyard, when they came they counted your eggs, each one. They asked like a little kid, "Today when you stayed home, did your mom or dad give you something to eat?" But the children didn't know so they said, "Yes! My mother gave me this morning a boiled egg or a fried egg or something." Then your parent was gone from that town. They liked to kill dog, eat dog. When they came to your house if you had many dogs, they said, "Shoot the dog. Eat it." Your pigs, chickens, everything, they would count it. If one thing's missing, they would ask all the children, "How can you have this much chicken and this much pig? How come you miss one?" The children made trouble because they 
didn't know anything. The Communists were really nice to the children and the children told them, "This time my mother killed the chicken but ate it all. They killed the pig but for us to eat." Then the parent had trouble. Maybe they just took the father away, far away from home and they shot him and killed him. That's all.

They did really bad things like that. They had to shoot you, kill you, and rape you. If you're still not Communist and they're Communist, they came to your house and if your husband was not home, they just came to sleep with you like your husband. And when you went to grind the rice they helped you do that, do everything. Even when you carried water, they helped you to carry water. But when your husband was not home, they just slept with you like your husband. If your husband said any words, they shot your husband dead. They didn't mind if you're married or not. Your husband was dead, but they didn't care. They just worked with you. They said, “Hey, Lady, we are really nice. We're really nice people helping you. We should help you carry things and do things." So my father didn't like that. That's why they just got away from them and moved away.

My mother told me when we moved out from the mountain to the town I was two years old. And we lived in that town. The place where we lived I still remember but a little bit around the place. My brothers and step brothers they all went to school. They went about a week or two then they came back and went again. They were all gone. Only my older sisters and me and my stepsister (half-sister) stayed with my parents. That time, my stepsister and me just could not work the farm. We stayed home and fixed the chicken and pig in the home. 
My oldest sister, stepsister, was the first husband's girl. She was the one that was really nice in the parents' house when she lived with us. All the young brothers and sisters she lived with, she never hit them, never beat them. When my mom and dad beat them, she had to hold them and she said, "Don't cry." She was crying with the younger brothers and sisters because she knew that my father was not her father. She did really good things. She was not very lazy like us and she was kind of smart.

When I was six or seven, my oldest sister married my step-mother's brother. My oldest sister and her husband never knew each other. His family came over and saw my sister. She was really not the lazy one. She cooked everything and she really loved the the young brothers and sisters. And when my step-mother's mother went back and told him, he just came in two days to my house. He went to eat dinner at my uncle's house and came back and said; "I want to marry your daughter." So they just gave the money to my parents. I think she was eighteen but my brother- in-law was older. She had a boyfriend, and when my mother gave her to her husband, her boyfriend stayed outside and he knew that she married. He was really so sad. He just went up a tree and fell all over. My sister didn't like him to do that., but she could not do anything but just go stay with her husband. She didn't like him too much but she said: " OK, because of my father I will just stay with him until I like him." And she married him. After one year, she had a son. That time, I really don't remember a lot, only that I quit eating for three days. I was crying for her.

The time we still lived in Laos, the Lao government was really mean. They wanted my father to go to the big town where the general was living 
because my father had lots of sons and they needed the sons to be soldiers. My dad didn't want to go, so the soldiers just pulled my mom and Joua onto the airplane and they just kept crying. They wanted my father to go and then my father got up to the airport and then they took out the children. But they still held my two moms back in the airplane. So my father was arguing with them and the airplane flew and my mother had to jump out. Then there was like a fight, arguing and really mad at each other. Then they said, "OK, you go far away. Don't stay in that town. If we see your face, we will kill you because you don't want to go to the big town." And my father said, "No." So he got away with his family. He said, "Because I know that you want my sons to be a soldier. I don't want any one to die." My mother's brother's son, he was the one that was very nice, and he'd be the soldier too. And he was helping my father. He said, "Well, if you don't want to go and do this work, this job, then get out of this place and go to the mountains. You can live there." That's why my father just got out and went away. He was the one helping my father and I think later the Communists killed him. They made a bomb in the street and they came home and the bomb blew and then the axle under the car wheel went in his leg to the other side. Then one man, like an uncle, just got a knife and cut off his knee. He had no doctor and he died. But he was really the nice one. He was the only one helping my father get away.

The time we went to Thailand, they were having a fight in the big town, Vientiene. We didn't fight with them, we just heard that they were fighting in the town and we went ahead to Thailand. We just went because we were living close to Thailand. I think that time a couple families and us left, but the 
village wasn't moving yet. The place was scared and we couldn't stay there. Maybe the bad people just came around in the night. The dog was barking all night long and we couldn't stay. We just followed them to Thailand. It was difficult too because I think we took five days to get there, walking, walking by a mountain and rivers, small rivers and walking. At that time, I was kind of not so big so I could not carry anything. I only carried two clothes, work clothes, Hmong clothes. I carried the small basket and put two clothes in there. I was maybe four or five or a little bit bigger, I don't know, I didn't see myself! My stepsister that's my age was just walking, but her foot just got like fat because we had no shoes. We used our feet for shoes. And then it was winter time too, a lot of water and rain.

\section{Thailand - Refugee Camps}

When we first came to Thailand no one of our people was there. There was other Hmong but we didn't know the people. My mother didn't know them because they lived in town when my mother lived in the mountains.

When we got to Thailand we just put some rubber to cover and cut bamboo to make a small house. We didn't have a place to live. We just made our own place. It wasn't really like a camp because that time not many people were there so they just let us stay in the town for a couple days and then the Thai people just let us go in the mountain. And we went to live in the mountain for a week. And then a lot of Hmong people came with us and we could go back a little bit closer to a small town. We stayed there I think a couple weeks or couple months, I don't remember. Then we had to move around and around till we got to the camp. 
Not so many people came to our camp. There was not only one camp, many camps, so the others went to the other camps. We were at the camp at the end of Thailand, Soptuang. It was not too big, not so small. The other big one was close to the town, the big town. I think there was the most people there. I think the one we were in is closed now. The Thai government moved people to the other camp.

The people couldn't leave the camp because if they did that and someone saw them, they beat them and killed them. That's why we didn't want to leave. They raped the women when they went out of the camp, even the young women. They cut the sheep, killed the sheep and used the part from the sheep, and put on the thing on and then they raped you. They just used that for you because they had to use a condom and put inside the woman. Like if you went out of the camp to cut wood for fire, and if they saw you, just raped you. And if you went with a man, they killed the man and they just raped you. Not soldiers, just the Thai people on the farm or something, going to the farm. Thai soldiers, when they saw you, they were all the same. They did the same. This happened to too many people, but not to us.'

When I was about eight years old or a little bit older, a lot of guys in the camp in Thailand liked me. When the teenager guys saw me, they really liked me. When they saw me go to carry water in the river, small river, they just said, " Hey, where are you going? Stop! We want to talk to you." But I was scared, running. I threw my water away! When I got home, my mother said, “Where's your water?” I said, “I don't know. Somebody just scared me and I just ran away." My mother told me that when I was young I was pretty, really pretty, and everybody saw me and they really liked me since I was a 
little baby. But when I grew up, I just got ugly.

When you liked a boy, if the parents saw you with him, it was a shame. It's like they said "broke the law!. Don't do it!" So we couldn't do that. Some parents didn't mind. You could have a boyfriend and girlfriend and lots of friends and work together on the farm and have fun and talk. The boy's family usually said, "This girl will be nice. The one you like you can marry." But they needed the one that's really not lazy. The one that works hard and not lazy and gets up early and goes to bed late. That's what the parents liked because they were really busy and needed help. But Hmong people usually there's not many lazy girls. All the girls, four or five years, they have to start working hard.

My father was mean to my mom and she wanted to die. But she still had us and loved us. If she died, maybe my father would find a new wife that didn't love us. She could die without us but she had us. That's why she stayed. Because before, my father beat her a lot, you know, every time she was working. He was really jealous that my mother had a new boyfriend. When my mother went to the far farm and took a longer time, he just went and waited for her behind the mountain and far from the town. And when my mother was there, he just cut this like long small tree and he beat her on the back. He thought that if she went a long time, maybe she went and made love with somebody else. But she didn't. She just went to work in the farm. Maybe she grabbed vegetables or pig food. You had to grab everything to carry home. Everything was in the farm so you had to go get it yourself. And then maybe you grabbed many things, took you longer time. That time we didn't have watches. So she just went and brought the food to our home and 
he got mad. He thought that was so long, maybe she got a boyfriend or something. And he just beat her up really bad. Before when we were living in our country, most men did that. They say in this country, you have to change. Whenever you do that you break the law. So you can't do that. I'm glad we moved to the United States.

If I had boyfriend come over and whisper to me,"Can we talk?," then my father just beat my mother on the bed because I talked to the boy. That's why I told her I didn't want to marry. That's why I was really careful. If I wasn't really careful, maybe I married in Thailand. But that time, when I just grew up like 13 or 14, two guys really liked me. But I couldn't talk to them because I was scared my mother would get beat up. Then I thought, "Well, just get away from me. Leave me alone," because I was so scared. I didn't want my mother to get hurt all the time.

I couldn't go everywhere. I was scared. When I asked my father, he said, "Yes, you can go for a really short time." You had to do whatever he said: a really short time. When you needed clothes, just grab your clothes and pay for it and come home. If you needed meat, just go in the afternoon and buy meat and then just come home. Never stay longer. If you didn't do that, when you got home your mom got trouble. He didn't make trouble for you, but for mom. Like I told my sister, "If I go long and he beats me, I'm happy. Don't beat my mother." If he hurt me, I'm happy because my fault, right? But he wouldn't hurt me, only hurt my mom. So I had to keep away from that. I was really scared so I never talked with guys at all.

My brother, Tsu, he knew what my father did to me and he said to my mother, "I don't like that. If he keeps doing that to my sisters, I will go away 
from your house. I hate to hurt a kid. If I'm going to the other person's house and they had a daughter and they did that to me, I don't like it. And now he's doing that,too?" He was really mad. He never said that to my father, but he said that to my mother: "Don't do that. I don't want to see it. I don't want to hear it because I don't like that. If somebody did that to me, I'm not happy. Let them do whatever they want. Right? Let them stay all their whole life." My mother said, "I don't know."

I think I had my period when I was twelve or thirteen. I think that time's still a little early. I was still a kid. I had my period but I didn't know anything. I thought maybe something bit me! I went to the big river and washed my clothes and I had blood but not much, just a little bit. And I knew that I felt sticky and took a look. I said, "Oh, Mom, somebody, something bit me." My mother said, "Shh, be quiet. That's not something bit you. Maybe your period. Gosh, you're too small. Why do you have it?" She told me, "Don't go closer to the boy. If you have your period and you touch the boy you won't grow up." She told me that! Then I really hated guys. When I met a guy in the street, I just went far away. I was scared!

When I was just 13 and we still lived in camp in Thailand, some friends came. Some guys came to talk to my older sister. I was scared. I was shaking! But it was not like the United States when the men come to date or stay to talk. They stayed outside in the dark and they just talked outside. And the girl stayed inside the bed so that's why we never saw their face or what they looked like. And they didn't see our faces and what we looked like too. But when we went out they saw us. So when I knew they were talking to my sister, I was shaking. And some guy asked her, "Tell your sister to talk to me." 
But I knew. I heard. And she said to me, "Come on. come on. Talk to them." And I said, "No!" In the morning we got up to cook something. She and me argued and fought. I was really scared of my father and really scared of the guys. I didn't want to talk to them.

The time my brother Tsu met Chia, I know that time because that year he had a girlfriend. She was my girlfriend. We were playing together. I think she was a little bigger than me. But I don't know why that girl loved boys so early. You see, after one year, she just grew up and was big like a woman. But I was still a kid. I don't know. We just played together every day in the camp. Before we didn't know each other, but when we got to the camp we lived together and we just played around together every day. And one year later she just grew up. And she really liked Tsu and she told me that.

Many people went to the United States. Five years and many people found out about the application. So many people did that and all my brothers were really interested. They just never told my father. They just went and made out the application and gave his name and the family to the people that came to interview. My sister Hua wanted to come. She said she wanted to come even if my father wouldn't let her come. She was not happy to stay. She really wanted to come. Tsu and Hua wanted to come and stay and my father said, "Where are you all going? Only my youngest daughter's the one that waits for me? She's only a girl. She doesn't know how to write, read, or talk Thai, everything. I want a boy to wait with me! Everybody will go later." He said that because he didn't want to come.

So after my three stepbrothers and my oldest brother and his wife and Hua all came, only one stepbrother, and his wife, my two mothers, and Tsu 
and me were all the ones left for him. So then my father said, "OK, the family's all gone. We will go follow them." That's why we came late. If my father didn't do that, I think we would come to United States earlier. First we just listened to my father. He said, "No". Then we didn't listen to him. He was old. If he didn't want to go, then he could just stay by himself. In a bad time, they just changed their mind and just went.

It's like he is the father so the mother and children can not go without the permission. So we always had to ask him first and do whatever he wanted to do and it was good for the family. If we didn't listen to him, if we did whatever we wanted, then the mother or the father would get sad and bad to us. Mostly Hmong had to listen to the parents, even when they were thirty, forty years old we had to listen to the mother and father. We could not do anything without them. The time that everybody decided to move to United States, maybe we changed our mind a little bit. If we didn't, then we are still there in Thailand.

When we first wanted to come to United States, some people, well, they just said when you go to United States, like a big monster had to eat you. It made you so scared to come. And some people just said, "No, when you get there, it's a nice country, freedom country and it's good." And then my oldest brother and his wife and my older sister, Hua came before us. They made sure about this country.

I always thought about when I get there l'll see some beautiful people, and beautiful country. My brother and Hua said, “Just don't listen to nobody. Just come. It's a really nice country and a nice place to live. We're living longer, and nice for our kids. They have a school to go to. But it's cold, really 
cold. And when we got here and didn't know how to speak English, that's the way it's difficult for us."

I was really happy to come. So I was waiting and waiting --"when is my name coming?" My brother and sister went, then I was happy to come. I was thirteen or fourteen then. I think I was a little bit older, but my mother doesn't know when the day or the year I was born. Maybe my age is older than that.

The time when you went to get the airplane to fly to America the people in the camp said a very bad thing. They said, "If you never wear pants and wear a skirt, they have a stick behind the door on the airplane, and if you don't wear pants, the stick will stick on your ass!" They made me so scared. They were trying to stop the people to come. When we lived in Thailand we didn't have a woman' pants. We had to go to measure and cut it and you don't have money, that much money. So we just wore a dress and bought like underwear and just wore that. And said "It's OK, maybe they're just liars." So we weren't so scared.

They said other really bad things to us and we were scared. They said when we go to Bangkok a couple nights extra before we went to United States, they have a lot of the things like when you throw some meat away and the flies come eat it and they make something like a mosquito, but it's not a mosquito, little white worms. They're really ugly. If there are a lot on the floor, you can't sleep on the floor. They go in you, in your body. But we just went and stayed in Bangkok one night so we didn't see that. But it was dirty and smelled. A lot of water smelled awful. They had a rug and under the rug was wet and the smell was awful. Too many people from different places, different towns come together. That's why. Not enough money and food was 
so expensive, and so crowded. The ones that came late had no place to sleep, just slept on the rocks.

The day we came to United States and we had to fly the plane, I can not remember much ... just like a dream. Was it really coming? Chia was throwing up a lot. She couldn't eat anything in the plane. When we saw the red apple they gave to us, we thought, "Don't eat it. If you eat that you will die." We didn't know how to eat it. We never saw it in our country. We knew how to eat only oranges and bananas. But if they gave us an apple, we threw it away. You know, they gave like a soft potato and soup and then chicken. We never liked American food. We said, “Ouu, so smelly! We don't like it!." We didn't take it.

We came to San Francisco and we thought that we just got to where we will live. We were really happy. When we got there, they said, "No, you're still far away." So we couldn't sleep until that night. In the morning we got up early and they said, "The bus will come and pick everybody up and go back to the airport." We flew to Portland in Oregon.

\section{Eastern Oregon}

My oldest brother met us. We saw him and said, "Wow! Why is Doua with the big and tall guy!" But we were brave of that. When he got there Doua told me, "That's OK. He is the one sponsor and he's the man that took care of you." So we happy about that. He looked so wonderful. We never saw the big and tall people like that in our whole life. I never saw that, only I saw a little beard, not real hairy! 
The first night we came to stay in Doua's house and in the morning we went to our house. It was so different and just made like a change...a new life. The houses were different. In Thailand we just got the leaves to cover the wall and the leaves to cover the top, that's it. We didn't have windows and we only had one door. They just put leaves on the top and bamboo to make like a door. It's nothing like the wall here. You could see out and you could see how many people were outside. We didn't have electricity so we put the oil from the pig to make a light. Or we had to use a dried bamboo. We made that for every light. Every time you went outside in the dark you had to use the bamboo. We didn't know how to turn off the lights. We didn't know how to turn on the stove. When we turned it off, we didn't know how to turn it on and we had to learn a couple times to do that.

And in this country we don't have all the trees in our country. All the grass is different and the rivers different too. We came in June, in the summer. You know, the country was like the world was turned around! Just looked beautiful, beautiful with the sunshine.

My sister Hua told me, "Well, when I first came to United States, I saw my uncle" --the uncle in Oregon that 's my mother's brother-- "I saw him but I was crying and crying. I missed my Ma a lot. I thought l'd never see my Ma forever because I was in the other place and really far away. Just fly in the sky, never knew the place I pass." And when Hua sent tapes to us in Thailand, she said, " Oh Mom, I dreamed that I died and Doua just put me away and I thought l'd never see you. And I really miss you." She was crying a lot. 
But when we came, I was really happy. I didn't miss anybody back there because they were all over here. And Chia and my mother and my brother, we were the last ones in the family to come. I didn't miss them back in Thailand. I was really happy when I came, and when I saw my family. I was just happy, that's all. And I didn't care if I saw Hmong people or I didn't. I was happy to be with my family. And my sister said "Write a tape back to your friend in Thailand." I still had some girlfriends back there. But I didn't care about that.

We watched TV a lot and listened to the TV more and more, and then we understood a little bit, couple easy words. But then, that time, we didn't know how to say the words. When they talked, we knew what they said, but we couldn't talk at all. I knew how to write just a little bit of Hmong language. If you know the alphabet, all the alphabet, you can write by yourself. They didn't teach you more than that in the camp. I started going to school after the summer, after one year. I was the only one. Just like a dream, that's all. Like you didn't remember anything and if they asked, "Where do you live?", I just shook my head. I didn't know. Maybe they tried to help, but I don't know. Some classes they tried to help and some classes they gave me like newspaper or some pictures to cut by myself and stay quiet in the corner until the class was over. They just did that. Only the English class, he tried. He sometimes asked some student to come over and sit down with me and help me look at pictures: "What does that mean? What is that called?" and he took me to the street and told me the street name, what it was called.

The girl that my sponsor told to bring me to school, her name was Mary Ann. She was so beautiful. So at that time she took me to every class. She 
just came and waited for me. She said, "Come on, you got to go to this class, your class." And she took me to that class and she went to her class. After that class, she had to run away and get me, then we went to the other class.

I was just like a little kid. Some people would always talk and I couldn't talk any with her because I knew what she was saying but I didn't know what to say. It was so hard for me. I lived there a year and never knew anybody. It was so hard. I didn't know much English and writing. I just knew a little bit.

But I was thinking why we were in this country and how long till we speak English or when we can take care and do everything by ourselves. I was thinking about that and then going to school...I never knew nothing. Like I told my sister, I went to school years and I never knew my name!

I was the only Hmong to go to school. It was very difficult. They knew that I couldn't speak English. This was my first time to start learning English. The girls don't go to school in Laos. That's why, when we came to Oregon, I went to school and I didn't know anything ... never was to school in my whole life. Just sitting there, sit in the corner or back and watch them. I always felt, "How come nobody teaches me how to talk?" But how could I say that? I didn't talk. I couldn't say a word. In the lunch time, I didn't know where to get my lunch. I didn't know how to get my lunch. I just stayed by the steps, stayed there till lunch time was over and we went to class. I didn't know where the cafeteria was so nobody brought me there. I didn't know so I didn't have money. How could I go there and pay them? I didn't go there for lunch. I didn't eat breakfast either. I just came home and ate dinner, breakfast and lunch together. 
One day I cried many times. That time when I was crying, right now I know why: because when I went to class, some boy was standing in the hallway and said, "Hey, you're stupid!” He was bad to me, that's why I cried. I knew what he said to me--bad words--but I couldn't talk. I couldn't say any words. I couldn't tell anybody.

One girl in the sewing class, her name was Kim. She was big and taller and she was really nice. When we went to class, every student there didn't like me at all. They said I didn't know anything. "She's so dumb. She doesn't know how to speak." And when they had sewing clothes and sometimes they made cooking, they didn't like me at all. They thought I was so dumb. I didn't know how to cook things together. The teacher was kind of nice. When I was sewing or I did things I didn't know, she asked the student right there to help me. But everybody didn't like me. Only Kim liked me. She said, “OK. I'll take her and teach her cooking and then I will teach her how to sew." She was the only one helping me. I couldn't tell her what happened at the lunch time. She just took me to lunch sometimes. So about a year after that , 1981, I went back to school, but I think she graduated high school maybe, and I didn't see her.

The first time I was going to school they wanted me to go to P.E. and get dressed. I was so shy about my legs. Oh, I didn't want legs! In my country we didn't wear shorts because we had too many problems from that. We had to wear long pants and long skirts and we were really shy about our legs. Some, like my Mom, they always told us that if you let some guy see your legs, they will be jealous for them and want to make love with you. If the girl put on a short skirt, they said, "Wow, that girl wants to marry " because she 
thought that she has beautiful legs, white legs. He must go find her, if they did that. So that's why we can't. When they saw your pretty leg, they will catch you and make bad things for you. That's why we didn't want somebody to see us. And there were no rules, so the guys did what they wanted. If they liked you, they came to catch you and do bad things. Nobody could stop it. If you told, they forced you to marry together. If you didn't like it, like if they had a wife, and you said, "He did bad things to me" so they said, "Well, just get married." If you didn't like it, you had to keep it secret.

That's why, when I went to school first time, I was really shy about my legs. I could not take off my pants and wear shorts. Just like when I went to P.E. class and I didn't want to take off my pants, the teacher got mad at me. They called my sponsor and said, "What happened? She won't wear shorts in the P.E." That's why they said that because I was really shy about my legs. I thought that my legs were kind of too small and maybe too yucky or something. I couldn't take off my long pants .

And then, after P.E. we went in the door and they took off underwear and the bra and then ran to the shower and took a shower. And my people never did that! When we took showers, we needed a very long dress to cover us. Like some Hmong people never took the shower, never took the things off. When they're four or five years, they have to cover. Then they're shy. They never show their bottom or anything to anybody. They have to keep by their self and go shower by themselves. Even with just other girls or by yourself, you should wear the dress to cover under your blouse. We're so shy. When you had to change, you had to have something dry to cover on the top and change the wet one. But because they're American people, it's 
different.

But that time I went to school, all the students when they got in the girls' room, they were taking off their clothes and threw them away and then joking, laughing. They just took their underwear away and took a shower. But I couldn't do that. I was too shy. And then Mary Ann said, "Take off your blouse and underwear and take a shower." But I couldn't.

\section{California}

When we moved to California, we had my step sister and Hua and me. In the New Year time we had to stay home. If we wanted to go, just ask my father's permission. If he let you go, it's OK to go. But if he said no, you have to stay. Every time I went with my girlfriends to play, I was really scared of him too. If I went out he said, "Who'd you go with there?" I'd say, "I went with my girlfriend, " and he'd say "OK, but don't go with a boy." If I went with a boy, I got in trouble if he knew. If I wanted to go, I didn't let him know, then he didn't worry.

I had some friends calling, talking. But when we talked on the phone longer, my father got mad at me, too. We could not talk on the phone like that. Thirty minutes, ten minutes, five minutes. But longer than that, he'd say, "Get off the phone! Somebody will call! Why you talk too long?" He yelled at me, but I just said, "Well."

\section{Marriage}

I was twenty three when I married. That was old. But I didn't care because I thought that I would never marry forever. You know, my father was really mean to me about marriage. It was hard for me. I was scared. I 
decided not to marry, just stay like that. I was working for myself. I was the only one and I wasn't worried about anything. I thought "Forget a husband." I don't know. I just got married when I was old. I thought I was too old. The boys, like the younger ones eighteen to twenty years old, they say, "Ouu, she's too old." The men, like twenty years old, marry the young lady, but not the old lady marry the young boy. Never like that.

My husband's brother bought his house and my husband doesn't want to go anywhere without his brother. So he doesn't want to get out of this city. If I want to go somewhere else and I ask him to go, he says, "No, I won't leave my brother. I have to stay with my brother whatever. If you guys want to go, you go ahead. Because if we go away, maybe you will do such bad things to me, the same as my ex-wife." But I said, "I won't do that. The ex-wife does that because she has a really bad heart, bad person, and she knows English. She knows how to read and write really well, the same as you. Right now, me, I don't know how to read and write. I'm waiting for you for everything. How can I do a bad thing to you? l'd never do such a bad thing in my whole life to my parents or you, either one. I didn't do a bad thing. You should know that." He said, “No, I don't trust you." He thought that someday I might do that to him.

I think I heard my father talk about the old old culture and they married too young, like three or two. And then they just hated each other. To start them for getting married they put the two kids together in one bed. The grandfather had to clean up the daughter-in-law's poo-poo and the father had to clean up until they grew up and they would be like a wife and husband. Even if he was a little boy, if he liked a girl and they liked each 
other, then they just had like a daughter and son two or three years old. When they grew up, they knew they would marry. But if the girl was the ugly one, then if the boy didn't like it, he'd marry another one. But if the girl's the pretty one and the boy the ugly one, she can not get another one. She had no choice. She had to stay with her own for her life. That's so sad.

The parents don't care who you choose. If they like somebody they saw, they say, "Oh, you have to marry him." We have to listen to our parents. We have to do whatever they tell you to do. If you don't listen today, they don't like it. They kick you out. Some parents are really mean. You have to be low and scared. If your mother tells you, you're not scared, but you're very scared of your father. Whatever the boy tells you to do, you do it. You have to. If you don't, then the mother and father argue and fight each other. That's not so good.

But I think it's a better thing that the parent has to help them choose because they're so young. Maybe they don't know if things are bad or someone's a bad person with a handsome face! Maybe they get married but the future will not be good. So you have to help them choose.

If my daughter marries a good person that's OK. But if they choose, you have to help because some Hmong people are really bad parents. Like the boy's parents don't like nice things, don't like everything clean. And then you have to choose the parents for her too. Maybe she doesn't know. She just chooses the boy she loves, but not the parents. But she has to live with them. Maybe you go to their house and see some dirty things, and then nothing to eat. They're really poor too and they smoke a lot. Then what can you do? She has to come back and cry to you, "Mom, you should give me some 
money. If you don't give it to me, I die." How can you get it? Have no money to give it to her. That's the big problem when you're looking for your daughter's husband. You have to help them to choose. Ok, these parents maybe are nice parents and not so poor and you should marry him. But you know when their parents are really bad, you have to stop them.

Some marry young, some their parents stop them. If you don't want your children to marry young, you have to stop them. But some parents don't care. They just say to the girl like eleven, twelve years old, "Go ahead. Make a friend and make love. Whatever you want, go ahead." There's some people marry young, really young too. But some parents understand that if you marry young, you can not get a job. How do you go to the AFDC (Aid to Families with Dependent Children)? It's very hard to apply for that. So they have to control all of them until they're sixteen or eighteen years old. Then they can marry. And some people don't care about their children. They just say, "Go ahead!" So when they're twelve years old, they start making love or have fun then get pregnant and go marry. That's all. And so people don't marry and they stay with the parents. That's the reason we like that girls finish with college. But when they grow up, they change their minds. It's hard to continue. Some of them listen to you, some they don't.

But some people they will be girlfriend and boyfriend for a long time. They don't marry. And they just talk on the phone. When they see each other, they get married. But I don't know. These young kids are different than the other ones. Their hearts look different.

If you're married and you have a boyfriend and pregnant, maybe your husband's not happy about you. Maybe he has very bad words. Maybe he 
hits you. Maybe he goes and marries another girlfriend and lets you stay there but never lets you go away. He never loves you like before. Some Hmong people say that's so bad. But in this country they can't beat you. But in our country they tied and beat them and made the boyfriend pay thousands of dollars to the husband. The wife goes back again but the wife has to pay the parents, his parents. And then you can go together back to the husband. You have to pay the husband, and your parents wash their face to be happy to see you. That's what we can do. Like my people, not many ladies go with another boyfriend without the husband, not many. You know Hmong people don't have "Playboy" or something! And we don't have the movie star like that. We don't have movies to show everybody. So when we were teenagers, some really ugly guys came to kidnap you and when you went three days, you came back and the parent didn't help because they said, "When you're happy you go," and they just kept the money and you should go with him. So when some lady didn't like it, you had to go stay with that boy years and you changed to love him or like him. You just have a baby and you could not die and you could not go away. You could stay with him. That's it. Some people they really didn't like it. They just killed themselves. But not in this country.

In our country the girl gets married and she has to be gone from her family so he has to pay for it. Not much different now, a little bit. Then, you had to pay for her to get her back. Like if they paid three thousand to you, you have to give back one thousand. You keep some to pay the time you had to take care of her when she was born until she grew up. But right now, they have to pay you but you have to return the money or give them .... If 
you have a gold necklace, you give it, as much as you can. So I think you have to return all the money, too. Some people get a car for the daughter like four thousand dollars, so they so they got nothing. They gave it all to the girl.

If the husband was really bad to the woman, they can not live together. They had the rule to separate, to divorce, too. If you divorced, you went back to your parents. If the husband didn't like you, so you had to separate and then go back to your parents. But if your husband died, you had to stay with your husband's parents until somebody married you. You could go away, but the children they wouldn't let you have. Sometimes, if you had four or five children and you had one girl and one boy, they could have it. They kept it. They said, "That's my son's child. I have to keep him in my family." So if I have a baby, I don't want to go chase another person. I have to keep my son lasting forever.

American culture says if you married, so you should let the guy see you. We never do that. We're too shy to let the other see! I talk about it but right now, me, I never let anybody see!

Our people say they just let a virgin be for the husband. Some ladies don't care. They do what they want. But some are really shy. They just talk only. They don't love each other. They just make friends, not for love. Just talking with friends, not for love until one's your husband. Then you can love him. Right now the girls are changing a lot. They just act like American people, kissing, hugging, everything. But in our country, we never kiss, we never hug and we are shy. Even the husband and wife, we don't kiss.

Sometimes there are men and they are not shy with you. They just kiss you on the face and on the mouth! But in the country, in the past in the camp, 
they talked like boyfriend and girlfriend but not in the day, just in the night in the dark. And they came to stay outside the house. The boyfriend stayed outside and the girl stayed inside talking between the wall. Sometimes they went in the day too, but you had to whisper only. But some people they went but they were so shy they never saw each other. So now the girls don't care. They say if the boys want to talk, they can come here and talk. But you don't take a girl out.

\section{Pregnancy/Childbirth}

When I was pregnant with my second baby, my oldest girl went to school, but she was kind of really nice. Time to go to bed she just said, "Come on, just go to bed." Then I went to bed and she got up but I slept. After a while, she just lay there. She was three years old when I was pregnant with my second, but my oldest daughter knew everything I told her to do. When I was tired I said, "You can stay up." But she said, "No, I'm going to bed with you.".

I had one baby I lost only three months pregnant. I went to put gas in the car, that's why it happened. I dropped it in the bathroom. I asked my husband to go get it. He didn't go. I went to get it and it looked like meat, that's all, and red stuff--half blood, half meat. I hurt for many days. I couldn't do anything. My father and my mother were disappointed. They wanted to see it. That's why I couldn't have abortion. That was my baby. I loved him. So I can't do that to one that I saw. How can you do that?

I know one Hmong lady had abortion, about two months. But she had like eight or nine kids, and the second wife was really mean. The husband 
beat everybody and had to fight with everybody. And when he got mad, he grabbed the knife and chopped everybody.

Before I was pregnant with the two twins, the last ones, I was 165. When I was pregnant, I was 140 . I couldn't eat. I hated vegetables, too. With these two I was more tired. You know every time I saw the bed, I had to lay on the bed. I didn't want to stand. I wanted to sleep all day. But I couldn't because my second daughter could not walk. She was crying all day and Chia and my mother stayed with me. But my second daughter was just very slow and when the baby was crying, she didn't help me to carry her. I was very tired. When my second daughter went to bed, I went to bed. When she was awake, I was awake. But she didn't sleep. So when I slept she just woke up and went ploop hard to the bed and fell down. When I heard she was yelling, I got up and held her. I did that every day because I was very tired. I brought my oldest daughter to school and then back and cooked breakfast for my husband. Afternoon I slept. I was so tired.

When I had the twins, I could not walk. I almost died. I went to the doctor for the ultra sound. They put a small pillow for me then let me lay down in the bed. Two babies, and they put the pregnant lady flat, flat on a small bed and really hard. I couldn't do that. I was kind of weak and I had a really big stomach and they just put a small pillow and really bad for to sleep on that and they did that a really long time. I couldn't breathe! I almost died. I held my hand up and said, "Stop! Stop! I can't breathe." But I couldn't get up! And they didn't stop. They didn't help me to get up one time when the doctor checked me. The doctor usually helped me but that time the nurse checked me. She didn't help me. They didn't pull me up and I was too heavy 
to get up myself. My head was back and my eyes were like something real shiny. When she talked I could only hear like very far far away. I kept doing like that until I had the baby born.

When I went to get ultrasound, they did the same thing to me. I was almost dead the first time and I was really scared to go myself. I had to ask Hua to go with me. Then the time I couldn't breathe I said, "Come on help me. I can't breathe." Then she held my hand and pulled me up. And the time she pulled me up, I couldn't understand, I couldn't hear everything. Like my eyes could not see. And the last time I went I said, "I need a high pillow. If you don't, I can not lie on your bed. I don't know why. It's too different for me." They let me so sleep flat. And then they were mad at me. I think they didn't really care about me because the time I did it, she got mad at me, "Why don't you stay put and I can do it faster!" The other time I couldn't breathe at all and almost delivered the baby. I turned on my side and that made to breathe a little bit, but not much. Still made me sick. So I was really really sick. I'm really scared to have a baby now if they do that to me.

In the hospital when you have your baby, you have to lay on the bed with your feet up. I didn't like it. They have one room that you can put your feet on the bed and they don't tie your legs. They have one like when you go check out the baby. You stay on your bed and when your baby wants to come out, they take half the bed away.

When I delivered the babies with my husband, I asked him, "Just get out. I can't stand it with you. Let me alone." I couldn't do that. So he had to stay with me all the time. But I said, "I don't need you. Let me alone." He was scared of me. Usually the parent tell when you have to deliver the kid; "Don't 
yell and don't cry. If you yell and cry then the baby's going to say 'Oh, Mom, she don't want me to go right now'! "”

Back in my country, we put the placenta in the ground after the baby's born. When the baby is born in the hospital we don't care about the placenta. We let the hospital keep it. Just let the doctor keep it. No problem, because we have no house, right? Right now American house we can not put it in there. In our country our house is like outside. Nothing covers the floor, no carpet, no nothing. We could dig every time we wanted. But in this country, we can't do that. If we take it home, where can we put it? So we just let them have it. They put it wherever they want to.

But if our people have a baby born and the baby has a cover on the face (cowl), you had to keep that or his future is difficult. If you keep that, he will be rich and he has to be a nice person. Our babies didn't have it, but if they had it, we should keep it. My uncle uncle had one girl like that and he forgot to keep that cover, tore it off and threw away. But if you remember, you should keep it. It's really good for the life. This is a special birth. But my uncle didn't take it, just left it there. His wife was really mad about that.

Our people say if you have a baby, so you have to not sleep with your husband up till one month. Somebody, if they don't, if like two weeks after they just sleep with their husband, then the uterus will come down. If you don't have good medicine that makes it go back, then maybe you will die. American doctor told me you have to wait for one week. When I had the two, I had the $\mathrm{C}$ section. When they were over one month, I went to see the doctor. They said, "Have you had sex with your husband yet?" I said, "No!" They said, "Why?" I said, "Because I don't want to!" My God, I hate it. If he 
says he wants it, I say, "Go out and find some girl!" I always tell him that.

"They have many extra outside women. I don't care about you now." He says, "Yeah? You let me go? " I say, "Sure, go ahead!"

\section{Motherhood/Children}

Because I had two babies at the same time, sometimes I'm really mad about it. I can't go anywhere and I cry. Then my mom says, "You should know that you have two babies. Take the long heart, then you don't cry. Keep your heart longer for your kids. Maybe the God gave it to you, that's why you have it. So be cool."

So sometimes I get really mad, but sometimes just keep thinking they're for good and I still love them. But they can't do anything. They're too small. When they grow up maybe they will help me do things too. But sometimes just make me so mad. When they both cry, they just make me dizzy and you hold one, carry one, but they're still crying.

Last night the the twins cried all night. I couldn't sleep. You know, some babies know if tomorrow it will rain, so tonight they cry. When my second daughter was crying, these two were crying and I put them to sleep and I went to sleep with my second daughter. And then she slept, and I got the twins to sleep. And then they were crying and the other started crying, too. Gave me a headache. Then about 12:00 at night, my husband was back home and they cried a lot. Sometimes he has to stay with my second daughter until she sleeps because I have another two to take care of.

Right now I have one friend that I just call Auntie, and every time I go pick up or go to school, I have to bring all my babies to her, "Can you help me 
watch them and take care of them?" And she says, "Yeah!" She really loves the children. Even if I don't go anywhere, she just comes to my house and helps me take care. If they both cry, she runs and grabs one and gets away from me and then takes good care for them and really helps. She's really a good helper. She's my husband's mother's step-sister. In our culture, if the same last name but kind of old like pa and ma, we have to call them Auntie. I would be like her child. Every time I go or I'm too busy, then I have to ask her to help and or take one. If I have to do my husband's breakfast, lunch, she has to help me take care of my children all the time. But when my ma stays home, she has to go to the other mother Joua's house and her sister's house so she's really not staying home. And so that's why if I want to go to the doctor or to the store I say, "You don't go. You have to stay here and help me to take care of my baby." I say this and she says, "OK, I'll stay." But when I get home, she says, "Do you have anything to do?" If I say "No," she just is gone.

When I had the twins in my stomach, I wanted to go to Tahoe and eat seafood. I really wanted seafood, and I asked my husband many times. He said, "Ok, this time I will go, next time you go. But next time he said, "No, you have to stay until I have time so we can go together." And then longer and longer. I could not work and he said, "Right now you can't work, you can't go because you got such a big stomach. If you had your baby there, what can we do? Better stay home. Go nowhere." Then I didn't go eat seafood. So I said last month I wanted to go but, "Oh, the twins are both sick now, maybe next week." 
I worry about my kid because she doesn't listen to me. In the camp in Thailand, they told us that Americans never spank their kids. If we spank the kid, then that's child abuse. That's why we were scared and we couldn't spank our kid. But in our country, a lot of children, when you ask them, don't listen to you. You have a stick to beat them and make them listen to you. In our country, the teacher had the right, if the student won't listen to the teacher and was making noise, they have to beat them. So they were really nice students and listened to their teacher. They didn't play like right now.

Right now our kids never listen to the parent because we are scared to make them listen. Our people should let the parent make our children listen to the parent. If they don't listen, you have to put them somewhere, teach them a lesson, or beat them to make them scared of you and listen to you. But right now we can't do that. Our people like to make the choice to listen to the parent, but like I said before, the policeman will come and say "You abused the kid. We will take them away from you." Some Hmong people beat their kids really hard, that's why. But some Hmong just teach them a lesson. But they still get in trouble. Right now they let them do whatever they want to. Now they are not going to school. But the teacher never tells the parents that their kid's absent, skipped school. They never tell the parent at all. Whenever the kid wants to go to school, one day or one week or two hours in the class is OK. They never care about the kid. The teacher doesn't care about you.

Our people, if you had the first child and are patient and be nice to the kids, and the younger ones will do the same. But if the first ones yell and say bad words, then the younger ones will do the same thing. It's hard to control 
when they grow up. Right now, I tell my oldest daughter, "How come you're always yelling at me? If you do that, your sister does the same thing as you." But she won't listen. I don't know how to control the children at all. Sometimes I don't want to open my mouth and say the word!

Our culture is changing a lot. In the past, the younger children listened to older ones to tell them what to do. And the children listened to the parent. If they could not do anything without the parent, they had to listen to them. The parents said, "We do this and they can do this. We do that and they can do that." But right now the parents say, "No!" The children say "Yes!" You say one word, they say many words to you. I don't know how to stop them now.

They really changed. Some people tell me the kid won't listen to the parent because they drink milk only. That's why they act like a cow! Maybe they say "Moo!" Before, they ate their parents breast...breast feeding. That's our bodies coming out, so they will listen to you. But right now they just eat milk from the cow. But it doesn't hurt, they're really strong. We hit so hard, so hard, but it won't hurt. It's like you talk to them and they just went "Moo0o."

Right now, you look at the kids, they're really different, too. Before, Tsu and my stepsister and me and all the kids were so scared of my father. When we saw he was coming, our face was buried. We could not look at him because we were scared. Could not talk. If he said one word, our body was shaking because we were so scared of him. Every time he asked us to do things, we just never answered. We just went ahead and did it. But now our kids are never scared of the parent at all. 
They listened to the mother more because the mother had to take care of the kids every day, every time, talking to them and they know the mother's heart: she can not do bad things to them. The father never usually talked to the kid. Some times, if they did something wrong, he just came and said, "You did this or that wrong! I will beat you!" That's it. But he just goes away. But this time, now days, kids are not scared of the dad at all. When you talk to them they say, "Don't say that to me! I'll kill you! Go away!" So it's really hard to talk with kids.

The girls now, like their hearts don't belong at home, outside now. When they go out, it's like something new for them. When they get home, it's like really boring. Even I went to play a lot, but sometimes I stay home a lot now. But in the United States, our people, the brother, sister, everyone is like American people, so they're not shy like in my culture. In my culture we are really shy with each other. If the brother saw the sister's boyfriend, they are really shy. But if the sister saw the brother's girlfriend, we will be fine. We're shy about boys, but our kids aren't shy. But when my people, the old culture, do something, we are shy with each other. I wouldn't let my brothers see my boyfriend. Sometimes in the United States, they come to the girl's home and they will have a place to talk, right? But when they came to see me about five minutes, ten minutes, I just had to say, "Go home!. I'm too shy of my parents." They said, “OK, you want me to go home. I will go.” I wouldn't let them stay longer. The reason is I was shy and scared of my parents. But the young kids now, they change a lot. 


\section{Health Concerns}

When we were in the camp, they talked about birth control and stuff about having babies. They had American doctor and they talked about birth control and whether or not to have a baby, stop pregnant., and stop the period, not to have a period and no baby. My aunt in Modesto, she had one shot in camp and stopped the period for three years and then she went back and got a shot again. So she stopped her period and her period was like men. When she moved to United States, she had one girl, that's all.

If you use it right, you can have control, but maybe you will have cancer like Doua's wife. That's the reason we're really scared. You have cancer like Yalee, then maybe you took the pill. Yalee took the pill nine months, and she had like the period coming out a little bit. It never stopped. Her uterus was very hard inside and they went to the doctor and the doctor was really mad. He said, “Because you didn't take the medicine that we told you to take, that's why you have this kind of problem. Right now you have cancer and you have to have surgery." That's why we don't like to take the pill. It's more dangerous. We remember that and we're scared. So we decide if we don't need a baby, we have to control ourselves, not to take anything, not to sleep together or be like really close. If the husband's happy and the wife's happy then we can do that. But if the husband can not do that, they have to do it with you all night, every night, maybe you'll have baby.

These young kids they just say that they won't have lots of kids, but when they marry, they never stop. They never know how to control themselves and they can not stop. They should have like one or two babies only. But when the older one's ten months, they already had the second one. 
Like Chia and me, we are the older ones from the past, so we should know how to scare them about having a baby. We should know to stop or wait a little bit longer and have another one. Not have to have one for one or two years, that's a little bit better. But these kids right now just say, oh they want it. So ten months or eleven months, they have another one. It's just ,"Oh, five kids," and they just try the same thing. I don't know why they couldn't stop.

One night my mother said she had a stomach ache. Then I heard this "pop" and it was really hard. Before she said that, she never ate nothing for fourteen days, drank nothing. She was so tired and looked different. We thought that maybe she just ate some food and it hurt, and we had to give her some Hmong medicine. We did everything but it was no better, just more hurting, hurting, hurting. That's why we went to take a picture at the hospital. When we took her to the doctor, he was really mad at us. He said, "Why did you wait so long? Fourteen days and just went to the doctor? What did you think about it? Explain to me." They said they were sorry. "Tsu said," ,"Oh, we'll just think about it." and the doctor was very mad: "Well, if you don't want to save your mother, then go ahead and think about it a couple more days. If you really want to save her, just a couple more hours for you." Then Tsu said, "OK, l'll call my father." Then he just called my father and my father said, "It's OK if they do that to save your mother." And they just went ahead and they took that out and right now she's better. They said that it was like water. It was not cancer. It was big, but water in it. But my mother told me that maybe the reason she had that was because the day she had me the enemy, the communists, followed my mother, and they had to sleep on the mountain. They had nothing, no food and nothing to eat, just only drinking water. So 
maybe that's why she had that kind of problem she told me: the time she bore me.

Right now, here, the doctors learn about Hmong culture because many different people are here. They know Hmong ladies cook the rice and chicken. But maybe the doctor asks, "Why do your people, not many of them, they don't have cancer or problems like old people? Not very many bad problems? Our people when they're old, they have too many problems." They say that. I don't know.

In Hmong culture we say In the months you go outside and the rain is cold like the winter time, and you don't wear something to cover your head, later on when you are old, you get very painful on your hands. And your eyes are dripping and water will come out because of the rain in the months you never stayed home, you went outside.

\section{Citizenship}

You go to the immigration to take the test, you have to pay ninety dollars. They make you speak English. When the time comes to do it, a little bit of English will be OK. The best thing is just to say "no" all the way. Don't say "yes". They just ask if you were in the United States, did you travel anywhere? You say;"No." Or if you were a soldier, people helping fight each other: You say; “No." They just ask many questions but you just say; “No. No. Not at all." They ask you which one's the right person and which the president. If you have a person that knows how to read and write really well, then you have to copy them. 
The last time we went, the Vietnamese guy that's the head of taking the test said they didn't find my test. And then I got mad. I said, "Why? I just gave it to you and then how come my test is already lost?" He said "OK, OK, l'll look again." He just took away from the whole bunch and he put them in another place, but he found it. I don't know. He kind of cheated Chia So she should go up there and say; "You cheated me, pay the money back!" You, know, he already told the people that the Hmong people always get citizenship more than the Vietnamese. And he said, "The Vietnamese are stupid. Never got a citizenship, never pass the test. How can the Hmong people always pass the test?" That's what he said.

Somebody told me that only Asian people who are not citizens, then the government won't help, and they can't find a job either. They told me illegal or not you can't find a job right now. Not a citizen, no job. That's why right now they check out the people and just the people that just came in, no papers, no anything...sneaking. Right now they're still checking that. Even our people who came a long time ago, ten or eleven years, they don't care. You're not a citizen, then you can not find a job at all. There's many people now they want to check out.

Some people told me that Hmong people in a gang broke into one house in Washington, so the government will send all Hmong people back to Laos. They told me that last month. And the Hmong government is coming to talk to the government in United States. Va Pao, the general, is coming to talk. They said they will send Hmong people for sure because the Hmong gang people broke into the one house in Washington. But I said, "Why? Black people always break into all the houses. How can they do that?" 
Ethnic Discrimination

Some people are really mean. They just give the finger to you like mean people do. That made me so sick, I don't know. I think, "Well, maybe I'm ugly or ucky or something" if they don't like me. Some kids when you go down the street, they say, “Chinese! Chinese! Have to give penny.” And I don't know why some American men, when you drive in the street and you go the same speed and they want to go very fast, they just say, "Fuck you!" And when they pass you they just say, "Fuck you." How do you like that!

When my husband and I went to the Albertsons, the speed they say is 45. And then the American guy ran really fast past our van and he opened the big window and said "Fuck you!" I said, "Well, how come? We didn't do anything wrong." My husband said, "It's OK. Calm down. Just let them do by themselves. We didn't do anything wrong." I don't know why. Right now they have many bad people.

\section{Language Concerns}

I think some Hmong don't want to learn much. They kind of don't want to talk English. Like my older sister,Hua, she's kind of shy and she'll say, "Well, when I talk it's not clear enough. So I keep not talking their language. So I try to talk my language. Maybe that's better." That's why she doesn't speak English. Right now, me too. I don't get to talk much English. But when I was going to high school, I had lots of friends like the Cambodian girl and we were talking to each other a lot. We had to use English for talking. When we talked English, I understood more than her but I couldn't speak well. 
When you got home, you just spoke Hmong. I wasn't married and my step-sister wasn't married. When we got together, we had to talk English. But after she was married, then only me, and no more English.

Right now I never talk English. When you're going to the store and you pay the cashier, maybe they ask some question and you answer. But if they don't ask you, just keep paying them, then go home.

One time my second daughter was a baby, I lost her in the store. I was really scared. The cashier wasn't helping me. I think she understood me, but she just kind of like thought that because she's Vietnamese she shouldn't. It's a Vietnamese store. She understood. She was acting like a queen or something like that!

One time Hua went to buy food in Albertsons and they cheated her money, about ten dollars or more. She came and paid one guy, American man, for it. She gave him twenty dollars and it was seven dollars something. And then he gave her change and she left. When she got home, she was looking at her receipt, "How come I got no money back?" So she could not see her money. She got only a quarter or something for change. And she said, "Why? Where's my money?" She looked around in her purse and she got nothing. They had only twenty dollars left. She was really mad and she called me that she needed me to go back there and talk to him. I said," How can I go? Because I don't speak English well, that's not a good idea." And she talked to Tsu, but he said, "No! just go get it!" Then she cried and she was mad and she asked my nephew. She took our nephew and they went to the office and then talked to the supervisor. They said, "Well, you don't speak English and just once so we will give it to you. But next time we won't do that 
again. “

People are afraid so they don't have account in the checking or in the saving. So they have to change money at the Albertsons store. They have like a bank. When you go you stand there and count it and you scoot over and somebody comes to your place and you count. But when you tell them, "Not enough!," they say, "You cheat.. In your pocket!" They counted and they say it's really enough for you and they didn't have to pay you back. You think that's fair? They have glass between both of you and they can count really fast. And like me, I can't count with them because they're too fast. I can't see what they count. They say maybe one hundred is two hundred. So how can they do that?

I have a bank account. When you go there and they know that you don't speak, so they have to count. Some young ladies count really fast, but you don't scoot over. You just count again yourself. And she has to watch you count. So if some kind of medium person or woman doesn't speak English, they have to count really slow for you, and then you can count with her. But that's easier. Some count really fast but some know that you are Asian people and they should talk slow with you. They're really nice. They say, "Well, if I talk faster you can not listen to it or you can't catch it, tell me slow down."

In the school for a conference you have to talk. I go myself. My husband doesn't have the time to go with me at all. To the school I go myself, but the doctor just calls and my husband makes appointment for me. I go myself. My husband never goes with me. Even when l'm pregnant or had a baby, I had to go by myself. Sometimes when he's not home, then I make 
appointment myself. I know how to do it.

I don't know why I can't understand when I read. When I went to school I studied the words. When you studied it's not in your brain. When you study and you come to class, it's gone. I don't remember at all. Like you have homework, and then the teacher just teaches you that. When you go home, you do this and do that. So when I came home, I forgot about that. I never kept it on my brain or my mind because I didn't remember everything. It's very hard to keep that.

Many people, if they don't speak English, they have really low income, like the minimum, about five dollars or four-forty-five. That's not enough if you have a family.

So now I'm worried about my future. Because I have lots of kids, I don't have time to go out and work and study. Only my husband works but he has to pay child support to his first wife. Now I want to work but I still have two small kids and two babies. The oldest is six and I'm pregnant. If I go to work, nobody takes them to the doctor. I always come back and take them to the doctor. How can I do it.? 


\section{CHIA HER'S NARRATIVE}

\section{$\underline{\text { Laos }}$}

My mother's mother and father were poor, but my father's pa had a lot of money. So my grandma said, "Hey, you want my daughter? You give me seven hundred of silver. So I give my daughter to you." She just said that many times. And my father's pa said, "OK, right now I give my money for you and I take your daughter."

So they gave a lot of money to them for my ma. And then my ma didn't like my father. My mother was the most beautiful, more than me, and my father was very handsome too. I don't know why they didn't like each other. But my mother had a boyfriend, another boyfriend.

But the grandparents were talking to each other and they sold her. My ma said, "OK! If I want it, it's up to me. If I like, I will stay for a couple years." She said that to my father. But when my father went to sleep with her, she fought him. They weren't sleeping together for, I think, three years. My mother didn't like it and she was always hiding, like years. But the Hmong have a way: they say , "You don't like me, then we will tie your hands and tie your feet." But they didn't do that; they just said it! That's why they were married four years and they didn't have a baby. And after that, they liked each other and they had a baby. Then they had me and I had two younger sisters. After that, my other sisters died.

If you are happy together, we say very good. But they say if you don't 
like each other and you marry, it's no good. One will stay and one will die. If they don't like each other, they eat medicine, get killed, kill themselves, get drunk, or something.

My father was sick because usually if the wife doesn't like the husband, the husband usually passes away. That always happens. I remember when I was 5 years old I lived in my father's house, but my father died. My ma told me how my father died. He was hurt so maybe somebody magic. You know, they have bad people. They make magic. That's why he died and my mother had to go marry another man.

When you married young and your husband died, you had to stay until somebody came to marry you again. So my ma just got married, I think three years after my father died. But Hmong people, if your ma marries the other guy, they don't let the kid go. They want to keep the kid. They said if my ma wanted me, so she had to pay. She said she will pay for me, but my grandma didn't let me go. My grandpa said "No" because I was the only one. I had two other sisters but they died so he wanted to keep me. He needed me to take care of him. So then I stayed with my uncle about 10 or 12 years in Laos, and in the camp in Thailand before we came here. I lived with my uncle until I married my husband. I saw my ma sometimes. She came to see me.

Right now my ma still lives in Thailand. She says my step-father is really bad, so my ma cries about my father. I laugh and say to her: "Oh, now you cry for him." But right now she knows. She says she misses my father and misses me. So she misses the time she did bad to my father and everything. 
My grandpa liked me. When I was small I always slept with my grandpa because his wife died. He never married. So he said I should sleep with him and he gave me something good to eat. After that he never saw anything and he couldn't walk, so I took care of him and cooked for him. But if I told him " the rice is here and the meat's here," he knew and he remembered. He didn't want me to fix everything for him. He needed to do it by himself. $\mathrm{He}$ could not see, but he could remember.

My uncle's wife was dead and he married another lady, but she was nice too. She helped me. If I didn't know something, I asked her and she told me. She's good. Right now she's still alive. She took care of all the kids. When my uncle's first wife died, his kids were very small. The younger one was 2 years old. But he married the lady and she came to take care of kids and sewing the clothes for them. That time we were very poor because all the kids were very small. The kids did nothing. We could not grow rice. But we had friends and they helped my uncle and his wife.

All the people had to make a home. They grew vegetables, corn, rice, everything. And had animals: pig, chicken, and goat. Back then, I was very small, but I had to fix the chicken and grind the corn. My uncle had two daughters the same size like me. We helped each other. He had two sons but they were very big and they went to do the farm. I had to stay home and take care of the chickens and pigs, everything. I cooked some rice when they came home and needed some. I still remember a little bit but not too much because I was very young.

We had to do everything by hand. When you were growing something, no machines, just by hand. I remember when I lost my finger. They put the 
corn on a big stone. The little girls my age did this. Me on one side, my uncle's daughters on the other side. Then another stone was moving. It came down on the corn and grinds the corn. My uncle's daughters moved the big stone up and down on the corn. I was sitting and stirring the corn with my hand. It was really hard. You had to push hard and you had to move fast. It cut my finger off because I was so little. They said I knew nothing, you have to move your hand fast. They said I was slow with it. That happened to a lot of girls, they lost their fingers. I feel so sorry I did that.

My uncle didn't have nothing. It was hard. We didn't have water come to our town. We had to go get water in the river. And we had to make this big long thing from bamboo, very big and very long. So we put water in it and carried the water on the shoulders, carrying two, three, four. Or we tied them together and carried on the back. The older ones had to carry two together. The younger ones could carry one. To shower they had a river. You had to put bamboo like a pipe for a shower. We never had hot water. If you wanted water hotter, so you have to put fire on it.

We had to go get food, do the farm, and we had to grind the corn. We had to go early every morning. We didn't have time to play. You know, for long days I never played. I didn't play like my daughters play. Just working, working. Go there and cut the trees, get wood, make a fire. The girls cut the wood. We were very small, not strong enough, so we had to cut the little ones. We were really busy all day! That's why I like to play now with my kids because I never played when I was a kid.

Girls didn't go to school. They said the girl will move out so they didn't let her go to school. That was the rule. They said the problem is they make 
their own food, so they needed somebody to help. They needed a girl to help. They let the boy go to school. They never asked girls to go to school. It was really far away in the town. They had lots of pigs, lots of chickens. You had to fix them, give food to them too. You had to fix your own rice. You had to grind the rice. So you're really busy all day if you're a very small kid.

We just stopped working for a celebration. In December or January you had to celebrate New Year. We had to stay like five days, no more than that. You see people but that's just five days. Boys and girls had some time if they wanted to talk when they started getting older, talk about getting married. They just talked like a couple days and then a couple months they just married. But they had no time to know each other. "You like me and so you want to marry me?" They just talked like that. After that, you had to work all year, all day.

When the boy is really old and the girl really young, they gave the money to the mother and she had to save the girl until she's like fifteen years old and they will marry. When they grow up they know they will marry. But she had no choice.

We left Laos because the country had some Communists. They came to our city to stay around. But we couldn't stay because if they came and you had a daughter, if they liked her, they killed you. They took them. That's why we didn't want to stay there. If they liked you, they just went and killed the husband. When you went to cook something, they said, "Oh, l'll help you." That was no good for us. If the men knew who was the ma, they killed the ma. They just said we were the stupid ones. That's why we didn't want to stay. We heard some people they had to do that. We never saw them. We 
had to move, move all over the place. If you had a son, they asked everything. If he told them a bad thing, they didn't like it.

We didn't want to go to Thailand because my grandfather was very old and we couldn't carry him. But the communists came to our city. The communists said, "Hey, you have to stay because the country has freedom." But they just said that. It wasn't like that. That's why my uncle said, "Oh, we have to go because my brother, my step-brothers are all going. We have to follow them." That's why. I had another uncle. They came first to Thailand. Then we had to follow them. Because my grandfather was very old, we didn't leave for a long time.

My mother lived in another city. I don't remember what it is called. I was too young. It was in the mountains. My ma just came to Thailand later because her husband didn't want to come before. He saw everybody come, but he didn't come. We came from Laos to Thailand in 1975, but my mother came in 1980. I didn't see her for a long time, 5 years.

I think I was 8 or 10 or something when I went to Thailand. That time my grandfather could not walk. But my uncle and my uncle's two sons, they just carried him on their back for a very long time. That's why they didn't let me stay with my ma. They wanted me to take care of my grandfather, cooking for him, serving the food for him, because he could not see anything. I had to fix the food. I really wanted to stay with my ma, but they didn't let me. They said I was just the only one so I had to take care of my grandfather.

When we left Laos to Thailand, we were just walking and carrying food. We went one day after day. It was hard to leave but we had to move. We had to hide. If they saw you, they killed you. My grandfather was really old, but 
we had to move. I carried nothing, just my grandfather's blanket, clothes, food. We took 8 days. We were really poor, too. No food and no nothing. No vegetables. We just brought a little rice because when we came to Thailand, the Thais were very mean and they sold rice but very expensive.

\section{Thailand - Refugee Camps}

When we first got to the camp we had to make everything: a house, school, hospital. We had to cut the trees and bamboo.

When we got to the camp, all the people were sick. They died too much. After about two months, my grandfather died. I didn't see him die. I went to find some food in another place, so he died and I didn't see.

They had a school in camp but it wasn't a good school, just a special school because they had Thai teachers. They taught in Thai language and Hmong and French. I think my husband knew more than me because he was going to school. Right now I read and write a little bit, but in Thailand I knew nothing because we were very poor. We had to go find food, but we didn't have to go to school. The boys, you know, they went. But we didn't. We were girls. My sister and my uncle's two other sons went to school. I tried to go one year but I had nothing to wear and no clothes so that's why I didn't go.

I met my husband in the camp. I think I was fifteen. Before we left Laos we never knew each other. He saw me in my friend's house at the other end of the camp. She was my aunt but my friend too. I went to visit and he saw me walking there. He liked me so he just followed me to my house! That's how we met each other. He didn't talk to my aunt, he just talked to me and my friend. I just liked him a little bit because I never talked to him before. He 
was the first, so I was scared of him. I just went home. So he followed me, followed every day. We just went to the farm and got some rice and things, but he just followed me. I think he followed me like one year.

There was another guy that followed me, but I always ran away to my house. He liked me too much, but I didn't like him. When they liked you and they saw you, they just caught you and took you to the house and married you there. When they liked you, they asked if you have brothers and sisters and cousins. Then they just hid in the dark, outside. When you went out, you didn't know. They just caught you on their shoulders and then took you to their home. They caught you and you can not move your hands. Your family can't do anything for it if you went in the house. If you stayed outside, they helped. But if you went in the house, they didn't help. You didn't like the guy, but you had to marry then. If you went back home, it's not good for your parents. You had to stay with them and after three days they made a party. Your parents said, "Well, you went in the house, you can not come back. You got to go." They sold you like an animal. But you know, we didn't like the rule like that. Some girls died. They ate poison or something.

That's why I was scared. But you know, when I saw that man, he just caught my hand and he said, "Right now you got no way to go. You stay with me." That's why I was scared! But he never saw me anymore. I said, "You never see me anymore. I hate to see you! " I like the guy if he comes to my house or comes to meet me and talk to me and just stay and talk to each other only. I don't like the guy that catches your hand. 


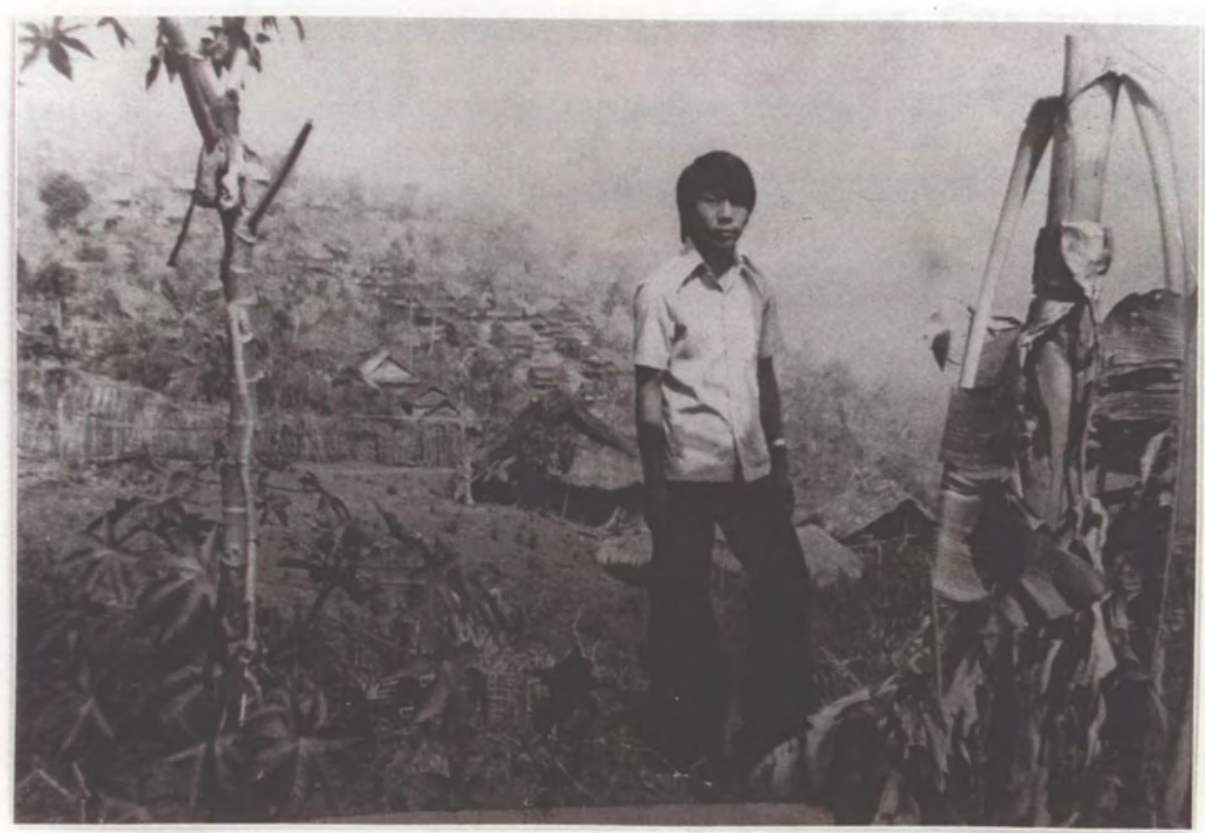

Figure 8. Tsu Vang. Thailand. 1978.

Figure 9. Chia Her. Thailand. 1978.

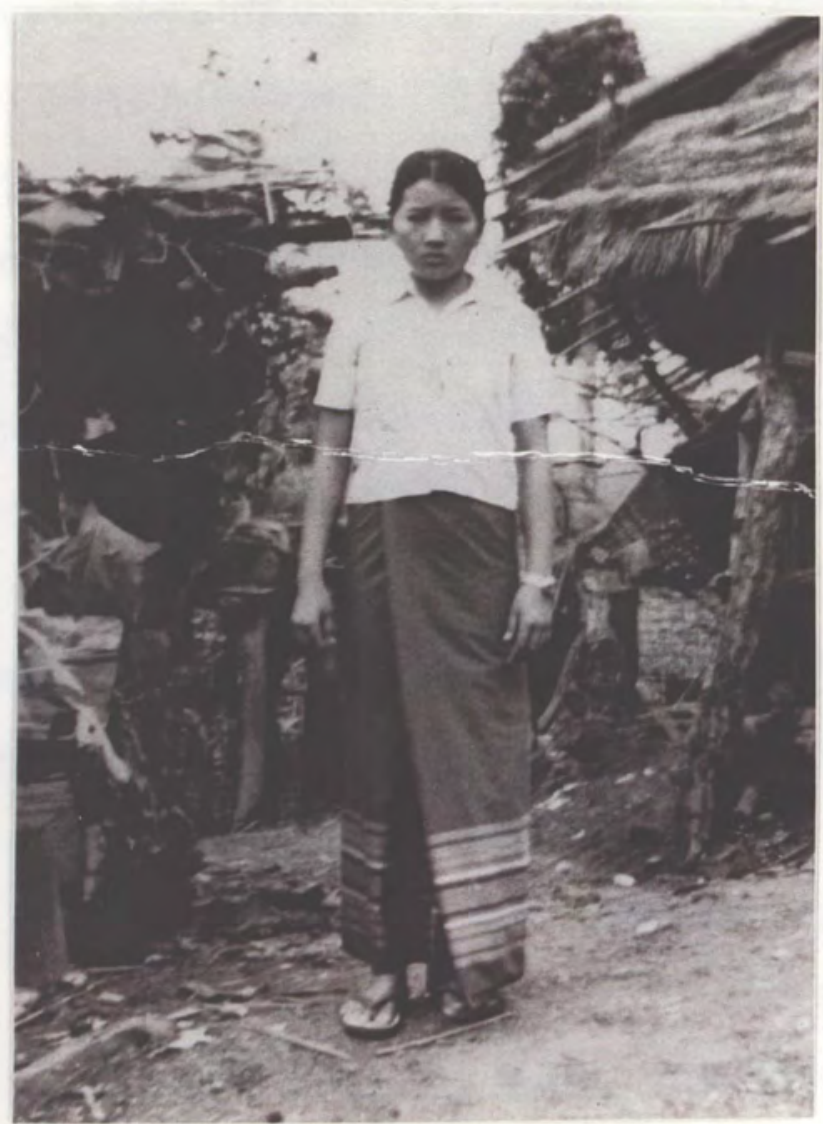


Some other guys they wanted to marry me. One guy he married before when he was small, but then his wife was very old. When he saw me and he liked me, he said he'd pay me money and he'd marry me. I said, “No, I don't like you because you have a wife. I don't want to marry a guy that has a wife. It's not good." But you know, before I said OK or not, he took me like five hundred dollars. I said, "I don't want it, forget it." That was no good. But he came to my house and asked my uncle to pay a lot of money and marry me. But I said “No." My cousins said., "OK, You don't like him, but you have to marry him if he comes.” But I said , “I don't want to. Don't come." Then he didn't come.

Tsu waited for me a long time. That's why he's jealous: he waited a long time! He told me he had three, four, five girlfriends already before me. He said he didn't like the ones that went really fast. He liked the one that he has to wait for for a long time.

That time I didn't go anywhere. I stayed home cooking and doing everything. So they didn't beat me. They didn't do anything because I was the only one cooking, farming, and working for them. So they didn't beat me. They didn't want to. I don't know why my.husband's father was so mean to his kids.

My uncle didn't control me. He let me go be with Tsu. I got pregnant before when I stayed in my uncle's house. In Hmong culture they don't talk about to have a baby or not. They don't have the thing to make like birth control. We married in 1979, I think November. I was pregnant I think eight months and married Tsu and had a baby. I lived in my husband's father's house when I had the baby. Tsu wanted to marry and do the papers to come 
to the United States, so we married and had to make a party and pay. Tsu paid my uncle some money after we moved to the United States. We were so poor when we moved from Thailand, we had nothing. But my uncle's nice. He said, "Oh, wait until you have it, you can pay." So Tsu's family just made a party and cooked for them. They just put a party on and said, "Later, I'll pay you." Down payment like for the car!

I had Chan (first child) at home. We had a hospital but too many people were sick and no room, no doctor. There was only one doctor, Hmong doctor. Tsu and his brother were like a nurse or something at the hospital. I wasn't bleeding so much with Chan, like I did with the next one. She was too small. I think like five pounds.

My uncle really loved Tsu and me because every time he went to buy clothes and things for our home he said, "Chia, you better stay home. If you go there, you spend all the money. You guys and the kids stay home, don't go." Now he's really old but he still remembers everybody.

A fire burned Chou Pao's house before we came to the United States. Mai wasn't home. She went to visit her older sister. Only me and Doua's wife, Yalee, were home and Kia and Hua. But all the men were gone. They made a New Year for the other camp and they went to it. I was home but I didn't help much because my stomach was really big. I couldn't move everything. But my uncle came to visit some friends near me. They made a party or something and my uncle and all my uncle's friends came to the friends' house. But they heard the fire burn and they came to help me.

It was our house and the other houses too. The wind just blew to my house very fast. I think thirty minutes it was all gone. But my uncle tried to 
help me take clothes or chairs outside. I got some things but still missed the rice we carried from the mountain the whole year, from very far away. It was very heavy and we could not move it. Yalee had two kids but she's small and she went very fast so she got some things too. She just left the kids for me and she went fast around. She was usually the fast one! I never followed her around because when I went with her I had to run. The other group of houses on the other side were safe. The fire went out by itself.

My ma's ma and pa went to the camp at different time. My grandpa didn't walk good. My grandma had a big thyroid around her neck. The Thai had the hospital, American doctor, too. So they made her sleep and pulled the skin back and cut it. When I came to the United States, the picture they gave me and said it was 1960 or '66. They gave me the picture because they lived in Thailand, but maybe I not see them until died because they didn't want to come. I didn't see them anymore.

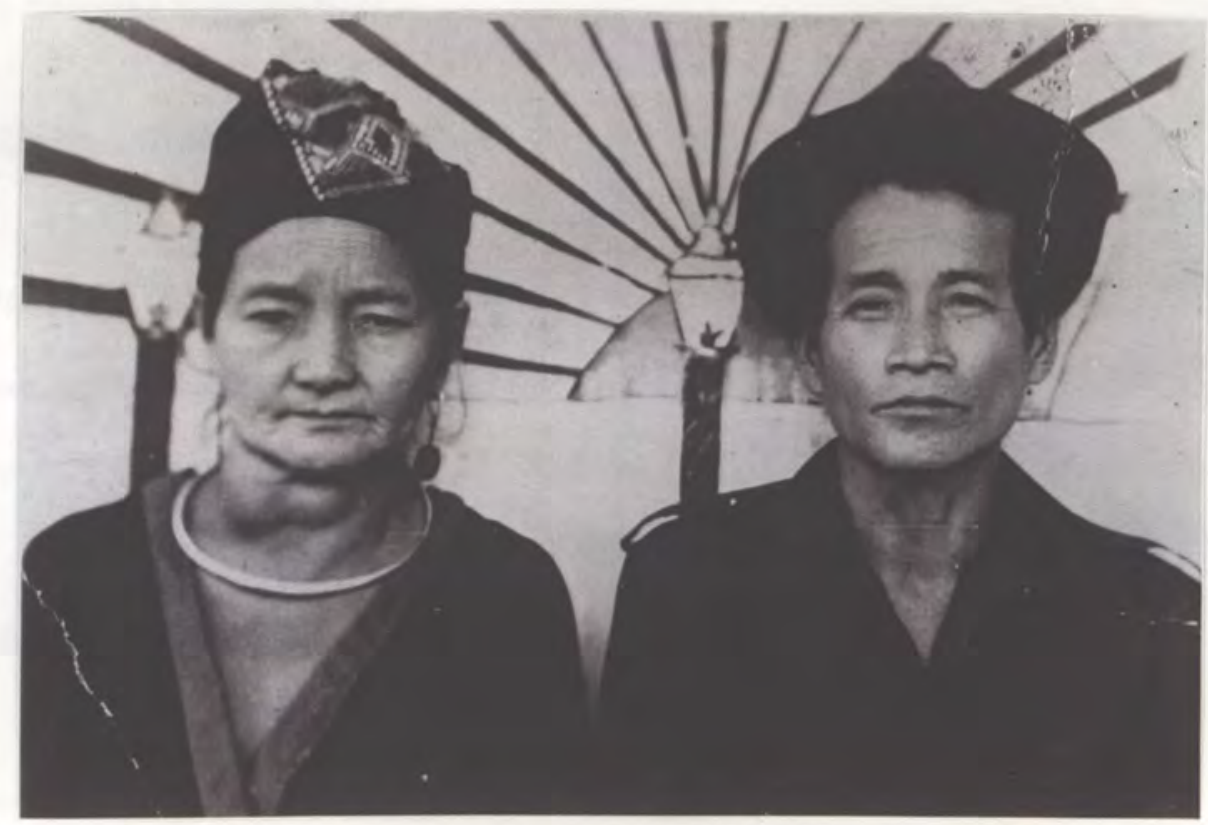

Figure 10. Chia's Maternal Grandparents. Laos. 1960s. 
My ma came to Thailand six months before I came to the United States so I never saw her before that. I never saw her since I was small and she married.

The time we were coming to United States, I was scared. You know, when we lived in Thailand, we heard somebody say that the toilets are really different! When we lived in Thailand, we went to the bathroom but we had to make just a hole or something. We had to go in it but we didn't use nothing. We used only water. I didn't want to go to the bathroom anywhere when we left Thailand. I waited until I got through to Oregon that night. Doua and Yalee showed me. But I went to the bathroom. I was scared because when we left Thailand they said many different things. You know, the problem is really our country they didn't have it, the bathroom, everything. That's why they see the bathroom they so scared. In San Francisco we saw some Hmong. When I saw the Hmong I was very happy. I thought I would never see Hmong anymore.

\section{Eastern Oregon}

I came in June, 1980. I forget the day. It looked beautiful but really different. Things were very different than Laos: different trees, different everything than my country. Everything's different because they change like new.

I was really sad to be here because I missed my ma and my uncle. You know, we had a whole family but we had to separate.

We never saw snow before. We don't have snow in my country. December, November just a little bit of cold in my country. 
I remember the first time I went to the doctor. They wanted to examine me. But, you know, our people don't do this. So I was shy for him. That's the problem. I was really shy so I didn't want to go. But I thought , "It's a different country so they do different things." Too many things different! We never let anyone see our body like that. That's why I think there's a little problem. In Laos we didn't have a doctor.

I think Chou Pao wanted to move away from Oregon. He said he needed family to be together, so he wanted to move. They didn't have the money to help in Oregon. Doua got laid off because the job closed. Tsu's brothers said come down to California. We didn't know how to speak and study. Some of the girls, Hua and Mai, they wanted to move too because they wanted to see a lot of friends. Me and Tsu didn't care. We married each other so we liked to stay there.

\section{California}

In California the government helped a little bit. My husband went to school first, I think two years or three years in Santa Rosa. They had one lady, her name was Sylvia, so she came to teach me and my sister-in-law a couple times at home. She came to my home one day a week and Yalee too. Sometimes we were busy so she said we can go to her house. We walked to her house. She taught me reading and writing or something like the food or eating or something. But the welfare didn't pay her, so she didn't teach anymore because if she did that, somebody had to pay her, right? But nobody paid her so that's why she quit. 
We moved to Sacramento but my husband's other brothers stayed in Santa Rosa. When we moved the rent was high. So that's why we moved to Sacramento. It was like three bedrooms will be a thousand or something. We didn't have any relatives in Sacramento. No relationships. My husband's mother and father, Chou Pao and $\mathrm{Kia}$, lived with us.

Doua's wife, Yalee, died in Santa Rosa. She was really my good friend. They had six kids. One was a baby. Some people think Doua killed her because Doua told her to do the operation for cancer, so that means he killed her. That's what they think. But it wasn't him killed her. She said she didn't want to have any more babies. She took pills, birth control, that's why. They had two American ladies help Yalee do the operation, too. They explained to her, "Do that and good. Do that, it's bad." So they helped too. But that's why she went to do it because they said, "You know if she doesn't do it, she will die really soon. If she does it, she will be safe, like 100\%" She went back to the doctor and they said, "maybe cancer." But she said she feels nothing hurts. So after that, people said she didn't have to go do the operation. But she said she would like to do that. Nobody stopped her. But they thought she didn't want to do it, thought Doua asked her to do it. Because she died, they didn't know. Nobody explained the truth to them, so they didn't know. That's why they said that, but right now they know. But too late because they got mad at each other. You know her father was so mean, too. And Doua's father was mean, too. That's because they can not think. 


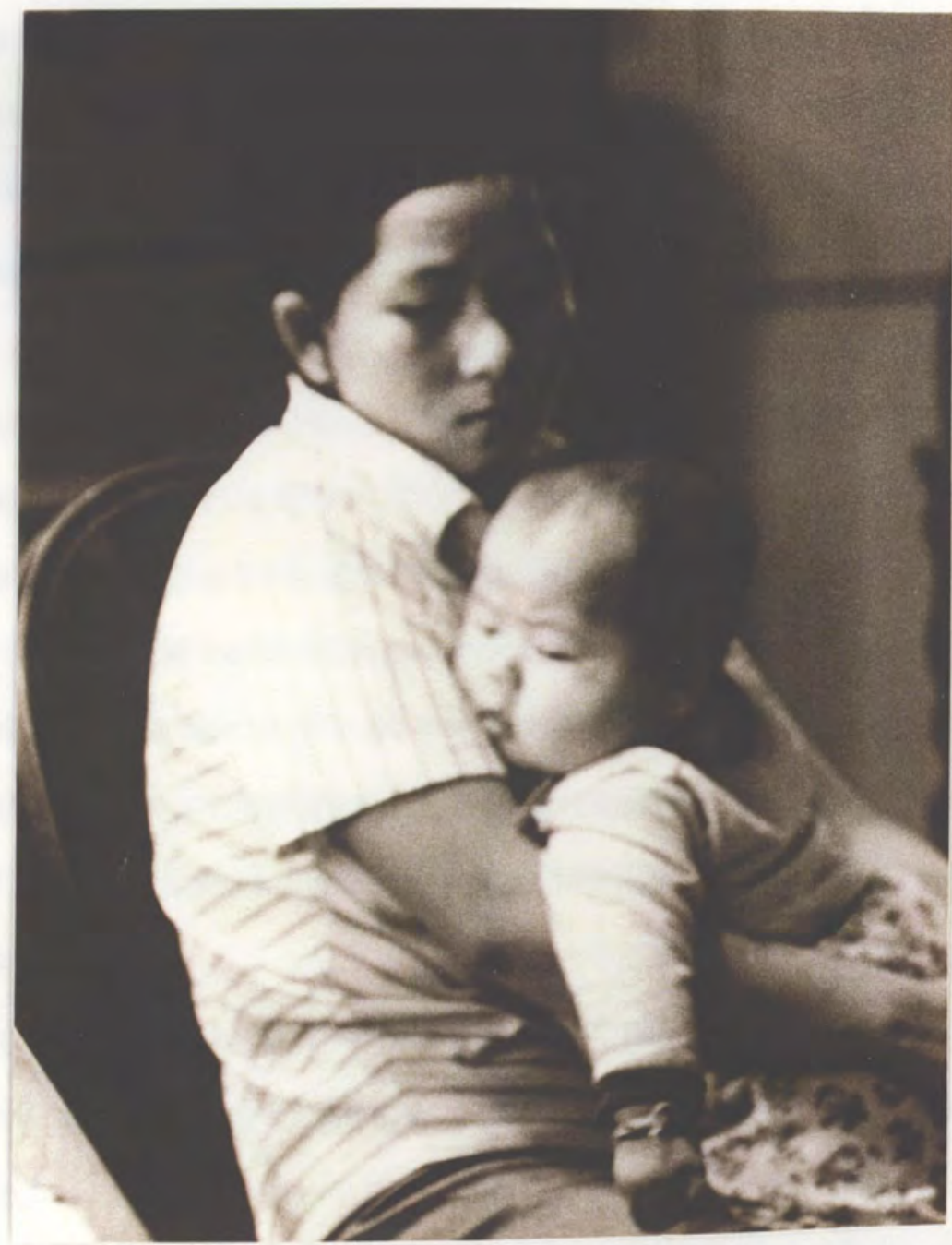

Figure 11. Yalee. Oregon. 1982.

When Yalee died, Kia and Chou Pao went back to Doua's house because Doua's two babies were small. But after, Doua married the other lady, and they came back. I think Kia was really mad because Doua married the other lady. But she said it's Doua's fault so it's OK. Kia is really old so she doesn't have to say nothing. We didn't know what to do, too, because people are not like animals, you have to sell or something. People are people, so you can do nothing. So forget it. 
Marriage

The husband doesn't listen to the wife. The wife has to listen to him. . In our family, he is the one I listen to. But my husband listens to me sometimes. But the other ones, they don't help the wife. When they want to eat, they need the wife to cook and everything. Tsu's brothers, they all don't listen to the wife. I like it because he helps me to cook. And when I was sick, he helped me. But, you know, he didn't want to help me with the babies. He helps me cooking but he's lazy to help with the babies! That's why he wants to cook! So I'm the lucky woman. He's really nice. If he goes to play with some girl or talk to some girl, so he knows l'm really mad, so he cooks for me or something. He knows l'm mad, so he needs to be good to me! My older babies, I did all the work myself. But for my little one, Nancy, he helps me. Only this one!

Hmong marry eighteen years old. It's the way and the way is so old, that's why. Hmong don't change. If they marry like fifteen years old, they say, "Oh yeah."

American people, if they don't want be married, so they separate. Our culture doesn't like that. They had to pay lots of money for the girl, so they need the girl to be good. When the girl goes to another boyfriend, they're not happy. When they see you or your boyfriend or something, maybe they will catch you and beat you.

\section{Pregnancy/Childbirth}

Our people have many things to do when you're pregnant. If you eat vegetables, you will be coughing, and if you eat fried food, it makes you have 
diarrhea. So you have to drink hot water and eat hot food and only chicken and pork. When I was pregnant with my boys I hated vegetables. When I had girls I liked vegetables a lot. You have to wear really long clothes and cover your legs and your head. If you don't cover, when you get old, your skin will be dry or you will get headaches or your bones will hurt. Maybe you eat fruit, so when you get old your meat (flesh) smells like fruit. They say that. I saw that before. That's why we are scared to eat some things, we saw too many before.

So $I$ ate things like bread, not fruit, not juice. .Americans bring you lots of juice, water too. But right now they have too many Hmong people so in the hospital they ask you, "You like something to drink? Hot water or something?" But in Oregon. they didn't have Hmong people, so they bring you juice, ice, water, fruit.

You know, some lady, a nurse, asked me, "Why do your people always drink hot water? We saw all your people after they had the baby they drink hot water," We can not drink cold water. I saw some Hmong lady when she had a baby, she ate a vegetable, mustard greens. So her husband said, "Hey, I don't want you to eat that because my ma ate that and my ma was sick. So I don't want you to eat that." She said, "I don't care. Why don't you let me eat?" So he didn't stop her. Right now she's coughing a lot. She can not breathe. If she walked far, you heard the sound.

Most of the young girls don't want to learn because they stay in for the month and they have a really hard time the month after they deliver the baby. So she's tired and she wants to eat everything. 
After a girl was born we put the placenta under the bed. The boy we had a like a really big tree to make the house, and we put the boy's next to the tree. Right now I have a brother in Fresno. His wife's mother said "No, the firestone's lost so we have to put the placenta next to where we burn the fire in the fireplace." So she put it next to the fire and it all burned. It was all burning and that's why the baby girl had something like a burn all over her body. Her skin peeled off so she had no skin. I saw it when she was born, till she was sixteen. It smelled awful all day. They had to put some medicine on it. But right now she is really big and she uses lotion. She has two kids and she's better but the skin is different. Not like our skin. It's black like the tree.

You know when Hmong have a baby, if you say something bad, the baby isn't healthy or good. Like if you have a baby in this country and you didn't plan and don't want it, you say: "Oh, this baby, I want an abortion." But then you don't have an abortion, you just keep it. Then the baby comes out always sick. Like my fifth baby. I didn't want a baby, I wanted an abortion. But the doctor told me; "I made an appointment for you, but you have to go home and you have to really think about it. If you change your mind, so you have to call me again." So I came home and I slept all night and I was thinking about that. I changed my mind. I went to the doctor and said, "I'm not doing it, so you cancel my appointment." So he said, "OK". That's why, when I got my son, he was really sick and his head was really big and his body small. So we did a ceremony. We gave him something nice. We had a party for him, so that's why right now he's growing up and he's never sick. We had to do lots of things and make him happy. So we say: if you want to 
do an abortion, you have to do it.

I have one cousin's sister here. She didn't know when it was time to deliver the baby, why her stomach hurt. She said: "I will go to the bathroom." So she locked the door. She had really tight pants too. So she had to pull the pants off and the baby went down the toilet. She said:"I don't know what to do." She thought that the baby died. So she said: "Hey, come help me!" Nobody heard, just only one old lady. She heard her. She said, "Oh, why do you need help?" So she said: "Come on. I think I have a problem. Maybe my baby's dead." So she said:"OK, I'll do it." But, by that time, she had the baby so she couldn't go open the door. Her husband came in and just broke the door. But, you know, her baby couldn't stop in the toilet. It went in the hole. So they pulled and that's why it was almost killed. They got the baby but the baby drank lots of blood and lots of water. I think it got in the lungs. They called the doctor to come to get the baby. Right now she's one year, eight months or older.

I heard someone say one woman had a seven month baby and she had to go to the bathroom and just went in the bathroom and just put water on and the baby was gone. I think that's not true. Seven months is too big. It cannot go down the toilet. Maybe she put it in the garbage and took it out. She's lying. Maybe it died.

\section{Motherhood/Children}

You know, the kids change. I think the kids are alright now. They know everything changes more and more. We don't worry. I think they are free. Maybe they will change a little bit. My girls are really young. They know how 
to do nothing. They don't know of the future. That's why we like them to finish high school. They know how to find a job and that's easy for them. I want them to do that but I don't know for sure. But they will marry. That's why I say, “I want more from you. Stay with your school. I don't want to see Hmong anymore!"

My oldest daughter, Chan, she's so young. She's so young! When she sees a boy in school, she talks to them. She is changing. She doesn't want to go home, just go talk to the guys only, that's all. That's why we don't let her go.

Chan wants to go to college, but I don't know. She likes boys a lot, that's why. But she never goes with boys, just only plays sometimes and comes home. She doesn't go out right now. But Chan likes boys. She likes to talk with boys. Maybe she'll marry or something. You know, I want to stop her! So I ask her "You have to finish with high school." And she says "Yeah, I will finish my high school and not marry! I was just talking on the phone." She says that, but I don't know. It's not my body! That's why I can't stop her.

But my second daughter says she will finish because she doesn't like boys. Lisa doesn't like boys so she wants to stay not married until she finishes her school.

You know my daughters are different than me. Their hearts look different. Yeah, I married young, but you know, I didn't know anything. That's why. Maybe right now I know. I say "Why did I marry young? I should have stayed longer!"

Chan always says to me: "Why did you have a lot of children? I'll only have two and stop myself." She said that. I said: "Well, you can't say. You 
don't know, right? So maybe you say you need only two, but maybe have more. Maybe you say you need more, but have no kids." So I don't know. Right now the husbands say if they want or don't want to have children. But they don't want to do anything like birth control.

You know, the boy is better for staying not married because our people are not like American people. Our people say the girls should marry young. If they stay not married till they're old, so nobody marries. That's why they do that.

Our Hmong people, the boys are more important than the girls. But the Lao, they don't care about the boy. They care about the girl. If they have a baby girl, they are very happy. But if they have a baby boy they are sad because the boy marries the girl and stays with her people. I'm happy for either. I don't care because you can do nothing, right? It's not like you try something so you should get a boy only. Right now the Hmong change about that. Some don't change but some people change. I think they like the boy because when they get old they don't have nobody to take care of them. Some girls marry a good husband, so they can keep their mother, too.

\section{Health Concerns}

Before we left Santa Rosa, I had only three kids so my husband didn't help me. But I got headaches and my back hurt after we left Santa Rosa to here. My back hurt and my head hurt still more and more, so he helped me. He said sometimes I fell down on the floor. One time when I fixed the blankets, I fell and I pulled the blankets. I didn't know what I was doing, so I fell under the bed. He was listening to the radio and he didn't see me. After 
that, he saw me down on the floor so he said, "Why? Why did you do that?" I didn't hear anything, so he thought I died. He was crying, crying. So he called Mai and Kia. He said, "Hey, Come quick! What happened to Chia? I don't know why!" So they helped for the babies and everything. The children were so small.

After that I went to the hospital one time, maybe in 1987 or something. That time I was only three months pregnant. I was sitting in the chair doing the pa ndau (handstiching). Tsu went to Fresno for New Year so he was not home. I wasn't sick but after he left, an hour or something, Tsu's stepmother, she came to our house and she said, "Do you have something to eat? Can you give me some?" I grew some mustard greens outside so she said she wanted some. So I said, "Come on, get it. You can get it by yourself." After that I felt dizzy, more and more dizzy. I said, "Oh, what happened to me?" So I put one pillow on the floor and I slept. After that, I couldn't stand up anymore. You know, when you stand up, you fall down. I heard something like a bubble go through my stomach here. I couldn't breathe, I couldn't talk. That time was a terrible danger. I couldn't do nothing. I was lucky because Mai came. Maybe another time she was working. I didn't call her, she just came. She knocked on the door. I couldn't open it. My step-mother was still outside but I couldn't call to them. But she had the keys so she opened the door. Then I said, “Ah, you got to help me because maybe I will die or something " because I could not make it. When I went to the bathroom, I was throwing up. I fell down on the floor and I couldn't stand up. She had to help me. Then I called 911 and the ambulance came to get me to the hospital. They said, "Ouuu, you have a terrible thing!" But, you 
know, they couldn't find nothing. I was pregnant, so they couldn't give me medicine. They didn't want to do anything. So they gave me like water in the hand (IV) and the water went really fast, one after one, one after one. I could not talk. Tsu was not home so my husband's father called to my uncle's house to find him. He said he will come, but it was late, maybe 12 o'clock midnight. I stayed like seven days in the hospital. They said they couldn't find the one that made me sick.

From that time to now I still feel dizzy, dizzy when I'm pregnant. Right now too when I do something or eat something. That's why I'm scared. That was terrible. I can't take it. I don't want to do that. My husband was scared too because they tested my blood pressure and they said went really fast. They didn't tell me anything to do. They said maybe to get a medicine for me but I was pregnant so I couldn't take it.

So that time Tsu helped me more. My uncle in Fresno said Tsu had to help me because if he didn't, sometime I will die because that happened really fast. Tsu told me if I die, he can not take care of the baby because the babies only me takes care of. He thinks if I die then nobody helps him to do anything at home. And Chou Pao and Kia, only me takes care of them. Tsu has one uncle in France, this one's Chou Pao's brother but younger than Chou Pao. He said Tsu must help me because I do everything good for Chou Pao and Kia. I help them so Tsu needs me. So right now Tsu is helping me.

Right now I feel dizzy, weak in the muscles. If I drive, I can't see nothing. I see the floor just go around like a tornado or something. So I close my eyes. That's why my head aches. My headaches are a little better, but 
sometimes they hurt.

I have my other friend, her mother had cancer in her, but not inside, near the part where the baby is, but outside of the skin. So she thought it's something else. So she put a needle in to do something. After she did that, it got more and more bigger. So they went to check the doctor. They said, "Oh, too bad. It's cancer." But you know, too much cancer inside. They said if she does the operation, it's not safe for her because she will die when they do. She said she didn't want it. She wanted to leave it. So when she died, it was Ok for her. Right now she's dead because they said she's really in big trouble. They couldn't help her. The lady I talk about, she said she had it a couple years, maybe seven or something, but it didn't hurt her so she didn't know. That's why she died.

You know, we had this other man, he lived in Fresno. So he had cancer inside of the penis. Nobody helped him because he went to the doctor's but he didn't see nothing. But he said he hurt. So he drank lots of Hmong medicine. Then he had cancer on his head. Last couple months he died.

\section{Language Concerns}

My kids, the older ones, speak English at home, I think more English. My oldest son doesn't want to talk English, but he knows. He knows everything but he doesn't want to talk. But doesn't talk Hmong, too. He doesn't talk anything! But they know English more than our language. Some Hmong words they don't know. They ask me, "Ma, what's that called in Hmong?" I explain to them. I think that's because going to school and talking to friends a lot. I think the little ones will talk English. They're Hmong so they 
talk Hmong, but, you know, they're just like me in English: they don't know what the question, the things, mean in Hmong. They say they don't know what Hmong's called.

I learn English from my kids and some words I don't know so I ask Tsu. My kids don't sit and talk about it, just sometimes I say the word maybe wrong. So they say "Ma, it's not! You have to say that!" When I go to the doctor, I know everything but I don't know how to fill the papers or what the question means. I want to know what the question means, but I don't know. I know how to read but I don't know what they mean. I have another friend, neighbor from Samoa. She or her daughter talks to me. Maybe she sees me outside and I say "Hi," so they talk to me.

Sometimes I go to the store. If I don't know the medicine, I write the name or something. I go ask the man in the store and say, "You have some kind of medicine." He says, "What kind of medicine?" I say, "I don't know. I have the name but I don't know what kind." So he teaches me. We say we have too many kinds of medicine, so we have to make sure what kind you need.

The lady in the big store where we go, she's mean. When we go to the door she just seems really mad and sad to you. She doesn't say nice things. That's why I hate her so much. She understands but she can not do nice to you. She says something really fast.

I think the people hate me. Maybe they hate what I say, right? Maybe they hate the other Asian people. That's why they don't want to talk.

Some people they say when they see your black hair, "EEE, Chinese men, Chinese girls, Chinese ladies." Tsu, when he went driving, bad driving, 
a white guy, wanted to hit him. That's why I say they hate him. They say they hate Chinese people. Maybe they thought he's Chinese.

\section{Citizenship}

Mai got her citizenship so I want mine! But I can't make it to get my Citizen, America. I can not pass. They gave me one so I read it at home, and I learned from my kids. Sometimes Tsu helped me. So I read it at home, but when I went they gave me a different one. I have trouble because I know how to read but I don't know what the questions mean. Questions about the American president or about everything. I read the words but I didn't know what it means. When I went there they changed to different questions. That's why. The test is long, maybe thirty-six or forty. That's a lot! That's why I lost. You get twenty minutes to do the questions. I say they cheated me because the other lady, old lady, she didn't know how to read and speak English. Why did she pass?

My husband's brother, he studied so he knew. They let you copy the other one. They cheat, you know. They didn't care. But right now they care. Now they don't let you copy someone else. I said, "I will try again," but my husband said wait until Mai and Hua are finished because we were not sure. We wanted to be sure Mai or Hua got it or not. If they got it, I will go he said. If they didn't, it's just like losing the money. So I waited for them but later on I will because I already paid ninety dollars.

I have to wait because I don't have somebody to go with me so how can I go? I have to go with someone that knows. I think I will wait till my daughter is eighteen years old so she can go with me. That way it's easy! My husband's brothers and sisters already passed. They asked me to go but my 
husband said "You have to wait!" You know, everybody's a citizen. Only me, I'm not a citizen so I told him maybe I will to go back to Laos! That's OK because I want to see my ma in Laos, so I will go back to my ma.

\section{Work}

In my country they were poor so you had to not be lazy. You know the Hmong story about the food: the rice and corn they came in from the door. You never went to get them. So when they're ready, they will come to your house. Really funny! You had to clean your house only you didn't have to get them. The food came in your door. It's so funny. They say it's the beginning of the Hmong people. But the Hmong didn't like it. The Hmong were too lazy to open the door and clean the house and the Hmong said: "Hey, go away. When we need you, we will come get you. You don't have to come." So now we have to go get the food because they don't come.

In the United States the Welfare helps you. The trouble is we don't have a house and farm. In our country they had farms. If you didn't have something to eat, you went to the farm or went to the river and got your own fish and crab. If you were lazy, you didn't have anything to eat. But right now you just go to the store.

I feel sorry I don't have a house. I don't have a job. I don't have a farm or something. That's why there's trouble. I want to work. I want to have my own house. But I have kids. That's why I have troubles. (laughs). I let my husband work first. I wait until my kids grow big and take care of themselves.

The trouble is we aren't speaking English. We don't know how to read. That's why there's the trouble. You don't have experience for jobs too. I went 
to apply for one job in a school. So I didn't have experience that's why I didn't get the job. I went to a preschool for a job, a little preschool. I said I didn't go to school. They said: "Why are you saying that? You talk Laotian and Hmong and American so you are good to help." They had an old teacher. But that was only one day a week so I didn't want it. I said that was a waste of time. The trouble is we aren't speaking English. We don't know how to read.

\section{$\underline{\text { School Concerns }}$}

I go to a conference because I have a lot of kids, so I go two times in one year. But in junior high and high school, they don't have a conference. They say only on the Report Card what they got. In elementary they don't have trouble. But the trouble is the junior high and high school. That's why I want to move. They have trouble because the teacher doesn't stop the kids. You know, this is why we don't move. Right here it's really cheap, really, really cheaper. But the other places, rents are higher. But my house is really old. And it was flooded too. Flooded in 1986. They just changed the carpet and paint. I want to move but I don't have any money. I can't find a house, too.

\section{Traditions/Change}

We still keep the same religion but Hua and Mai changed. Tsu and Chou Pao don't want to go to the American church. We still keep the Buddha. We were Buddhist a long time ago when the Hmong lived in China. They moved to Laos but they never changed this, just keep the same. 
You know, Hmong they can not change the things that they make. Year after year they still have the same things. That's why they didn't want to come here because this country's very different and they want to go back to Laos, but they can not go back.

I want to be good. I want my children to be good. I want my husband to be good, even me good, too. So I don't want to do bad. I want to work. The problem's my children and Kia and Chou Pao, too. Right now they get old so they need me to take care of them, take to hospital, the doctor's, store. Every store they want to go to, I take them how far they want. But I don't know what to do because they get so old, I can't do everything. Everything's a mess. They don't like clean. They do like dirty or something. They don't want to clean the bathroom or sink.

They're old. They aren't like American ladies, just stay home and eat or something. They go outside and come back and do like that.

My house, everything's a mess. I wash the dishes, I wash the bathtub. They don't care. That's difficult for me. But I don't know, maybe I will do the same thing like they do. So I think I will have a daughter-in-law but not good like me. But I do good for Kia and Chou Pao; maybe someone will do good for me too!

Hmong people don't put the parents in the rest home. Usually the younger son will stay with the ma and dad until they're gone. Sometimes the younger son marries the really bad wife. So they will move to another boy's house. But if the wife's so good, they can not move so they have to stay until they're gone. They don't care about the daughter because the daughter will go marry. So they care for their youngest son or the only one son. They 
have to stay with him until they die.

You know old women they don't have breasts. Everybody should not have pretty breasts, right? But I saw very old American women and they had pretty breasts so I said, "Why? They're old but it's sticking right out like this?" When you get old they just go flat. You know mine. I would like to have it That's why I want bigger. So maybe l'll do the operation! (laughs) Hmong men think young women are a little bit better. But when Hmong are old, so that's old. They don't know how to do an operation on their face like American women. They would not do this. Getting old is OK. They die and the next generation comes. That's what they say. Because old people can not do like young people. People die and can not wake up again, right? Some they do a lot of work so they get old faster. Someone fifty years is not real old, just half/half. In Laos old people are working so they have lots of muscle, but it's not a good country. You know right now in this country the old people have no work to do so they stay and stay and sleep or eat something. They get sick. So all my people when they get old like Kia and Chou Pao, in this country they get sick or something.

The children change here. They act like American right now. We tell them (Hmong traditions). I don't think they keep them or not. Right now I can not decide for them. I say if they want to go different things, so they can go. I don;t know how to say it because they 're old enough, so they want to do what they want. They can stay with us or they can just do what they want. 


\section{CHAPTER V}

\section{SUMMARY AND DISCUSSION}

During the course of a discussion about children and their changing values, Chia made this statement: "But I don't know the world, I know the past only" (Transcript \#2, p.49) Through knowledge of the past, individual and cultural identity is maintained or altered to accommodate present reality. The perspectives of the women in this study, which will be discussed in this chapter, reflect their past reality and demonstrate their attempts to adjust to a new cultural environment.

\section{The Narratives as a Reflection of Hmong Women's Perspectives and}

\section{Experienced Hmong History}

In support of his reliance on folk tales, legends and personal stories to document Hmong history, Tapp (1989) claims that "the analytical observations of the ethnographer are of no greater 'objective value' than the descriptions and analysis of his informants" since the same data is used by all involved (p. 3). Tapp presents what he calls a "real" history which he defines as: "an experienced one, which may be made up in part, wholly, or not at all, out of events which truly occurred" (p. 4). "We select our own histories," he explains, "which are the significant events for us now, isolated from the mass of events which we have truly encountered, and they become 'real' to us" (p. 175). Although Tapp's informants were men, his point of view of "real" or "experienced" history is well-served by the conversational 
narratives of the Hmong women in this study.

Donnelly (1994) suggests that Hmong women's minds "were shaped by the actual material world and their experience of it" (p. 4). Certainly, in these narratives, the "real history" of the women's lives is most often expressed in the immediate, the practical, and the everyday experience. Rather than an expansive or analytical view of their culture and history, these women speak about the results and consequences of events, traditions, and customs on their lives and on their families and friends. For example, when discussing communism and its effect on the Hmong, Mai does not speak of communist ideology, political goals, social concepts, or why the communists were hunting the Hmong. Rather she tells of the effects the communists had on daily life in the village: their questioning of children in order to implicate parents in hoarding food; their offering women whose husbands were away help with daily chores and then demanding sexual favors; or their killing of people in her own family.

This perspective of history as an immediate and experienced process, and away from abstract political concepts, might be expected in a people, men or women, whose history had involved migration even before war disrupted their lives in Southeast Asia. Settling and resettling, their changing environment and circumstances left little opportunity to develop an attachment to place or defense of land. Furthermore, living in usually isolated mountainous areas that did not respect national boundaries, the Hmong generally remained uninvolved in national politics before their contact with Westerners. 
Still, it is apparent that Hmong women would be even more focused in the home and less concerned about national or international politics or what occurred outside of their immediate experience except as these things interfered with or disrupted their families.

The role of Hmong women in the family, as well as their experience of historical events, contributes to this immediate and personal perspective of history. For one thing, their traditional role centered Hmong women in the home and generally excluded them from engagement in decision making or politics. In addition, most Hmong women did not attend school where they might have learned to look at history from a more abstract perspective. Furthermore, as Hmong men were drawn into the unstable and volatile political landscape of Southeast Asia, Hmong women were left to concentrate even more on the immediate struggle to maintain the integrity of their families.

The maintenance and integrity of their families remain a major interest of the Hmong women in this study and is evident in Mai and Chia's stories, which evolve through memories and concerns decidedly focused on family and relationships, rarely describing place or discussing historical context. This emphasis on family structure and gender relationships, especially marriage, is one of the most frequently occurring themes in the narratives and supports Donnelly's (1994) assertion that the gender concepts, on which family structure is based, are what "organize and give meaning to daily experience" (p. 12).

On the other hand, it is apparent that this concern with family and gender concepts, viewed and expressed in this study through concrete 
descriptions of effects and consequences, suggests that the daily experience itself both shapes and changes the form and meaning of the gender concepts and traditions. These Hmong women, for whom transition and change have become a way of life, are now attempting to understand the organization and meaning in their own traditions as well as in American gender concepts, especially as they conflict with Hmong culture. Chia, discussing her marriage agreement and bride price, reveals this attempt to both define the changing customs and relate them to the context of her present cultural environment:

Tsu paid my uncle some money (for the bride price) after we moved to United States. We were so poor when we moved from Thailand, we had nothing. But my uncle's nice. He said, 'Oh, wait until you have it, you can pay.' So Tsu's family just made a party and cooked for them. They just put a party on and said, 'Later, I'll pay you.' Down payment like the car!

With this wry observation, Chia recognizes not only the necessity of changing the custom of bride price traditionally paid before marriage, but also its association with financial arrangements in Western social contracts. As they select and express their histories, these women are examining, comparing and making connections between the two cultures that now organize and give meaning to their lives.

The intercultural comparisons and adaptations expressed in the conversational narratives reflect the necessity and challenge Hmong women face to maintain self and cultural identity. Donnelly discusses the immediate effects on first generation Hmong of the disruption of cultural identity in the process of resettlement: 
They could not continue many of the activities that had comprised their daily life in Laos. Like other refugees and most immigrants, they lost their former economic and living arrangements. They found themselves without many of the daily habits and trappings of identity they had taken for granted, that had supported their view of themselves and of reality . . .. Since the sense of social identity is affirmed in interaction with the social environment, such radical environmental changes can call selfidentity into question. (p. 4)

Refugees and immigrants face not only the questioning and loss of identity, as Donnelly suggests, but the necessity to refashion their identity within the context of traditional culture and their new social and physical environment as well. Chia, describing her hopes for her daughters to finish high school, sees these ongoing cultural shifts caused by exposure to American education and relates them to her own past:

You know my daughter is different than me. Their hearts look different. Yeah, I married young, but you know, that time I didn't know nothing. That's why. Maybe right now I know. I say 'Why did I marry young? I should have stayed longer!'

Mai, on the other hand, recognizes and reinforces her traditional identity and subordinate position in the family as well as the effects of literacy on traditional Hmong social structure when she describes her attempt to convince her husband that she won't behave badly, as he believes his exwife did. In her narrative, Mai addresses her husband:

The ex-wife does that because she has a really bad heart, bad person, and she knows English. She knows how to read and write really well, 
the same as you. Right now, me, I don't know how to read and write.

I'm waiting for you for everything. How can I do a bad thing to you?

Self identity and cultural identity are reinforced or reconstructed not only by the social and physical environment, but also by the communication of that emerging identity. The process of remembering and expressing affords the opportunity for the first generation Hmong informants themselves to discuss, analyze and compare the common and opposing practices and traditions of their own culture and the dominant American culture and can play a role in culture and language learning as they recreate a cultural context.

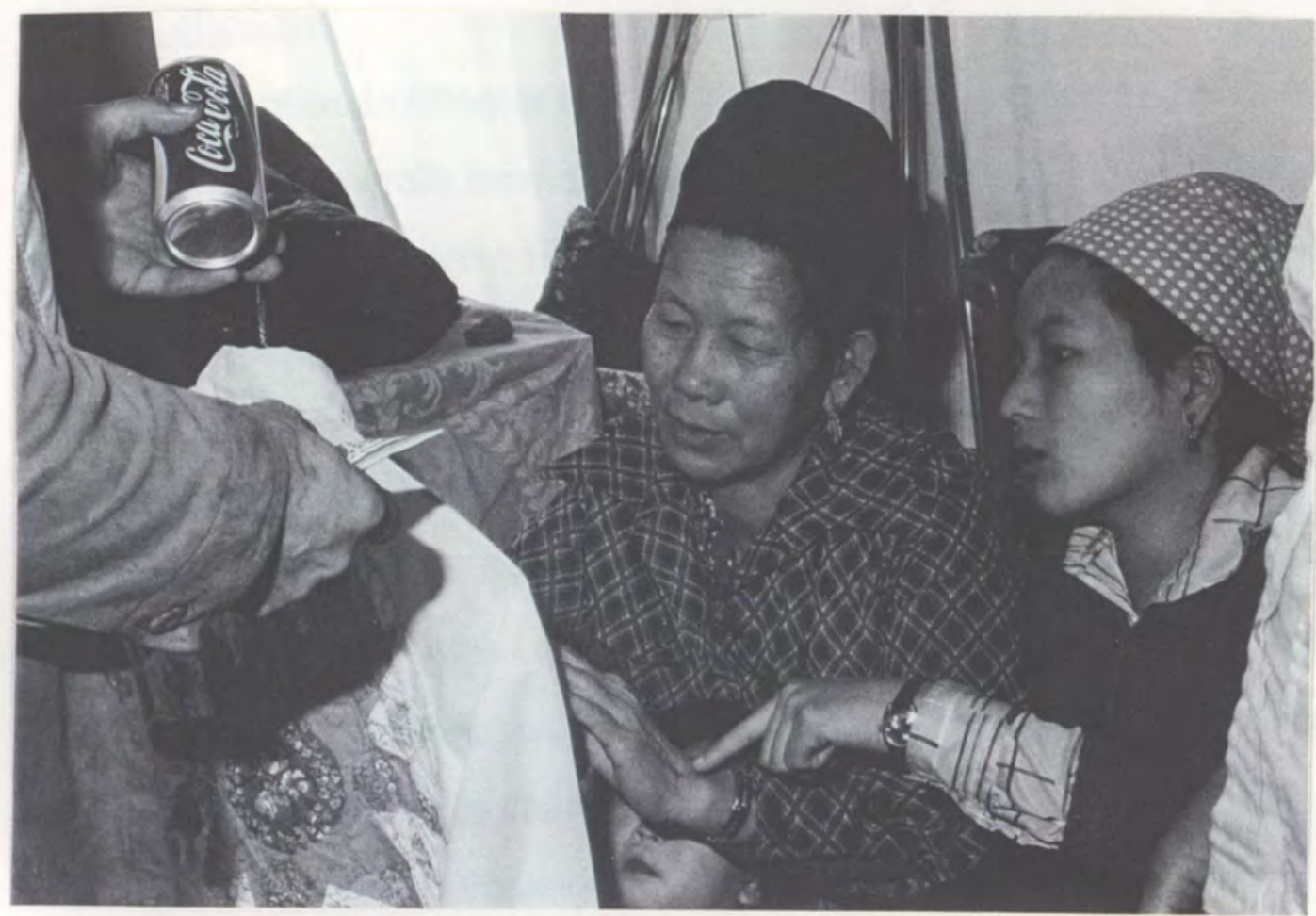

Figure 12. Kia and Chia. Oregon, 1982. 
The Value of Hmong Womens' Experienced Histories

The creation of "real" or "experienced" histories in the form of conversational narratives and oral history is especially appropriate and valuable for first generation Hmong women not only as a framework for the discussion, analysis and criticism of intercultural differences and similarities, as discussed in the previous section, but for several other reasons as well: as an expansion of Hmong women's voices in previous research on the Hmong; as an opportunity to provide second generation Hmong with an "experienced" first generation Hmong history; and as a means for Hmong women to maintain, for themselves and their children, connections with their families of origin.

As discussed in Chapter II, the voices of Hmong women in ethnographic research have generally been unheard for several reasons: their place in the family and social hierarchy; limited opportunities for interaction outside the Hmong community; demands of child rearing; illiteracy and lack of former educational experience; and lack of available or relevant educational programs. Yet, their crucial role in the functioning of the family and the upbringing of children distinguishes them as the "heart" of the family. In her narrative, Mai explains the relationship in this way: "They (children) listened to the mother more because the mother had to take care of the kids every day, every time, talking to them and they know the mother's heart ." This distinction makes the perspective of Hmong women not only valid, but essential in recording experiential data which supports and adds a new dimension to historical research. By eliciting and recording Hmong women's stories, a significant and crucial perspective on Southeast Asian history, as 
well as American history, is preserved.

In addition, the Hmong come from an oral tradition and a culture in which access to written work is relatively recent. This access has been limited particularly for women who were usually unable to attend school in Laos and in the refugee camps in Thailand because, as Mai explains in her narrative: "Girls didn't go to school. They said the girl will move out so they didn't let her go to school. That was the rule. They said the problem is they make their own food, so they needed somebody to help. They needed a girl to help." Consequently, Hmong women refugees were often illiterate upon arrival in the United States. As second generation Hmong are exposed to American education, the gap has been widening between history experienced by often illiterate first generation Hmong passed on through the oral tradition and history learned by second generation Hmong with a reliance on written Western sources. Ng (1993), professor of Asian American studies at California State University in Fresno, says: Unlike the ChineseAmericans and Japanese-Americans who have established historical societies to study their ethnic experiences, the Hmong must rely on the contributions of others" (p. 61). His students, he explains, when asked to write about Hmong history, turned to written sources, as they had been taught to do in school. $\mathrm{Ng}$ questions whether these sources were having an effect on his students' perspective of Hmong history. For example, one particular trend $\mathrm{Ng}$ noticed in his student papers was an idealization of the Hmong homeland. $\mathrm{Ng}$ states: "It became apparent to me that my Hmong students were incorporating external, printed sources of information in English to complement their internal, community-based oral traditions and folklore" ( $p$. 
55). The creation of an experienced history elicited from first generation Hmong women affords an opportunity to bridge this gap between the oral tradition of their generation and the increasingly written tradition of their children's more assimilated generation.

Another reason for the relevance and potential advantage of the creation and documentation of Hmong women's "experienced" history relates to their distinct traditional social position and to Hmong marriage customs which foster a loss of connection with a woman's family of origin. When a Hmong woman marries, she becomes wholly a part of her husband's family and clan. She is then expected to take on her husband's relatives and ancestors, honoring them in religious ceremonies, and at her death joining them in the spirit world, finalizing separation from her original family.

In addition to Hmong marriage customs, the prolonged war in Laos, the flight into Thailand, and resettlement in the West has further exacerbated the painful separation from their own relatives that Hmong women have experienced. In conversations during the past fourteen years, the informants in this study, as well as other women in their extended family, have often ardently expressed the sorrow that daughters feel having to leave their own families when they marry, and the pain of mothers whose daughters, in their words and in their experience, "leave and never come back."

This physical and spiritual separation, resulting from Hmong marriage customs and the disruption of war, involve for many Hmong women not only a limitation of continued relationship with their family of origin, but the loss of their own family history as well. Chia, who was separated from her mother when she was five or six years old, showed throughout the interview process 
an eagerness to record her original family's history for her children. After one interview session she produced the only photo she had of her maternal grandparents, firmly requesting that it be used in her history so that, she said, "my children will know" (personal communication, April, 28, 1995). Tapp states that "history as we understand it depends upon our participation in it; that is, there can be no history without consciousness of it“ (p.176). The reinforcement of the consciousness of history through the process of remembering, questioning, expressing, and ultimately recording and sharing their experienced histories provides an opportunity for these Hmong women to affirm and preserve connections between their original families, themselves, and their children.

With increasing displacement of ethnic groups and communities around the world, as well as rapid and dramatic social changes in the United States where many of these displaced ethnic groups find refuge, the alteration of traditional culture is assured. In groups like the Hmong, with, until recently, a dependence on an oral tradition to transmit their culture and history, the contribution of refugee and immigrant perspectives through oral testimony becomes more urgent and significant. The perspectives of retrospective and contemporary experience of the Hmong women in this study, while shaped by traditional culture, have already been altered by their exposure to American customs and values. For this reason, although not representative of traditional Hmong women, their stories and their views, opinions, and insights, are meaningful as accounts of transitional culture, the intersection of Hmong and American traditions, and a link between the past and future. 


\section{Implications for ESL and Refugee Resettlement}

Culture Learning. Just as language acquisition involves interrelationships between a learner's native language and the target language, it also involves the inter-relationships between a learner's native culture and the dominant cultural environment. According to Watson-Gegeo (1988), learning a second language includes "more than a structure for communication; we are also learning . . . social and cultural norms, procedures for interpretation, and forms of reasoning" (p. 582). Indeed, as Brown (1987) points out, "the successful synchronization of linguistic and cultural development can be crucial in determining whether a learner progresses in both language arts and psychological aspects of the target culture" (pp. 132-34).

The significance of cultural development, or culture learning, in the process of language acquisition and resettlement is especially evident for first generation refugees since they face the challenge of not only learning the target culture, but reconciling or compromising those psychological aspects that conflict with their native culture as well. These psychological aspects are often more intense, enduring, and confusing than those experienced by their children or by other second language learners such as international students. Most refugees have been forced to leave their families and friends, possessions, and homeland and are unable to return because of repression or persecution. To survive in a new and different environment they face a choice between assimilation or isolation and possible alienation from the dominant society as well as from their children as their children inevitably assimilate. If, as Brown (1987) suggests, a culture 
"establishes for each person a . . blueprint for personal and social existence," and that second language learning involves the "deepest form of acculturation" (p. 123), then the challenges refugees face as they attempt to adjust, if not assimilate, to a new culture and to learn a new language are indeed profound.

The Role of Culture Learning. The concept of culture learning in relation to both language learning and refugee resettlement usually implies members of the newcomer culture learning about and adapting to the dominant culture. In both government refugee policy and in education, expectations for refugee economic, social and learning success in the United States generally follows this aspect of culture learning. Moreover, Tollefson (1989), in a study of U. S. economic and educational policies for Indochinese refugees, claims that refugee programs:

... assume that there is a unified American culture and character; that the refugees' cultures and characters are the source of their social, psychological, and economic problems; and that the purpose of the program therefore is reeducation: to teach the refugees to give up their old ways of thinking, believing, and behaving. (pp. 59-60)

Culture learning, however, can be a two-fold process that also encompasses learning about the refugees' culture on the part of the educators, sponsors, social workers, and others involved in their resettlement. It is this aspect of culture learning, or culture sharing, that will be discussed in relation to the conversational narratives of Hmong women.

The Value of Oral History and Conversational Narratives. As refugees become more familiar, if not comfortable, with the dominant language and 
culture, they are under tremendous pressure to adopt not only the language, but the lifestyle, values, and traditions of their new homeland. This pressure may come from outside or from within their own families or ethnic communities. Newcomers will experience, to varying degrees depending on the circumstances, culture shock as they attempt to adjust. Brown (1987) proposes that "we should not expect learners to deny the anger, the frustration, the helplessness and hopelessness they feel," and that expressions of these feelings are "a very powerful and personal form of learning" (p. 132). One form of expressing these feelings and other concerns as well, involves the refugees sharing their native traditions, values, dreams and history, on both a personal and communal level, with the dominant culture in the form of oral history or conversational narratives. This aspect of culture learning is potentially of great value to both the refugees and to those who assist and interact with them as they resettle.

Like language learning, culture learning serves many purposes. For educators, sponsors, social workers and others involved in the process of resettlement, the individual perceptions, opinions, and experiential data available through oral histories and conversational narratives can provide meaningful reflections of cultural processes, attitudes, and values. Although the information in these histories and narrations may not be verifiable, Fetterman (1989) asserts that they provide "a unique look at how the key actor thinks and how personal and cultural values shape his or her perception of the past" (p. 61). As expressions of events and experiences from the point of view of particular individuals, oral histories and conversational narratives enrich our understanding of the culture that 
sustains and defines those individuals, and in addition, provide material for contextual and cultural interpretation and analysis.

Additionally, the resettlement experience, when viewed from the perspective of the refugee, allows educators and resettlement workers a better understanding of the effects of educational and social policies. By increasing awareness of how others view the dominant social and educational systems, refugee oral histories and conversational narratives can facilitate evaluation and possible improvement of those systems. Grele (1985) suggests that oral histories and conversational narratives are essential "not only for the preservation of a record of what really happened in the past, but for our own understanding of ourselves" (p. viii).

For educators, a better understanding of their learners' cultures gained through the perspective of oral history or conversational narratives, especially the challenges and struggles facing individuals and groups, contribute to the development of language teaching strategies as well as curriculum. They can be especially significant for adult refugee learners since, as Johnson (1992) points out:

The vast majority of the L2 (second language) research on older learners is descriptive, correlational, or experimental. Yet relationships between the cultural adjustment of adults and language learning are important both for developing richer theories of second language acquisition and for improving teaching. (p. 138) As teachers, research that draws us into the lives of our students can facilitate teaching in the context of our students' lives and can make the learning process more meaningful and successful. This is an especially 
relevant teaching strategy for adult refugee students since they are less likely to be able to separate their family and workplace concerns and responsibilities from the learning environment.

Furthermore, because of the essential and fundamental part that Hmong women play in raising children, their perspective on the process of Hmong history and cultural adaptation is a potentially valuable resource for educators, administrators and program developers. Haines (1989) discusses this pivotal role of Hmong women emphasizing their part in "the supervision, motivation, and socialization of the children within the family." This is, he asserts, especially significant in light of the fact that the education of children "is relied upon as perhaps the principal strategy for socioeconomic mobility" and it is "the mother's (not the father's) resources that are most predictive of the children's educational attainment" (p. 172).

For the refugees themselves, the preservation of their history, the reinforcement and continuation of their cultural identity, and the recognition of both differences and connections with the dominant culture are invaluable potential outcomes of the process of remembering and expressing. Moreover, oral histories and conversational narratives are one means through which first generation adult refugees can contribute something of value to their children whose perceptions and memories of their cultural heritage change rapidly and are often lost as they assimilate. Pa Tong Yang (1996), a Hmong college student, and Chia and Mai's nephew, expresses his perspective on the importance of an experienced Hmong history:

As I grew to become who I am today, I have realized that knowing where I come from is a very important part of who I am. I would be 
lost if I didn't know where my ancestors came from and how they had lived their lives. (p. 1)

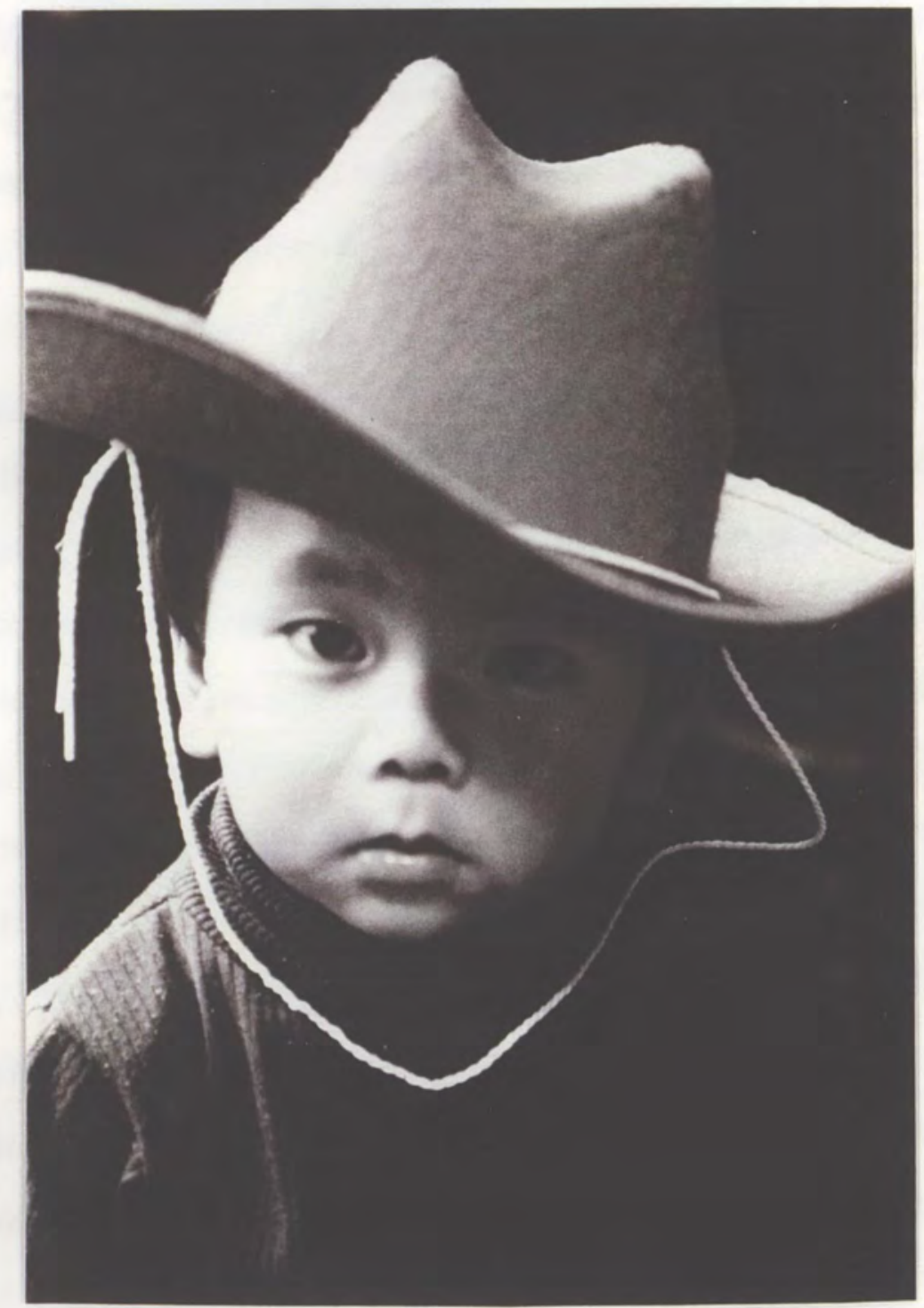

Figure 13. Pa Tong Yang. Oregon, 1982.

Finally, in the current climate of anti-immigrant reaction in the United States, it is even more important that those of us in the field of language 
education and refugee resettlement encourage not only linguistic but cultural and generational connections between new Americans and the general public. Alice Kessler-Harris (1985) proposes that "collecting data from ordinary people contributes to developing a shared sense of what happened" (p. 4). "What happened" and continues to happen in the refugee and immigrant experience in America is, indeed, a part not only of our shared history, but of our common future.

\section{My Experience of the Research Process as an ESL Teacher}

This study was both complicated and enriched by the connections of friendship, motherhood, and family between my informants and myself. During the course of the study, I realized that a process oriented approach to the interviews worked because process informed our daily lives as women, cutting across cultural differences. It was through this interactive and dynamic process of culture sharing that we were all learning, even as goals and expectations were lowered or lost. Through my participation in this study, I recognized that the same flexibility, innovation, and informality that made this process based orientation effective and productive are also qualities that are applicable and constructive for work with adult immigrant and refugee second language learners in the classroom. This is especially true for women refugees whose exposure to formal educational settings and methods has been limited. Using a student centered approach to language teaching that provides opportunities for students to share their knowledge, expertise, concerns, and life experiences is a practical, powerful and meaningful teaching strategy. Language learning is, after all, built upon 
connections made between the context of the learner's life experience and culture and the target language and culture. Culture learning on the part of both teachers and students provides a shared context through which these essential cultural connections can be made.

Today, a majority of educators in the United States serve refugee and immigrant students in some way. As the population of adult refugee and immigrant students continues to grow, those of us involved in adult ESL education, face opportunities and challenges to develop and provide appropriate and relevant language programs and curriculum. In order to address this challenge, I believe it is necessary to recognize that language should not be taught in a static environment and that culture learning on the part of teachers as well as students can only stimulate and benefit all involved. Fox (1989) maintains that learner based teaching is improved when teachers appreciate "the way particular students in particular situations understand their world" (p. 9). Moreover, with this appreciation comes an acknowledgement of the commonality of human experience and the basic similarities that cut across cultural, religious and ethnic boundaries as well as an awareness and appreciation of the significant differences in perspectives, values, beliefs and behaviors embodied in particular cultures. This process of culture sharing helps to create a classroom atmosphere that increases student confidence and facilitates language learning.

My participation as researcher in the process of completing this study has had a positive and productive effect on my development as an ESL teacher. For one thing, my involvement and interaction with the individuals of all ages in this extended Hmong family has increased my awareness of the 
diverse perspectives, needs, and interests of various age and gender groups in relation to language and culture learning. It became apparent to me that the traditional roles and expectations associated with age and gender groups influence both attitude toward learning and learning styles. The Hmong women in this study, for example, wanted practical knowledge that could be immediately applied to their home centered lives. Cha and Small (1994) made a similar observation in their study of Hmong women in the Thai refugee camps: "Hmong women chose to participate in programs that provided perceivable rewards or improvements in their current lives" ( $p$. 1050) while the men were interested in improving their education and chances for employment in the future. For the Hmong and for other refugee and immigrant women whose concerns, attention and cultural roles revolve around their families, curriculum that is student and teacher generated and relevant to these concerns, as well as programs that make the learning situation accessible to home-bound women with children, would increase these women's ability and confidence to function in American society, enhance their contribution to their families' success, and enrich the programs for others.

In the process of conducting this study, the social and economic problems faced by my informants emphasized the reality that language learning does not occur in isolation from the cultural, social, economic and political environment and that these problems accompany students into the classroom. The concerns these women chose to express in the narratives accentuate their interest in and need for learning to negotiate the dominant social system. Both women, for instance, expressed concern about contact 
and communication between their children's' teachers and themselves. This is a problem for many refugee women who recognize that education is essential to enable their children to make choices that the women themselves never had the opportunity to make, yet feel constrained participating in their children's' education either because they cannot speak English or cannot read One solution to this, and other concerns as well, would be the development of women centered programs in which mothers could participate in their preschool children's' education while learning to communicate in English and becoming comfortable in an educational setting without being separated from their children. An educational program that is not dominated by male students would enable women to share their knowledge and expertise in raising children, and their strategies dealing with or adapting to American cultural practices. An emphasis on process and on group learning that allows the learners themselves to contribute to the learning process of others, rather than an emphasis on individual achievement, would be an appropriate approach for learners from cultures like the Hmong in which the focus is on the group, not on individuals.

Finally, because of my participation in the preparation, research, collection and evaluation of data involved in this study, I am convinced that ESL teacher education should place a greater emphasis on cultural study and ethnographic research. The value of qualitative cultural studies based on learners' perspectives lies in their power to alter and increase readers' understanding of the informants' cultural context and individual experience. This understanding, Thompson (1978) points out, "can break down barriers between teachers and students, between generations, between educational 
institutions and the world outside; and . . . it can give back to the people who made and experienced history, through their own words, a central place" ( $p$. 2). Cultural studies should play a more significant role in teacher education, not only involving students in reading ethnographic accounts and oral history, but participating in the process of creating them.

\section{Limitations and Further Research}

My task in this study has been to work with these Hmong women to create the narratives and to indicate how they would be valuable to the women, their families, researchers, and to those involved in immigrant and refugee resettlement and education. This study was not intended to be a comprehensive look at Hmong culture and history, nor was it intended to micro-analyze the transcribed data, examine in detail the language used by the informants, or to analyze cultural practices, such as gender roles, as Donnelly (1994) has done, although the raw data is potentially valuable for use in these ways. Rather, I have focused on the process of creating the narratives, the perspectives of the women involved, and the potential of oral history and conversational narratives as a resource for language and culture teaching and learning, especially targeting women from a culture in which their lives are centered in the home and revolve around children.

While answering the research questions (listed on p. 7), this study has brought up many other unanswered but essential questions that could be used as as suggestions for further study. What are the language learning needs of refugee women in home settings? Is the emphasis in language programs on employability appropriate as a basis for immigrant language 
education? Are there successful programs targeting refugee women from cultures in which group identity and family is central? Can women from these cultures maintain their roles as caretakers in the home and still participate in language and literacy programs? How appropriate is it for ESL educators to impose North American values on other cultures when these values conflict? What are the possibilities for the development of programs and curriculum that focus on womens' concerns, such as health care and non-traditional medicine, child care practices, cultural conflicts, and marriage and divorce? In what ways can educators involve refugee and immigrant women in the creation and implementation of the learning environment and experience?

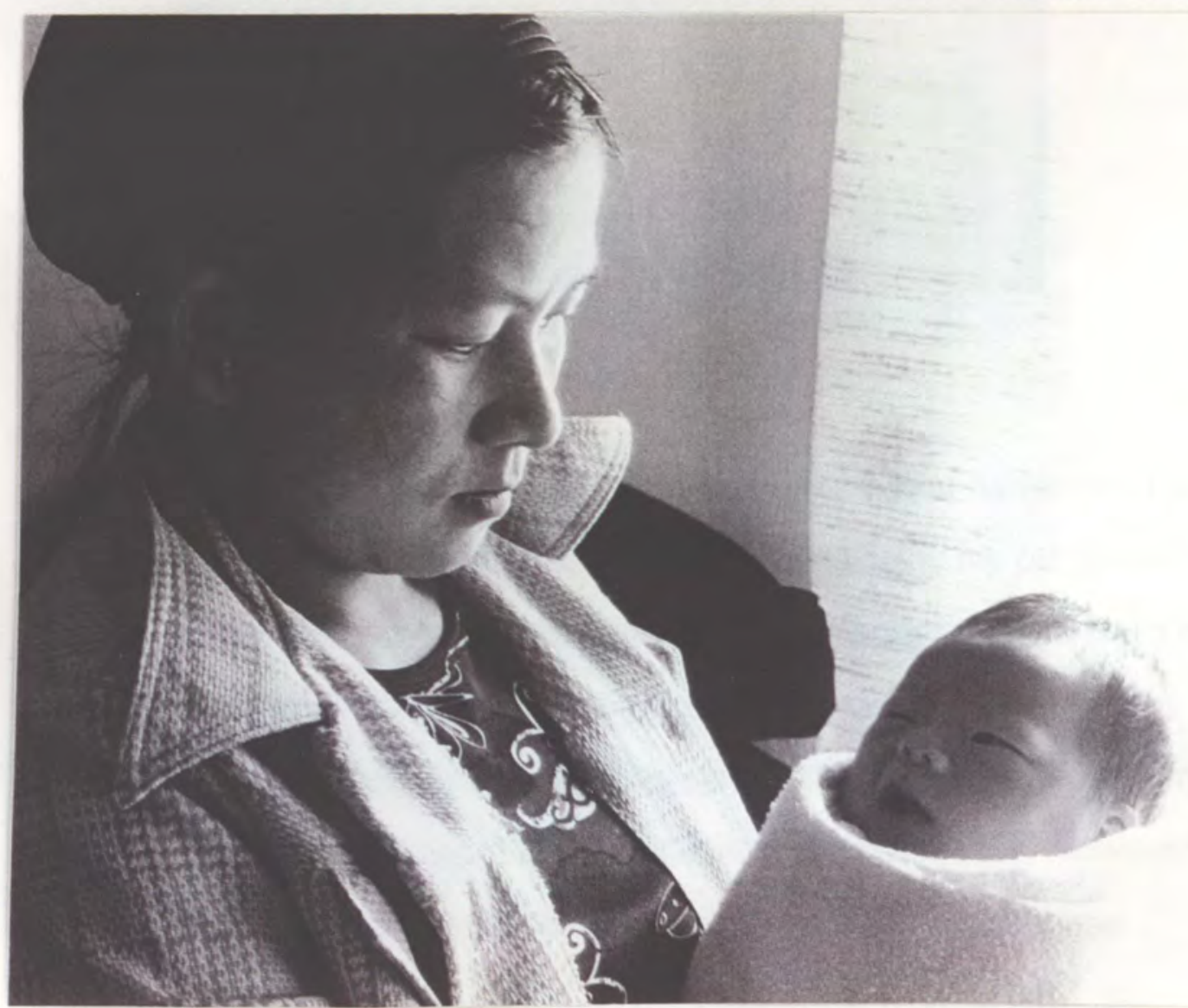

Figure 14. Yalee. Oregon, 1982. 


\section{Conclusion}

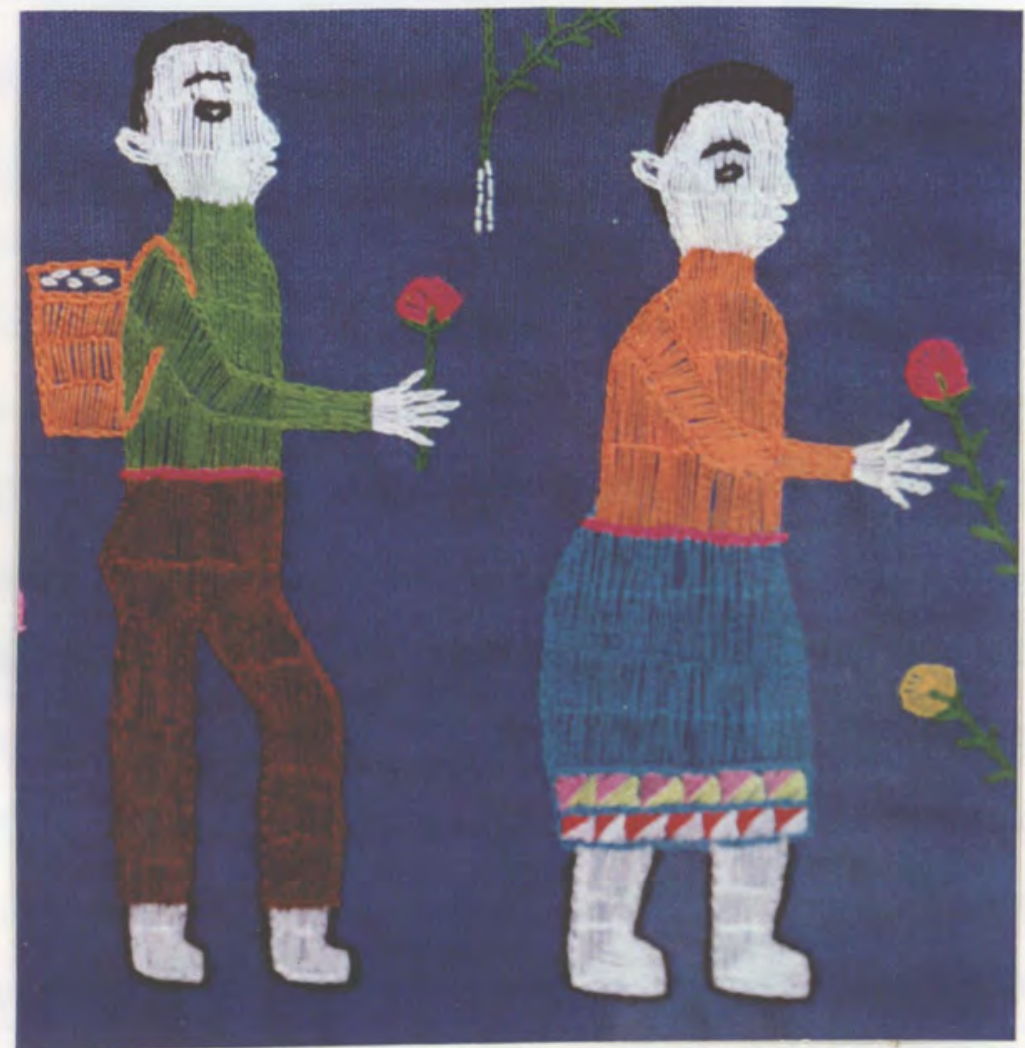

Figure 15. Detail of Hmong tapestry.

Before I began interviewing for these conversational narratives, I spent some time with my informants, Mai, and Chia, discussing my purposes for conducting the interviews, purposes including: an opportunity to learn more about their individual lives and personal stories; the completion of my academic studies; and an ongoing interest in Hmong culture and history. Neither of the women expressed any reluctance to participate; however, Mai did ask why I was interested in talking only to the women since, she explained, "The men know more, but the women know nothing." In response, I said that usually when people interview Hmong and ask them 
about their lives and history, they only interview men. I told Mai and Chia that I wanted to learn about and understand Hmong women's ideas, feelings, and memories. Mai thought for a moment, nodded her head, and, laughing, replied: "Oh yeah. The men know more, but the women tell the truth" (personal communication, August 19, 1992).

It is my hope that these narratives provide a window into the "truth" of these women's lives; into the reality of a segment of Hmong history as it has intersected and connected with American history; and into the common experience of refugee women in transitional cultures.

I propose that the most significant value of these women's stories lies in the process of giving voice to the individuals involved and recognition to their place in their unique and changing culture. Their history is now an integral part of the history of immigrant American women. Perhaps their stories can be viewed, as Grele (1985) suggests, as "a way of involving people heretofore uninvolved in the creation of the documents of their past," and as "an opportunity to democratize the nature of history, not simply by interviewing them but by seeing that involvement as a prelude to a method that allows people to formulate their own meanings of their past experiences “ (p. viii). 
References

Aschenbrenner, D. (1992, Jan-Feb). Butchering the Hmong way.

Countryside and Small Stock Journal, 76, 54-56.

Brown, H. D. (1987). Principles of language learning and teaching.

Englewood Cliffs: Prentice-Hall.

Cha, D., \& Small, C. A. (1994). Policy lessons from Lao and Hmong women in Thai refugee camps. World Development, 22 (7), 1045-1060.

Cooper, R. (1984). Resource scarcity and the Hmong response. Kent Ridge: Singapore University Press.

Donnelly, Nancy D. (1994). Changing lives of refugee Hmong women. Seatile: University of Washington Press.

Fetterman, David M. (1989). Applied social research methods series: Ethnography step by step. 17, Newbury Park: Sage Publications.

Fox, Diane N. (1989). Chinese voices: Towards an ethnography of English as a second language. Unpublished master's thesis, Portland State University, Portland, Oregon.

Geddes, William R. (1976). Migrants of the mountains: The cultural ecology of the Blue Miao (Hmong Njua) of Thailand. Oxford: Clarendon Press.

Green, K.R., \& Reder, S. (1983). Factors in individual acquisition of English: A longitudinal study of Hmong adults. Conference II: The Hmong in transition (pp. 17-19). Minneapolis, MN: National Institute of Education.

Grele, R. J. (1985). Envelopes of sound: The art of oral history. Chicago: Precedent Publishing. 
Haines, David W. (Ed.). (1989). Refugees as immigrants: Cambodians, Laotians, and Vietnamese in America. New Jersey: Rowman \& Littlefield.

Hamilton-Merritt, Jane. (1993). Tragic mountains: The Hmong, the Americans, and the secret wars for Laos, 1942-1992. Bloomington: Indiana University Press.

Helsel, D., Petitti, D.B., \& Kunstader, P. (1992, Oct.). Pregnancy among the Hmong: Birth weight, age, parity. The American Journal of Public Health, $\underline{82}(10), 1361-1365$.

Hendricks, Glenn L. (Ed.). (1986). The Hmong in transition. Staten Island, New York: Center for Migration Studies, Inc.

Hoopes, James. (1979). Oral History. Chapel Hill: University of North Carolina Press.

Howard, Katsuyo K. (Ed.). (1990). Passages: An anthology of the Southeast Asian refugee Experience. Fresno: California State University. How-Man, Wong. (1984, March). People of China's far provinces. National Geographic, 165(3), pp. 283-333.

Ives, Edward D. (1974). The Tape Recorded Interview. Knoxville: The University of Tennessee Press.

Johnson, Donna M. (1992). Approaches to research in second language learning. New York: Longman.

Kessler-Harris, Alice. (1985) Introduction. In R. Grele, (Ed.), Envelopes of sound: The art of oral history. Chicago: Precedent Publishing.

Mason, Sarah R. (1986). Training Hmong women for marginal work or entry into the mainstream. In G. L. Hendricks (Ed.), The Hmong in Transition. (pp. 101-118). Staten Island, New York: Center for Migration Studies. 
Meredith, W. H., \& Rowe, G. P. (1986). Changes in Hmong refugee marital attitudes in America. In G. L. Hendricks (Ed.), The Hmong in Transition (pp. 121-130). Staten Island, New York: Center for Migration Studies.

Moore, David L. (1990). Between cultures: Oral history of Hmong teenagers in Minneapolis. Vietnam Generation, 2 (3), 38-52.

$\mathrm{Ng}$, Franklin. (1993). Towards a second generation Hmong History. Amerasian Journal. 19 (3), (51-69).

Quincy, Keith. (1995). Hmong: History of a people. Cheney: Eastern Washington University Press.

Seldon, Anthony, \& Pappworth, Joanna. (1993). By word of mouth. London: Methuen \& Company.

Smalley, William A. (1986). Stages of Hmong cultural adaptation. In G.L. Hendricks (Ed.), The Hmong in transition (pp. 7-31). Staten Island, New York: Center for Migration Studies, Inc.

Strouse, Joan. (1985). Continuing themes in U.S. educational policy for immigrants and refugees: The Hmong experience. (Doctoral dissertation, University of Wisconsin, 1986). Dissertation Abstracts International, 49, DA 8516791.

Tapp, Nicholas. (1989). Sovereignty and rebellion: The White Hmong of northern Thailand. Singapore: Oxford University Press.

Tenhula, John. (1991). Voices from Southeast Asia: The refugee experience in the United States. Ellis Island Series. New York: Holmes \& Meier. 
Thompson, Paul. (1978). The Voice of the Past: Oral History. Oxford: Oxford University Press.

Tollefson, James W. (1989). Alien winds: The reeducation of America's Indochinese refugees. New York: Praeger.

Watson-Gegeo, K. A. (1988). Ethnography in ESL: Defining the essentials. TESOL Quarterly, 22(4), 575-589.

White, Peter T. (1987, June). Laos. National Geographic, 171(6), $772-$ 795.

White, Peter T. (1968, December). The Mekong: river of terror and hope. National Geographic. 134(6), 737-787.

Yang, Pa Tong (1996). 80 year old legacy. Unpublished manuscript. 